\title{
OS SERVIÇOS DE APOIO À REABILITAÇÃO AOS USUÁRIOS DO HOSPITAL DE REABILITAÇÃO DE ANOMALIAS CRANIOFACIAIS: DIAGNÓSTICO DAS NECESSIDADES DE CAPACITAÇÃO DE REABILITADORES.
}

\section{SILVANA AP. MAZIERO CUSTÓDIO}

Tese apresentada ao Hospital de Reabilitação de Anomalias Craniofaciais, da Universidade de São Paulo, para a obtenção do Título de Doutor em Ciências da Reabilitação.

Área de Concentração: Distúrbios da

Comunicação Humana

Bauru 
UNIVERSIDADE DE SÃO PAULO

HOSPITAL DE REABILITAÇÃO DE ANOMALIAS CRANIOFACIAIS

OS SERVIÇOS DE APOIO À REABILITAÇÃO AOS USUÁRIOS DO HOSPITAL DE REABILITAÇ̃̃O DE ANOMALIAS CRANIOFACIAIS: DIAGNÓSTICO DAS NECESSIDADES DE CAPACITAÇÃO DE REABILITADORES.

SILVANA AP. MAZIERO CUSTÓDIO

Orientador: Prof. Dr. José Alberto de Souza Freitas

Tese apresentada ao Hospital de Reabilitação de Anomalias Craniofaciais, da Universidade de São Paulo, para a obtenção do Título de Doutor em Ciências da Reabilitação.

Área de Concentração: Distúrbios da

Comunicação Humana

Bauru

2007 


\section{UNIVERSIDADE DE SÃO PAULO \\ HOSPITAL DE REABILITAÇÃO DE ANOMALIAS CRANIOFACIAIS}

R. Silvio Marchione, 3-20

Caixa Postal: 1501

17012-900 - Bauru - SP - Brasil

Telefone: (0xx14) 3235-8000

Profa. Dra. Suely Vilela - Reitora da USP

Prof. Dr. José Alberto de Souza Freitas - Superintendente do HRAC-USP

Autorizo, exclusivamente para fins acadêmicos e científicos, a reprodução total ou parcial deste trabalho.

Silvana Ap. Maziero Custódio

Bauru, __ de Agosto de 2007.

\section{Custódio, Silvana Aparecida Maziero}

C969s Os serviços de apoio à reabilitação aos usuários do Hospital de Reabilitação de Anomalias Craniofaciais: diagnóstico das necessidades de capacitação de reabilitadores. Silvana Aparecida Maziero Custódio. Bauru, 2007.

117f.: il.; $29,7 \mathrm{~cm}$.

Tese (Doutorado em Ciências da Reabilitação - Área de Concentração: Distúrbios da Comunicação Humana) - HRACUSP.

Cópia revisada em:

Orientador: Prof. Dr. José Alberto de Souza Freitas

Descritores: fissura labiopalatina - formação/capacitação profissional - pólo de educação - telessaúde humanização 


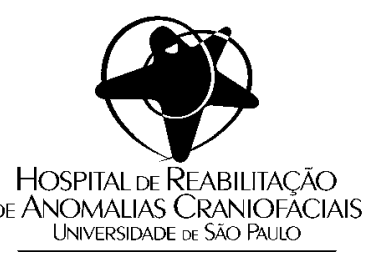

\section{FOLHA DE APROVAÇÃO}

Tese apresentada e defendida por

SILVANA APARECIDA MAZIERO CUSTÓDIO

e aprovada pela Comissão Julgadora em 1

Prof.(a) Dr.(a):

Instituição:

Prof.(a) Dr.(a):

Instituição:

Prof.(a) Dr.(a):

Instituição:

Prof.(a) Dr.(a):

Instituição:

Prof. Dr. José Alberto de Souza Freitas

HRAC-USP/Bauru - Orientador

Profa. Dra. Inge Elly Kiemle Trindade

Presidente da Comissão de Pós-Graduação do HRAC-USP

Data de depósito da dissertação junto à SPG: 


\title{
MINI-CURRÍCULO
}

\author{
Nome \\ Silvana Aparecida Maziero Custódio \\ 28 de Abril de $1963 \quad$ Nascimento \\ Bauru - SP \\ $1981-1983$ \\ Graduação em Serviço Social, Faculdade de Serviço Social de \\ Bauru. Instituição Toledo de Ensino, ITE. Bauru/SP. \\ $1993-1995$ \\ Especialização em Serviço Social. Instituição Toledo de \\ Ensino, ITE. Bauru/SP. \\ $1998-2000$ \\ Mestrado em Serviço Social. Universidade Estadual Paulista \\ Júlio de Mesquita Filho, UNESP-Franca/SP, Brasil. \\ $2003-2007$ \\ Curso de Pós-Graduação em Distúrbios da Comunicação \\ Humana, em nível de Doutorado, no Hospital de Reabilitação \\ de Anomalias Craniofaciais da Universidade de São Paulo, \\ Bauru/SP.
}

\section{ATIVIDADES PROFISSIONAIS}

1985 - até a presente Assistente Social do Hospital de Reabilitações de Anomalias data Craniofaciais da Universidade de São Paulo (HRAC/USP)

2003 - até a presente data

Docente da Faculdade de Serviço Social de Bauru (FSSB), da Instituição Toledo de Ensino (ITE)

2004 - até a presente Membro do Pólo de Educação Permanente em Saúde do data Sistema Único de Saúde. 


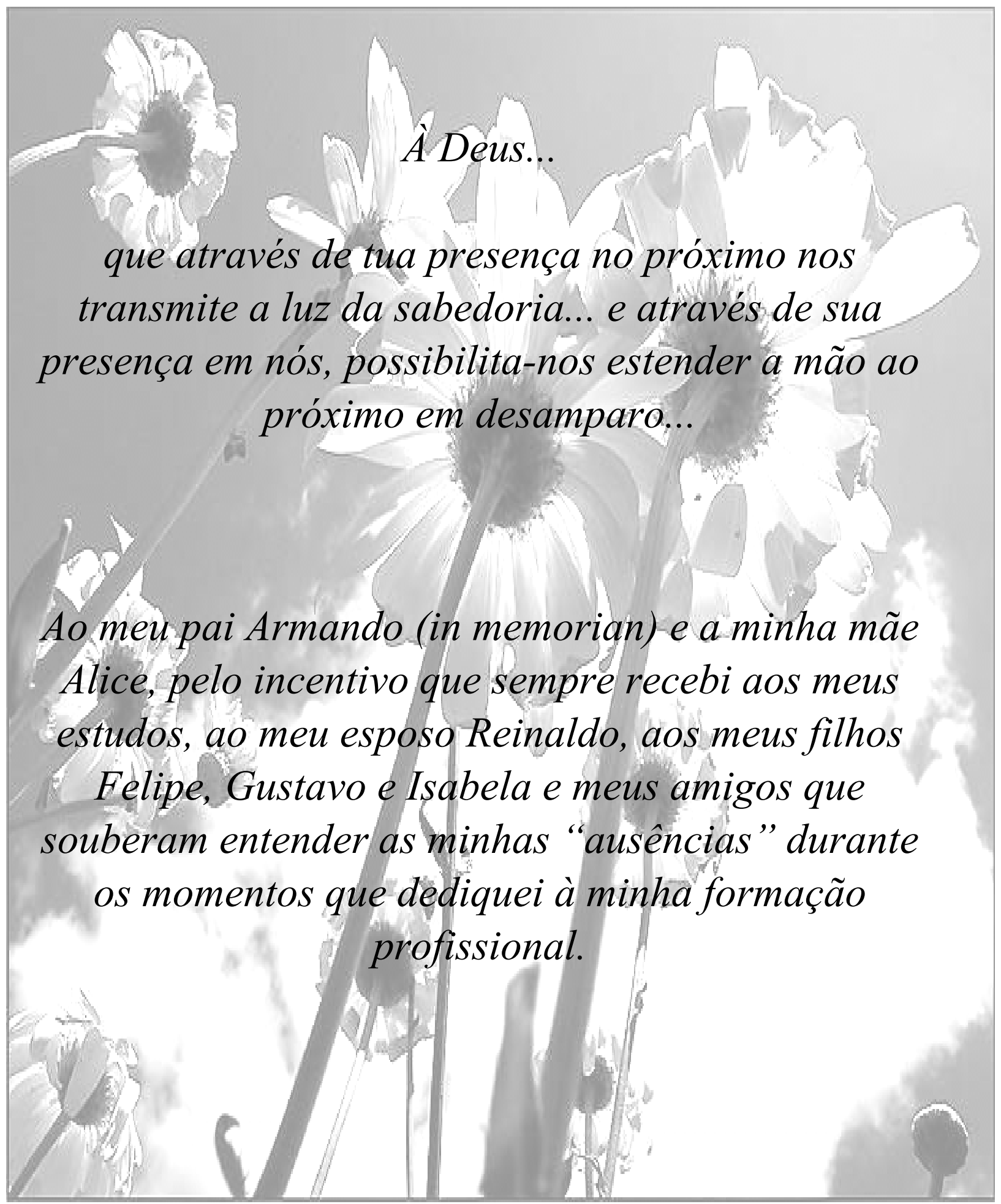




\section{Ofereço uma rosa}

A quem me deu perfume, a quem me deu sentido, a quem só me fez bem, ofereço uma rosa àqueles que sorriram comigo, aqueles que comigo partilharam lágrimas, aqueles que souberam da minha existência.

Ofereço uma rosa, aos nobres do sentir, aos ricos do viver, aos imperadores do amor.

Ofereço uma simples rosa, àqueles que simplesmente foram amigos, que ternamente fizeram do silêncio sair sons, que cantaram comigo, que me olharam e me sentiram.

Ofereço a minha rosa, Àqueles realmente interessantes!

(Autor desconhecido) 
Aos amigos do Centrinho,

\section{Castelos de areia}

Compreendi que tudo em nossas vidas, todas as coisas que gastam tanto de nosso tempo e de nossa energia para construir, tudo é passageiro, tudo é feito de areia; o que permanece é só o relacionamento que temos com as outras pessoas.

Mais cedo ou mais tarde, uma onda virá e destruirá ou apagará o que levamos tanto tempo para construir.

E quando isso acontecer,

Somente aquele que tiver as mãos de outro alguém para segurar, será capaz de rir e recomeçar.

(Autor desconhecido) 
Aos amigos da Faculdade de Serviço Social,

"Depois de algum tempo você aprende que

verdadeiras amizades continuam a crescer

mesmo a longas distâncias, e o que importa

não é o que você tem na vida, mas quem você

tem na vida."

William Shakespeare 
Maria Inês,

Agradeço sua amizade que, gentilmente, você me permitiu desfrutar. Agradeço a energia que, positivamente muitas batalhas você me ajudou a ganhar. Agradeço a força que, bravamente, você conseguiu me ensinar. Agradeço de coração todo carinho que pôde me dar... 
Sonia,

Amizade não se explica Amigos sabem quando serão amigos, pois compartilham momentos... dão força...

Estão sempre lado a lado...

Nas conquistas...

... nas derrotas..

Nas horas boas...

... e nas dificeis...

Amizade nem sempre é pensar do mesmo jeito...

Mas abrir mão... de vez em quando...

Amizade é compartilhar segredos...

... emoções...

É compreensão...

... é diversão...

É contar com alguém...

... sempre que precisar...

E ter algo em comum...

É não ter nada em comum...

$\dot{E}$ saber que se tem mais em comum

do que se imagina...

Amizade que é amizade nunca acaba... 
Reinaldo,

De almas sinceras a união sincera Nada há que impeça. Amor não é amor Se quando encontra obstáculos se altera Ou se vacila ao mínimo temor.

Amor é um marco eterno, dominante, Que encara a tempestade com bravura; E astro que norteia a vela errante Cujo valor se ignora lá na altura.

Amor não teme o tempo, muito embora Seu alfanje não poupe a mocidade; Amor não se transforma de hora em hora, Antes se afirma, para a eternidade.

Se isto é falso, e que é falso alguém provou, Eu não sou poeta, e ninguém nunca amou. 
Tio Gastão,

Agradeço por sua luta incansável pela mesma causa que, hoje, oficialmente defendo e espero que todos nós possamos participar dos frutos que certamente serão positivos se você continuar em cena.

\section{E lembrando São Francisco, nosso protetor, sabemos que é a nossa missão:}

ser instrumento de paz levar o amor levar o perdão levar a união levar a fé levar a verdade levar a esperança levar a alegria levar a luz. 
SUMÁRIO

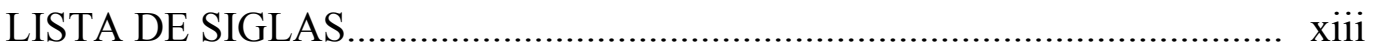

LISTA DE FIGURAS...........................................................................

LISTA DE TABELAS.................................................................... xvi

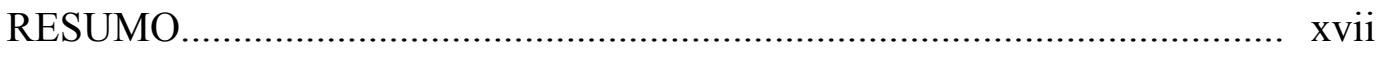

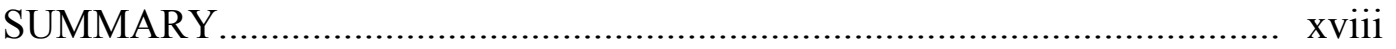

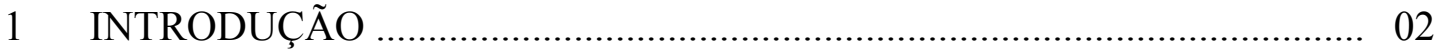

2 FUNDAMENTAÇÃO TEÓRICA............................................................. 06

2.1 A política nacional de saúde................................................................ 06

2.2 A questão da humanização e da qualidade nos serviços de saúde............. 10

2.2.1 Humanização....................................................................... 10

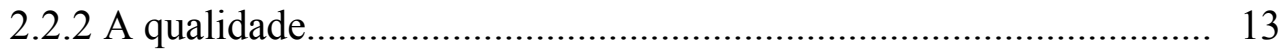

2.3 A formação e a capacitação dos profisssionais de saúde............................ 16

2.4 Política de Educação e Desenvolvimento para o SUS................................ 19

2.4.1 Pólos de Educação Permanente em Saúde........................................ 22

2.4.1.1 As funções dos pólos....................................................... 22

2.4.1.2 Composição dos pólos de Educação Permanente em Saúde para o SUS ............................................................... 23

2.5 As malformações labiopalatinas.............................................................. 25

2.5.1 Etiologia, conceituação e classificação........................................... 25

2.5.2 Aspectos estéticos funcionais e psicossociais................................. 27

2.5.3 As condutas terapêuticas para reabilitação das malformações

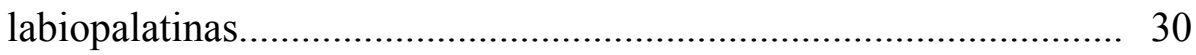

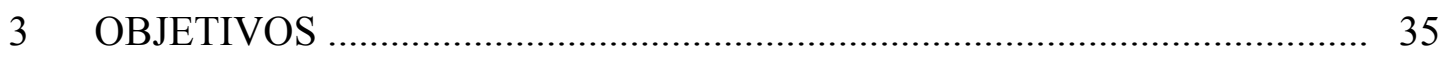

3.1 Objetivo Geral ............................................................................. 35

3.2 Objetivos Específicos ......................................................................... 35

4 MATERIAL E MÉTODO _...................................................................... 37

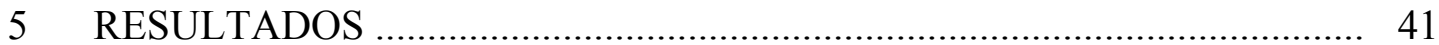

5.1 Conhecimento e cadastramento dos serviços de reabilitação englobando as diferentes áreas (fonoaudiologia, odontologia, psicologia e serviço social). 
5.2 Identificação das formas de articulação/parceria dos serviços/reabilitadores com órgãos locais (universidade, secretaria de saúde e outros).

5.3 Perfil profissional dos reabilitadores das organizações identificando sua procedência, seu nível de articulação técnico, científico e funcional com o HRAC

5.4 Identificação das necessidades e interesse dos reabilitadores em participar do programa de capacitação do HRAC.

5.5 Ampliação das formas de intercâmbio e articulação dos serviços/reabilitadores com diferentes organizações públicas, privadas e ou do Terceiro Setor.

5.6 Contribuição para a construção de um pólo de capacitação de reabilitadores tendo com compromisso a humanização e qualificação 96 da atenção.

6 CONSIDERAÇÕES FINAIS................................................................... 103

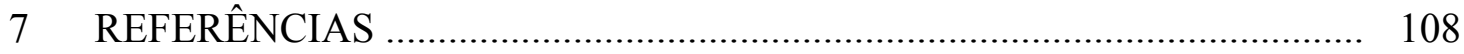

ANEXOS 
LISTA DE SIGLAS

ABRAHUE Associação Brasileira de Hospitais Universitários e de Ensino

CBO Classificação Brasileira de Ocupações

CCEB Critérios de Classificação Econômica Brasil

CEFOR Centros Formadores

CNE Conselho Nacional de Educação

CNES Cadastro Nacional de Estabelecimentos de Saúde

COL Cursos On-Line

CONASEMS Conselho Nacional de Secretários Municipais de Saúde

CONASS Conselho Nacional de Secretários Estaduais de Saúde

DATASUS Departamento de Informática do SUS

DEGES Departamento de Gestão da Educação na Saúde

EAD Educação a Distância

ENSP Escola Nacional de Saúde Pública Sérgio Arouca

EPS Educação Permanente em Saúde

ESP Escolas de Saúde Pública

ETS-SUS Escolas Técnicas de Saúde do SUS

FIOCRUZ Fundação Oswaldo Cruz

FMUSP Faculdade de Medicina da Universidade de São Paulo

FOB Faculdade de Odontologia de Bauru

FUNCRAF Fundação para o Estudo e Tratamento das Deformidades Crânio-Faciais

GT Grupo de Trabalho

HRAC Hospital de Reabilitação de Anomalias Craniofaciais

IBGE Instituto Brasileiro de Geografia e Estatística

LOAS Lei Orgânica da Saúde

MEC Ministério da Educação e Cultura

NESC Núcleos de Saúde Coletiva

NIH National Institute of Health

PEPS Pólos de Educação Permanente em Saúde

PET Programa de Educação para o Trabalho 
REDE Rede Nacional de Associações de Pais e Portadores de Fissuras Lábio PROFIS Palatais

RRTDCF Rede de Referência no Tratamento das Deformidades Craniofaciais no Brasil

RUTE Rede Universitária de Telemedicina

SAC Serviço de Atendimento ao Consumidor

SES Secretaria Estadual de Saúde

SGETES Secretaria de Gestão do Trabalho e da Educação na Saúde

SIH Serviço de Informática Hospitalar

SUS S Sistema Único de Saúde

TFD Tratamento Fora do Domicílio

UF University of Flórida

USP Universidade de São Paulo 


\section{LISTA DE FIGURAS}

Figura 01- Proposta política do Ministério da Saúde ......................................... 21

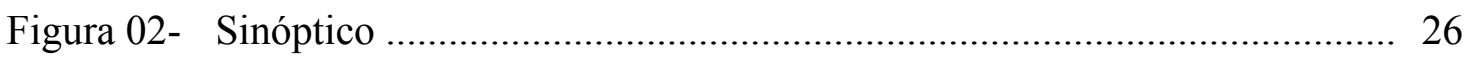

Figura 03- Seqüência de tratamento das fissuras labiopalatinas .......................... 31

Figura 04- Distribuição do universo e amostra da pesquisa segundo: número de pacientes, situação de tratamento e abrangência geográfica ................. 43

Figura 05- Distribuição do universo dos serviços e abrangência geográfica ........... 45

Figura 06- Recursos comunitários de apoio à reabilitação na cidade/região dos pacientes cadastrados no HRAC e sua participação em associações ..... 49

Figura 07- Distribuição dos serviços segundo cidade e Estado .............................. 53

Figura 08- Número de Pólos de Educação Permanente em Saúde (PEPS), por região e estados .......................................................................... 84

Figura 09- Hospitais de Ensino que atendem malformação labiopalatal (buco maxilo-facial) e/ou malformações craniofaciais ............................... 94

Figura 10- Estabelecimentos de saúde credenciados pelo Ministério da Saúde ...... 95 


\section{LISTA DE TABELAS}

Tabela 01- Motivos da não realização de tratamento na cidade/região de origem..... 41

Tabela 02- Classificação dos serviços identificados pelos pacientes em tratamento na cidade/região de origem segundo: tipologia, natureza, áreas de atendimento e satisfação com os tratamentos

Tabela 03- Caracterização dos serviços identificados segundo: finalidades, 54 natureza, áreas de atendimento, elegibilidade e instrumento de avaliação da satisfação dos usuários

Tabela 04- Articulação dos serviços/reabilitadores com outros órgãos locais e com o Hospital de Reabilitação de Anomalias Craniofaciais

Tabela 05- Formas de articulação dos serviços/reabilitadores com o Hospital de Reabilitação de Anomalias Craniofaciais

Tabela 06- Desenvolvimento institucional de programas/projetos de capacitação profissional (humanização, qualidade e outros)

Tabela 07- Outros cursos de capacitação profissional .... 59

Tabela 08- Perfil dos reabilitadores segundo procedência

Tabela 09- Perfil dos reabilitadores segundo: formação, experiência e desenvolvimento profissional ..........................................................6 64

Tabela 10- Perfil dos profissionais segundo vínculo com o serviço ....................... 67

Tabela 11- Perfil dos profissionais segundo facilidades para intercâmbio .............. 69

Tabela 12- Perfil dos reabilitadores segundo articulação técnico-cientifico e funcional com o HRAC …................................................................. 71

Tabela 13- Participação em programas e projetos de humanização e qualidade ...... 73

Tabela 14- Diagnóstico dos problemas apresentados pelos pacientes .................... 75

Tabela 15- Ocorrência e especificação das principais dificuldades para o atendimento do paciente ................................................................ 77

Tabela 16- Principais programas/atividades/ações ............................................... 78

Tabela 17- Recursos terapêuticos ................................................................... 81

Tabela 18- Existência, dos Pólos de Educação na cidade ...................................... 85

Tabela 19- Conhecimento do Pólo de educação permanente na cidade ................... 86

Tabela 20- Necessidade e interesse na criação do pólo de capacitação ................... 86 


\section{RESUMO}

Custódio SAM. Os serviços de apoio à reabilitação aos usuários do Hospital de Reabilitação de Anomalias Craniofaciais: diagnóstico das necessidades de capacitação de reabilitadores. [tese] Bauru: Hospital de Reabilitação de Anomalias Craniofaciais, Universidade de São Paulo; 2007.

Este estudo mapeou os serviços de reabilitação no Brasil utilizados pelos usuários do Hospital de Reabilitação de Anomalias Craniofaciais da Universidade de São Paulo (HRAC/USP) e faz um diagnóstico das necessidades de capacitação dos profissionais que os atendem nas áreas de fonoaudiologia, odontologia, psicologia e serviço social. Os objetivos dessa pesquisa foram: identificar formas de articulação dos serviços/reabilitadores com órgãos locais e HRAC; levantar o perfil dos reabilitadores e conhecer suas necessidades e o interesse em participar do programa de capacitação do HRAC; propor a ampliação das formas de intercâmbio e articulação dos serviços/reabilitadores com diferentes organizações e contribuir para a construção de um pólo de capacitação, tendo como compromisso a humanização e qualificação da atenção. $\mathrm{O}$ estudo teve dois momentos: $1^{\circ}$ ) remessa de questionário para os pacientes do Projeto Florida (475) - projeto interdisciplinar desenvolvido em parceria com a Universidade da Flórida - para identificar os serviços / reabilitadores de seus municípios e/ou região de origem; $2^{\circ}$ ) remessa de questionário aos serviços/reabilitadores identificados (61). Dentre esses, obtivemos resposta de 21 serviços em 19 cidades, oito Estados e três regiões, em sua maioria de natureza pública e do Terceiro Setor, prestando serviços de reabilitação e assistência social, estabelecendo relações de parceria/convênios com o próprio HRAC, com Prefeituras Municipais/Secretarias de Saúde e Associações de Pais e Pessoas com Fissura Labiopalatina. Os profissionais (72) relataram dificuldades para a prática profissional na área da fissura, com destaque para área de fonoaudiologia, o que sugere medidas urgentes no sentido de se estabelecer estratégias. (95,4\%) dos profissionais demonstraram interesse e a necessidade de participar de cursos de capacitação. As sugestões para o atendimento dessa demanda são: aprofundamento no conteúdo dos cursos específicos ministrados no Curso de Anomalias Craniofaciais, ampliação do conteúdo da disciplina de Política de Saúde e Reabilitação ministrada nos cursos de Pós-graduação, chegando à criação de um Núcleo de Telessaúde do HRAC/USP, Articulação da Rede Nacional de serviços na área da fissura labiopalatina que podem impulsionar a criação do pólo de capacitação do HRAC na área, em parceria com outros pólos de educação permanente do SUS no Brasil e do programa de descentralização do HRAC/USP.

DESCRITORES: fissura labiopalatina - formação/capacitação profissional - pólo de educação - telessaúde - humanização 


\section{SUMMARY}

Custódio SAM. The support services for Hospital for Rehabilitation of Craniofacial Anomalies patients: focusing the needs for further training of rehabilitators. [thesis]. Bauru: Hospital for Rehabilitation of Craniofacial Anomalies, University of São Paulo; 2007.

This study investigated the services/programs accessed by patients from HRAC-USP, at their cities of origin, focusing on the professionals' reported need for further training in the areas of communication disorders, dentistry, psychology and social work. The objectives of this research were: 1) to identify the route followed by professionals/services in the hospital and other organizations to locate and to have access to out-services/programs for continuity care in craniofacial area; 2) to describe the profile of professionals serving the HRAC's patients in their cities of origin and to learn about these professionals need and interest in further training in the craniofacial area; 3) to propose means to expand exchange of services and exchange between professionals among existing organizations serving patients with craniofacial anomalies; and 4) to contribute to the development of a network for continuing education focusing on humanization and quality of services. The study had 2 phases: 1) during phase 1 a Questionnaire investigating the existence and the access to outservices/professionals in the patients' city of origin, was distributed to 475 patients participating in another research involving the HRAC and the University of Florida (Florida Project); 2) during phase 2 another questionnaire was sent to the services/ professionals serving the HRAC's patients in their cities of origin and to learn about their profile need and interest in further training in the craniofacial area; was sent to all 61 services identified during phase. Out of the 61 services contacted a total of 21 replied to the second questionnaire. These services represented 19 different cities, 8 states and 3 regions of the country. Most of the services were supported with public or non governmental organizations resources and offered social or rehabilitative services by means of partnerships with the HRAC, local city government or parent/patients' support groups. The 72 professionals from the 21 services investigated that replied to the second questionnaire reported limited abilities to practice in the craniofacial areas, mainly Communication Disorders, suggesting the urgent need for the development of a network for continuing education. A total of $95.4 \%$ professionals indicated need and interest to participate in further training programs. The author's suggestions for attending the reported needs are: 1) to advance the content of already existing courses at HRAC in the Craniofacial Area; 2) to improve the content of the Political Health and Rehabilitative Services discipline already ministered at the Graduate Program at HRAC; 3) the development of a Center for Interactive-Distant Learning at HRAC (Telessaúde HRAC-USP), 4) the organization of all national services in the Craniofacial Area fostering the development of a National Network for Training in Craniofacial Anomalies in a partnership with other networks supported by the Ministry of Health (SUS) and in agreement with HRAC goal for decentralization of services.

Key Words: Cleft Lip and Palate - Professional Education/Training - Network for Continuing Education and Distant Learning - Humanization 
1 INTRODUÇÃO

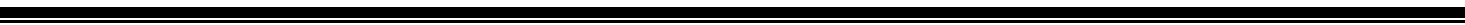




\section{INTRODUÇÃO.}

O Hospital de Reabilitação de Anomalias Craniofaciais da Universidade de São Paulo (HRAC-USP), criado em 1967, é hoje um exemplo concreto do avanço técnicocientífico e das possibilidades de reabilitação. Tem por finalidade o ensino, a pesquisa e a extensão de serviços a pessoas com anomalia craniofacial, síndrome relacionada e/ou distúrbio da audição. É considerado, por profissionais nacionais e estrangeiros, um dos mais completos centros especializados de reabilitação na área.

O tratamento inclui todas as etapas terapêuticas necessárias para a reabilitação e integração social e é realizado por uma equipe interdisciplinar. Essa interdisciplinaridade é definida como a interação de várias disciplinas, numa relação de reciprocidade e mutualidade; pressupõe uma atitude diferente a ser assumida frente ao problema de conhecimento, isto é, substituir a concepção fragmentária pela unitária do ser humano (Sampaio et al 1989).

$\mathrm{O}$ atendimento prestado é integral, suportado financeiramente com recursos da Universidade de São Paulo (USP) e Ministério da Saúde especialmente por meio do Sistema Único de Saúde (SUS), mantendo o Hospital relações de parceria com a Fundação para o Estudo e Tratamento das Deformidades Crânio-Faciais (FUNCRAF).

Ao todo, são mais de 71 mil pacientes matriculados (até dezembro de 2006) com diferentes anomalias craniofaciais. Deles, 45.085 com fissuras labiopalatinas, 2.417 com outras malformações e 23.597 com deficiências auditivas. São pessoas procedentes de várias localidades do Brasil e de países vizinhos. Especificamente os pacientes com fissuras labiopalatinas são procedentes das diferentes regiões do país, assim distribuídos: Sudeste (61\%), Sul (18\%), Centro-Oeste (11\%), Norte $(5,0 \%)$, Nordeste $(4,7 \%)$; além do Exterior $(0,3 \%)^{1}$. De um total de 5.560 municípios existentes no Brasil (INSTITUTO BRASILEIRO DE GEOGRAFIA 2001), 3.701 (66,6\%) estão cadastrados no HRAC/USP.

$\mathrm{Na}$ sua maioria, esses pacientes pertencem a estratos baixos ou médios, de acordo com a classificação socioeconômica utilizada no HRAC, que compreende os seguintes indicadores: situação econômica da família, número de membros, escolaridade, ocupação e habitação, sistematizados em seis estratificações: baixa inferior (BI) (24\%), baixa superior (BS) (47\%), média inferior (MI) (20,5\%), média

\footnotetext{
${ }^{1}$ Fonte: Serviço de Informática Hospitalar (SIH) - HRAC/USP.
} 
(ME) (7\%), média superior (MS) (1,4\%) e alta (A) (0,1\%). Tal classificação baseia-se na metodologia de Graciano et al (1999). Independentemente dos indicadores adotados, esses índices vão de encontro aos índices estabelecidos pelos Critérios de Classificação Econômica Brasil (CCEB) (Associação Brasileira de Empresas de Pesquisa 2007) ou "Critério Brasil", que separa os consumidores em classes (A, B, C, D e E ) nas seguintes distribuições: A1 (1\%), A2 (5\%), B1(5\%), B2 ( 9\%), C (36\%), D ( (31\%) e E (4\%). Portanto, a maior parte da população brasileira também pertence a camadas menos favorecidas.

Como o hospital tem um compromisso assumido com os seus usuários na viabilização dos serviços de apoio à reabilitação nas diferentes regiões do país, mediante parcerias com associações, núcleos, fundações (subsedes), prefeituras municipais e outros, surgiu o interesse em conhecer os serviços de reabilitação utilizados pelos usuários do HRAC, diagnosticando as necessidades de capacitação dos reabilitadores.

Nesse sentido, acreditamos que este estudo contribuirá para o reconhecimento do HRAC como um pólo de capacitação na área das fissuras labiopalatinas, promovendo a articulação de organizações para a capacitação e educação permanente de recursos humanos em saúde/reabilitação com o compromisso de humanização e qualidade da atenção.

Esses pólos são orientados para atenderem a demanda de capacitação do pessoal constituindo-se em uma rede de organizações comprometidas com a integração ensinoserviço, (Cerveira 2002).

O presente trabalho está estruturado em capítulos, à partir da fundamentação teórica. O segundo capítulo aborda a política nacional de saúde; a questão da humanização e da qualidade nos serviços de saúde; a formação e a capacitação dos profissionais de saúde; a Política de Educação e Desenvolvimento para o SUS e as malformações labiopalatinas.

O terceiro capítulo refere-se à definição dos objetivos do estudo: mapear e caracterizar os serviços de reabilitação no Brasil utilizados pelos usuários do HRAC, diagnosticando as necessidades de capacitação dos reabilitadores nas áreas de fonoaudiologia, odontologia, psicologia e serviço social.

O material e o método são apresentados no quarto capítulo, que detalha os dois momentos do estudo, a saber: o $1^{\circ}$ momento que consiste na identificação dos serviços / 
reabilitadores utilizados pelos pacientes do HRAC e a sua caracterização sob a ótica do usuário; no $2^{\circ}$ momento, atendendo propriamente aos objetivos do estudo, chegou-se a caracterização dos serviços/reabilitadores, a identificação das formas de articulação dos órgãos locais (universidades, secretarias de saúde e outros), o perfil profissional dos reabilitadores e a identificação de suas necessidades e interesse em participar do programa de capacitação do HRAC.

No quinto capítulo foram apresentados os resultados correlacionando-os à fundamentação teórica em resposta aos objetivos propostos pelo estudo.

A relevância deste estudo está na possibilidade de responder aos questionamentos sobre o interesse e a necessidade de capacitação dos reabilitadores nas áreas de fonoaudiologia, odontologia, psicologia e serviço social, assim como de contribuir para construção de um pólo de capacitação/formação de reabilitadores.

O que se conclui basicamente é o HRAC, antes de se constituir em um pólo, firme-se como integrante do processo de teleducação - em princípio, em forma de teleconsultoria multidisciplinar, contemplando todas as áreas envolvidas na reabilitação - para garantir uma assistência qualificada e descentralizada às pessoas com fissuras labiopalatinas não só matriculadas no próprio Hospital como as de outros centros. Esse seria um primeiro passo para a criação do pólo de capacitação do HRAC na área, em parceria com outros pólos de educação permanente do SUS no Brasil e do programa de descentralização do HRAC/USP. 
2 FUNDAMENTAÇÃO TEÓRICA 


\section{FUNDAMENTAÇÃO TEÓRICA.}

\section{1 - A política nacional de saúde.}

Com a promulgação da Constituição Federal de 1988, (Brasil 1988), a Política Nacional de Saúde passou a ser elaborada de acordo com os dispositivos nela contidos referentes à saúde, adquire uma nova face do ponto de vista jurídico. A Constituição anterior (1969) apenas mencionava a saúde como direito do cidadão, reduzindo-a ao conceito de "Assistência Sanitária Hospitalar e Médico-Preventiva” (Lima 1996 p17).

O sistema de saúde implantado pelo SUS e o que o antecedeu são opostos, destacando-se no sistema atual a ampliação do entendimento do que é a saúde, ou seja, que esta não se limita à presença de enfermidade e sua cura, mas sim à ausência de doenças, como resultado de múltiplas condições sociais, econômicas, sanitárias e alimentares que permeiam o cotidiano das pessoas.

Atualmente, a saúde não é mais considerada como mera assistência médicohospitalar, curativa ou preventiva; é o resultado de políticas públicas do Governo.

Na Lei Orgânica da Saúde - Lei 8080 (Brasil 1990 p1), o art. 3 dispõe que "a saúde tem como fatores determinantes e condicionantes, entre outros, a alimentação, a moradia, saneamento básico, o meio ambiente, o trabalho, a renda, a educação, o transporte, o lazer e o acesso aos bens e serviços essenciais; os níveis de saúde da população expressam a organização social econômica do país".

Pela nova Constituição, a Saúde, a Previdência Social e a Assistência Social compõem a Política de Seguridade Social, que compreende um conjunto integrado de ações de iniciativa dos poderes públicos e da sociedade, destinadas a assegurar os direitos sociais, substituindo as políticas sociais compensatórias, capazes de processar a garantia e o acesso aos mínimos de dignidade e cidadania (Brasil 1988).

$\mathrm{Na}$ Constituição de 1988 a saúde se apresenta como a área que mais sofreu transformações significativas, como:

- alteração do conceito de saúde - como um processo de convergência de políticas públicas, econômica e sociais;

- a instituição da saúde como direito de cidadania e dever do Estado;

- a estratégia do SUS como profundo reordenamento setorial - novo olhar e atuação sobre a saúde individual e coletiva; 
- a construção de um novo modelo de atenção à saúde;

- a descentralização das ações para esfera estadual e municipal, delegando poderes para formulação de política de saúde de acordo com as prioridades locais;

- a democratização do poder local, mediante o estabelecimento de novos mecanismos de gestão, por meio dos conselhos.

Essas mudanças se referem à incorporação do princípio da universalidade, que indica ampliação do acesso, na medida em que toda a população passa a ter direito aos serviços de saúde até então restritos aos contribuintes da Previdência Social.

A formulação de uma política voltada para a organização de um sistema de saúde equânime, integral e resolutivo requer, para o atendimento efetivo dos problemas de saúde da população, a realização de um conjunto de ações articuladas entre os diferentes níveis de complexidade da atenção à saúde. $\mathrm{O}$ modelo atual de organização da atenção está estruturado em três níveis hierárquicos complementares de atenção à saúde: atenção básica, de média e alta complexidade (Brasil 2007a).

\section{Atenção básica à Saúde}

Constitui o primeiro nível de atenção à saúde, de acordo com o modelo adotado pelo SUS. Engloba um conjunto de ações de caráter individual ou coletivo, que envolve a promoção da saúde, a prevenção de doenças, o diagnóstico, o tratamento e a reabilitação dos pacientes. Nesse nível da atenção à saúde, o atendimento aos usuários deve seguir uma cadeia progressiva, garantindo o acesso aos cuidados e às tecnologias necessárias e adequadas à prevenção e ao enfrentamento das doenças, para prolongamento da vida.

A atenção básica é dispensada pelas seguintes especialidades básicas: clínica médica, pediatria, obstetrícia, ginecologia, inclusive as emergências referentes a essas áreas. Cabe também à atenção básica da Saúde encaminhar os usuários para os atendimentos de média e alta complexidade. Uma atenção básica bem organizada garante resolução de cerca de $80 \%$ das necessidades e problemas de saúde da população de um município e consolida os pressupostos do SUS: eqüidade, universalidade e integralidade.

A estratégia adotada pelo Ministério da Saúde como prioritária para a organização da atenção básica é a estratégia Saúde da Família, que estabelece vínculo sólido de co-responsabilização com a comunidade descrita. A responsabilidade pela 
oferta de serviços de atenção básica à saúde é da gestão municipal, sendo o financiamento para as ações básicas à saúde de responsabilidade das três esferas de governo. (Brasil 2007a).

\section{Média Complexidade}

Compõe-se por ações e serviços que visam atender aos principais problemas de saúde e agravos da população, cuja prática clínica demande disponibilidade de profissionais especializados e o uso de recursos tecnológicos de apoio diagnóstico e terapêutico.

Os grupos que compõem os procedimentos de média complexidade do Sistema de Informações Ambulatoriais são os seguintes: procedimentos especializados realizados por profissionais médicos, outros de nível superior e nível médio; cirurgias ambulatoriais especializadas; procedimentos traumato-ortopédicos; ações especializadas em odontologia; patologia clínica; anatomopatologia e citopatologia; radiodiagnóstico; exames ultra-sonográficos; diagnose; fisioterapia; terapias especializadas; próteses e órteses; anestesia (Brasil 2007a).

O gestor deve adotar critérios para a organização regionalizada das ações de média complexidade, considerando a necessidade de qualificação e especialização dos profissionais para o desenvolvimento das ações; os dados epidemiológicos e socio demográficos de seu município; a correspondência entre a prática clínica e capacidade resolutiva diagnóstica e terapêutica; a complexidade e o custo dos equipamentos; a abrangência recomendável para cada tipo de serviço; economias de escala e métodos e técnicas requeridas para a realização das ações.

\section{Alta Complexidade}

Conjunto de procedimentos que, no contexto do SUS, envolve alta tecnologia e alto custo, objetivando propiciar à população acesso a serviços qualificados, integrando os serviços aos demais níveis de atenção à saúde (atenção básica e de média complexidade).

As principais áreas que compõem a alta complexidade do SUS, e que estão organizadas em "redes", são: assistência ao paciente com doença renal crônica (por meio dos procedimentos de diálise); assistência ao paciente oncológico; cirurgia cardiovascular; cirurgia vascular; cirurgia cardiovascular pediátrica; procedimentos da 
cardiologia intervencionista; procedimentos endovasculares extracardíacos; laboratório de eletrofisiologia; assistência em traumato-ortopedia; procedimentos de neurocirurgia; assistência em otologia; cirurgia de implante coclear; cirurgia das vias aéreas superiores e da região cervical; cirurgia da calota craniana, da face e do sistema estomatognático; procedimentos em fissuras labiopalatais ${ }^{2}$; reabilitação protética e funcional das doenças da calota craniana, da face e do sistema estomatognático; procedimentos para a avaliação e tratamento dos transtornos respiratórios do sono; assistência aos pacientes com queimaduras; assistência aos pacientes com obesidade (cirurgia bariátrica); cirurgia reprodutiva; genética clínica; terapia nutricional; distrofia muscular progressiva; osteogênese imperfecta; fibrose cística e reprodução assistida (Brasil 2007a).

$\mathrm{Na}$ tentativa de superar a fragmentação das políticas e programas de saúde, a qualificação da gestão e o reconhecimento da autonomia dos entes federados, o Ministério da Saúde por meio da PORTARIA № 399/GM, de 22 de fevereiro de 2006 (Brasil, 2007b), Divulga o Pacto pela Saúde - Consolidação do SUS e aprova as Diretrizes Operacionais do Referido Pacto.

O Pacto pela Saúde é um conjunto de reformas institucionais do SUS pactuado entre as três esferas de gestão (União, Estados e Municípios) com o objetivo de promover inovações nos processos e instrumentos de gestão, visando alcançar maior eficiência e qualidade das respostas do SUS. Ao mesmo tempo, o Pacto pela Saúde redefine as responsabilidades de cada gestor em função das necessidades de saúde da população e na busca da equidade social. O Pacto pela Saúde implicará o exercício simultâneo de definição de prioridades articuladas e integradas nos três componentes: Pacto pela Vida, Pacto em Defesa do SUS e Pacto de Gestão do SUS. (Brasil, 2007b)

O Pacto pela Vida está constituído por um conjunto de compromissos sanitários, expressos em objetivos de processos e resultados e derivados da análise da situação de saúde do País e das prioridades definidas pelos governos federal, estaduais e municipais.

As prioridades do Pacto pela Vida são: saúde do idoso; câncer de colo de útero e de mama; mortalidade infantil e materna; doenças emergentes e endemias, com ênfase na dengue, hanseníase, tuberculose, malária e influenza; promoção da saúde; atenção básica à saúde.

2 O HRAC foi cadastrado como um serviço de alta complexidade na área das fissuras labiopalatinas em 1994, conforme portaria n. 62 - Ministério da Saúde. 
O Pacto em Defesa do SUS envolve ações concretas e articuladas pelas três instâncias federativas no sentido de reforçar o SUS como política de Estado mais do que política de governos; e de defender, vigorosamente, os princípios básicos dessa política pública, inscritos na Constituição Federal.

As prioridades do Pacto em Defesa do SUS são:

- implementar um projeto permanente de mobilização social ${ }^{3}$

- elaborar e divulgar a carta dos direitos dos usuários do SUS.

O Pacto de Gestão estabelece as responsabilidades claras de cada ente federado de forma a diminuir as competências concorrentes e a tornar mais claro quem deve fazer o quê, contribuindo, assim, para o fortalecimento da gestão compartilhada e solidária do SUS.

As prioridades do Pacto de Gestão são: definir de forma inequívoca a responsabilidade sanitária de cada instância gestora do SUS; estabelecer as diretrizes para a gestão do SUS, com ênfase na descentralização; regionalização; financiamento; programação pactuada e integrada; regulação; participação e controle social; planejamento; gestão do trabalho e educação na saúde. (Brasil, 2007b)

O Pacto pela Saúde do SUS o efetivará como "política pública em defesa da vida", reconhecendo que estados, municípios e serviços de saúde estão implantando e implementando práticas de humanização nas ações de atenção e gestão, com bons resultados.

\section{2 - A questão da humanização e da qualidade nos serviços de saúde.}

\subsection{1 - Humanização.}

O sentido atribuído ao termo humanização se refere à articulação entre a qualidade técnica da assistência e o reconhecimento dos direitos do usuário e os seus valores e subjetividade, aliados à valorização profissional.

\footnotetext{
${ }^{3}$ Tal projeto tem a finalidade de: mostrar a saúde como direito de cidadania e o SUS como sistema público universal garantidor desses direitos; alcançar, no curto prazo, a regulamentação da Emenda Constitucional $\mathrm{n}^{\circ} 29^{3}$, pelo Congresso Nacional; garantir, no longo prazo, o incremento dos recursos orçamentários e financeiros para a saúde; aprovar o orçamento do SUS, composto pelos orçamentos das três esferas de gestão, explicitando o compromisso de cada uma delas. PORTARIA № 399/GM de 22 de fevereiro de 2006. (Brasil 2006b)
} 
Humanizar é, por definição, tornar humano, dar condição humana; implica em acolhimento e, sobretudo, em empatia e diálogo. Humanização envolve estratégias dirigidas a aumentar o poder do doente ou da população em geral perante o poder e autoridade do saber e das práticas sanitárias (Bosi e Uchimura 2006).

A humanização na área da saúde tem sido um assunto bastante tratado nos últimos tempos, pois existe uma grande preocupação por parte dos profissionais da saúde em oferecer uma assistência com qualidade, apresentando desta forma como objetivo central o atendimento das necessidades individuais dos pacientes e o contato mais próximo com os familiares (Santos et al 1999).

A família deve ser compreendida como um aliado importante da equipe, podendo atuar como um recurso por meio do qual o paciente pode reafirmar e, muitas vezes, "recuperar" sua confiança no tratamento de forma a investir nas suas possibilidades de reabilitação (Santos et al 1999).

Na construção de um serviço humanizado é preciso transitar, constantemente, de uma forma a outra. Trocar velhos modelos por novos hábitos, exercer a criatividade, a reflexão coletiva, o agir comunicativo, a participação democrática na busca de soluções que sejam úteis para cada realidade singular. A humanização da assistência à saúde envolve, necessariamente, o trabalho conjunto de diferentes profissionais, em todos os níveis de atendimento (dos profisssionais de primeiro contato à alta direção). $\mathrm{O}$ trabalho humanizado pressupõe o debate sobre a vida institucional, suas dificuldades, angústias frente ao mundo do trabalho e metas a serem alcançadas; presume que os trabalhadores participem de alguma maneira na tomada de decisões, na definição das tarefas e na construção de projetos que lhes digam respeito.

O trabalho de humanização desenvolve atividades que envolvem o paciente e seus familiares, contribuindo efetivamente para a diminuição da ansiedade; melhoria na qualidade de vida; incentivo à troca de experiências; maior reflexão sobre o processo de saúde, resgatando no paciente a condição de "ser humano" (Fontana et al 1998), proporcionando, assim, maior acolhimento, sem perder de vista o caráter educativo.

Aspectos como a efetividade do acolhimento, a qualidade das relações interpessoais na organização dos serviços, a ética no cuidado, as linguagens em que se desenvolvem os diálogos e a natureza da escuta que se realiza no processo assistencial, dentre muitas outras dimensões do cuidado, exigem a avaliação qualitativa dos programas de humanização (Bosi e Uchimura 2006). 
A humanização é uma política transversal, perpassa as diferentes ações e instâncias gestoras do SUS que implica em traduzir os princípios do SUS em modos de operar dos diferentes equipamentos e sujeitos da rede de saúde; construir trocas solidárias e comprometidas com a dupla tarefa de produção de saúde e produção de sujeitos; oferecer um eixo articulador das práticas em saúde, destacando o aspecto subjetivo nelas presente; contagiar, por atitudes e ações humanizadoras, a rede do SUS, incluindo gestores, trabalhadores da saúde e usuários. Para isso, de acordo com Brasil (2002), a Humanização do SUS se operacionaliza com:

- a troca e a construção de saberes;

- o trabalho em rede com equipes multiprofissionais;

- a identificação das necessidades, desejos e interesses dos diferentes sujeitos do campo da saúde;

- o pacto entre os diferentes níveis de gestão do SUS (federal, estadual e municipal), entre as diferentes instâncias de efetivação das políticas públicas de saúde (instâncias da gestão e da atenção), assim como entre gestores, trabalhadores e usuários desta rede;

- o resgate dos fundamentos básicos que norteiam as práticas de saúde no SUS, reconhecendo os gestores, trabalhadores e usuários como sujeitos ativos e protagonistas das ações de saúde;

- a construção de redes solidárias e interativas, participativas e protagonistas do SUS.

“A proposta de humanização dos serviços públicos de saúde é, portanto, um valor básico para conquistar uma melhor qualidade no atendimento à saúde dos usuários e nas condições de trabalho dos profissionais de todo o sistema de saúde. A humanização tem como meta uma nova cultura institucional, que possa instaurar padrões de relacionamento ético entre os gestores, técnicos e usuários” (Brasil 2002 $\mathrm{p} 20)$.

Tal proposta nos remete a uma reflexão sobre a qualidade pretendida nos serviços de saúde que levou à criação de estratégias que envolvem recursos institucionais, humanos e materiais, como poderá ser visto a seguir. 


\subsection{2 - A qualidade.}

Internacionalmente, a qualidade encontra sua primeira fundamentação na Conferência de Alma Ata da Organização Mundial da Saúde, em 1978. A declaração dessa conferência recomendou a cooperação entre profissionais e usuários como parte de uma estratégia mundial para melhorar a saúde, porém somente a partir dos anos 90 a qualidade adquiriu relevância nas políticas públicas de saúde (Serapioni 2006).

Segundo Nogueira (1994), citado por Serapioni (2006 p207), "a novidade do movimento contemporâneo é destacar, em primeiro plano, a opinião do usuário como um aspecto determinante no julgamento da qualidade. A qualidade, de fato, implica na presença de culturas, competência e métodos de avaliação que se desenvolveram nos últimos 15 anos, quando a centralidade do cidadão foi reconhecida e incorporada nas administrações públicas e nos sistemas de saúde, superando as resistências das corporações administrativas e profissionais".

Diversas razões contribuíram para o desenvolvimento de estratégias de garantia da qualidade, entre elas cabe mencionar:

- a inadequada segurança dos sistemas de saúde;

- a ineficiência e os custos excessivos de algumas tecnologias e procedimentos clínicos;

- a insatisfação dos usuários;

- o acesso desigual aos serviços de saúde;

- as longas listas de espera;

- o desperdício inaceitável advindo da baixa eficácia.

A Organização Mundial de Saúde considera que uma assistência de qualidade deve incluir, pelo menos, alguns elementos, tais como: qualidade técnica, uso eficiente dos recursos, controle dos riscos oriundos das práticas assistenciais, acessibilidade da atenção, aceitabilidade por parte dos pacientes, de acordo com Roemer e Aguilar (1988), citado por Serapioni (2006 p209).

As abordagens para a garantia da qualidade da atenção e das práticas assistenciais, segundo Donabedian (1989), citado por Serapioni (2006 p210), são:

- abordagem estrutural que analisa a força de trabalho, condições físicas, instalações, equipamentos e estruturas organizacional, que vão determinar o credenciamento das práticas dos profissionais de saúde e a "acreditação" das estruturas de saúde; 
- abordagem de processo, que analisa se a execução das tarefas e técnicas e procedimentos está sendo como prevista;

- avaliação do processo, que se detém na interação e comunicação entre profissionais e pacientes nas metodologias utilizadas no nível de informação oferecido ao paciente e na dimensão temporal (tempo de espera para conseguir o atendimento e sua duração).

Apesar da tríade estrutura-processo-resultado não ser propriamente uma definição de qualidade, mostra-se como uma importante abordagem para a apreciação da qualidade dos serviços de saúde que possibilita o levantamento de dados sobre as condições estruturais do serviço, as atividades e procedimentos que descrevem a prática da atenção à saúde e os resultados alcançados pelo serviço.

Nessa definição o tema da qualidade está relacionado às outras dimensões: efetividade, eficiência, qualidade técnica, confiabilidade, satisfação, humanização e equidade $^{4}$. Equidade salienta Altieri (1997), citado por Serapioni (2006 p214), "significa criar as condições que permitam a cada usuário potencial tornar-se usuário efetivo".

Para esse fim, os serviços públicos de saúde devem atender não só aos critérios de efetividade, eficiência, qualidade, mas também de equidade, além de responder às exigências legais, éticas, contratuais e às diretrizes estabelecidas pelas autoridades do país, como refere Ovretveit (1996), citado por Serapioni (2006 p212).

Para atender às expectativas do cidadão, atualmente, renovações estruturais e operacionais têm sido buscadas. Com isso, o Programa de Qualidade do Governo Federal $^{5}$ tem como grande desafio tornar o cidadão mais exigente e elevar o padrão dos serviços (Almeida 2002).

As Diretrizes do Programa de Qualidade são: ações para qualidade do atendimento e avaliação continuada de níveis de satisfação dos usuários dos serviços públicos, dentre outras.

\footnotetext{
${ }^{4}$ No que diz respeito à relação com a equidade quando a OMS afirma "cada paciente" seguramente está se referindo a "cada paciente em potencial" e não somente aos que já utilizam os serviços. De fato, é importante não apenas satisfazer as necessidades dos pacientes, mas garantir que todos os que precisam do mesmo serviço possam consegui-lo.

${ }^{5}$ Programa de Qualidade do Governo Federal está em franco desenvolvimento nas organizações públicas brasileiras e é fundamentado na filosofia da Gestão pela Qualidade.
} 
A preocupação com a qualidade e os critérios de que se revestem os procedimentos profissionais afetam diretamente a vida dos usuários e a observância dos princípios adotados pelo SUS: eficácia, efetividade, eficiência, otimidade, aceitabilidade, legitimidade e equidade, constituem, segundo Bittar (2001), os "Sete Pilares da Qualidade”.

A equipe de saúde deve estar preparada para a prestação dos serviços e, também, para o atendimento das necessidades dos indivíduos, nas dimensões biológicas, psicológicas e sociais, a partir do conhecimento teórico e técnico de cada profissional.

“É necessário que o profissional estabeleça algumas etapas para aprimorar seu desempenho mediante uma avaliação:

- conhecimento dos usuários;

- identificação dos recursos disponíveis e/ou necessários;

- planejamento das ações pertinentes;

- monitoramento dos resultados;

- realimentação do processo" (Truite 1995 p13).

As informações fornecidas pelos usuários são imprescindíveis quando transformadas em indicadores que estabelecem metas para o bem-estar da população. Eles identificam e dirigem a atenção para assuntos específicos a serem avaliados e são pontos importantes na condução de outros processos, de avaliação dos serviços.

Alguns indicadores são levantados na literatura (Pesquisa 2002) para melhor avaliar a satisfação dos usuários como: confiabilidade do serviço e pontualidade na execução dos mesmos, capacitação técnica, cortesia no atendimento, acessibilidade, eficiência na resolução de problemas, agilidade na resposta e clareza nas informações prestadas.

“A avaliação em saúde tem como pressuposto a avaliação da eficiência, eficácia e efetividade das estruturas, processos e resultados relacionados ao risco, acesso e satisfação dos cidadãos frente aos serviços públicos de saúde, na busca da resolutividade e qualidade" (Brasil 2004a p5)

Chiavenato (1981) aponta um dos objetivos fundamentais da avaliação: fornecer oportunidades de crescimento e condições de efetiva participação a todos os membros da organização.

Torna-se, portanto, necessário se empenhar no levantamento de informações para a avaliação da satisfação dos usuários, imprescindível para a construção de uma 
base sólida na tomada de decisões, no que tange o fazer profissional, que depende de sua formação e possibilidade de capacitação constante.

\section{3 - A formação e a capacitação dos profissionais de saúde.}

A formação profissional, segundo Silva (1984), não pode se reduzir ao período da graduação ou da pós-graduação. A formação profissional é entendida como um processo dialético, portanto, aberto, dinâmico e permanente, incorporando as contradições decorrentes da inserção da profissão e dos profissionais na própria sociedade. Esse processo contínuo de preparação científica e técnica de profissionais fornecerá subsídios para dar resposta às demandas sociais que se apresentam para profissão, de produção de conhecimento de extensão de profissão.

O Conselho Nacional de Saúde (Brasil 2001) reconhece, conforme resolução n. 218 , de 6 de março de 1997, como profissionais de saúde de nível superior as seguintes categorias: assistentes sociais, biólogos, profissionais de educação física, enfermeiros, farmacêuticos, fisioterapeutas, fonoaudiólogos, médicos, médicos veterinários, nutricionistas, odontólogos, psicólogos e terapeutas ocupacionais.

Este reconhecimento reflete a importância da ação interdisciplinar no âmbito da saúde e a imprescindibilidade das ações realizadas pelos diferentes profissionais de nível superior, constituindo-se num avanço que tende à concepção de saúde e à integralidade da atenção.

De acordo com o Conselho Nacional de Educação - CNE (Brasil 2002), A formação do profissional de saúde tem por objetivo dotar o profissional dos conhecimentos requeridos para o exercício das seguintes competências e habilidades gerais:

I - Atenção à saúde: os profissionais de saúde, dentro de seu âmbito profissional, devem estar aptos a desenvolver ações de prevenção, promoção, proteção e reabilitação da saúde, tanto em nível individual quanto coletivo. Cada profissional deve assegurar que sua prática seja realizada de forma integrada e contínua com as demais instâncias do sistema de saúde, sendo capaz de pensar criticamente, de analisar os problemas da sociedade e de procurar soluções para os mesmos. Os profissionais devem realizar seus serviços dentro dos padrões de qualidade e dos princípios da ética/bioética, tendo em conta que a responsabilidade da atenção à saúde não se 
encerra com o ato técnico, mas sim, com a resolução do problema de saúde, tanto em nível individual como coletivo;

II - Tomada de decisões: o trabalho dos profissionais de saúde deve estar fundamentado na capacidade de tomar decisões visando ao uso apropriado, à eficácia e ao custoefetividade da força de trabalho, de medicamentos, de equipamentos, de procedimentos e de práticas. Para este fim, os mesmos devem possuir competências e habilidades para avaliar, sistematizar e decidir as condutas mais adequadas, baseadas em evidências científicas;

III - Comunicação: os profissionais de saúde devem ser acessíveis e devem manter a confidencialidade das informações a eles confiadas, na interação com outros profissionais de saúde e o público em geral; envolve comunicação verbal, nãoverbal e habilidades de escrita e leitura; o domínio de, pelo menos, uma língua estrangeira e de tecnologias de comunicação e informação;

IV - Liderança: no trabalho em equipe multiprofissional, os profissionais de saúde deverão estar aptos a assumir posições de liderança, sempre tendo em vista o bemestar da comunidade. A liderança envolve compromisso, responsabilidade, empatia, habilidade para tomada de decisões, comunicação e gerenciamento de forma efetiva e eficaz;

V - Administração e gerenciamento: os profissionais devem estar aptos a tomar iniciativas, fazer o gerenciamento e administração tanto da força de trabalho, dos recursos físicos e materiais e de informação, da mesma forma que devem estar aptos a atuar como empreendedores, gestores, empregadores ou lideranças na equipe de saúde;

VI - Educação permanente: os profissionais devem ser capazes de aprender continuamente, tanto na sua formação, quanto na sua prática com responsabilidade e compromisso com a sua educação e o treinamento/estágios das futuras gerações de profissionais, mas proporcionando condições para que haja beneficio mútuo entre os futuros profissionais e os profissionais dos serviços, inclusive, estimulando e desenvolvendo a mobilidade acadêmico/profissional, a formação e a cooperação por meio de redes nacionais e internacionais (Brasil 2002). 
Santana e Christófaro (2003) refletem sobre as repercussões desses processos entre elas, o aumento da cultura científica das populações, concorrendo para mudanças nas suas formas de demandar, selecionar, consumir e avaliar os serviços e produtos disponíveis.

A incorporação da Internet, da telemedicina e da miniaturização de equipamentos e outros avanços tecnológicos na área deverão transformar a maneira de planejar, organizar, administrar e realizar os cuidados à saúde, a partir da atenção básica na forma de meios de apoio diagnóstico e terapêutico que se agregarão ao arsenal de recursos tradicionalmente manejados nesse nível de atendimento.

Compreender essa realidade e entender seus desdobramentos específicos para o trabalho e para a educação no setor saúde representa um desafio, a começar pela definição de papéis e ações no espaço de trabalho e de formação/capacitação profissional do setor que extrapolam normas e processos de auto-regulação profissional.

As articulações entre o processo de formação de profissionais e trabalhadores de saúde e a produção de serviços do setor expressam particularidades da relação geral entre educação e trabalho na sociedade.

$\mathrm{Na}$ atualidade brasileira, esse duelo foi levado para o âmbito jurídico e institucional, ao fazer-se constar na Constituição Federal (Brasil 1988) que compete ao SUS ordenar a formação de recursos humanos na área de saúde.

Uma idéia recorrente na história das relações entre o setor educação e saúde, gira em torno da utilização de incentivos propiciados pelo sistema de saúde para a reordenação curricular das profissões da saúde.

O Ministério da Educação e do Desporto, em consonância com o Conselho Nacional de Educação, estabelecerá diretrizes curriculares nacionais, constantes de carga horária mínima do curso, conteúdos mínimos, habilidades e competências básicas, por área profissional ( Santana e Christófaro 2003).

Dificuldades existem para o processo de reordenação do ensino superior que se somam à das dificuldades no contexto geral das instituições universitárias.

Não basta adotar um conceito de competência, entre os muitos existentes, para pensar a educação profissional dirigida à produção de serviços de saúde. Pensar em formação profissional hoje exige mais que adotar um conceito e um método, uma vez que esse espaço é um mundo onde se inscrevem a educação básica, a educação continuada e especializada e onde é preciso considerar os modelos, as teorias, a 
legislação e a regulamentação da própria educação, do trabalho, da saúde. Pensar a educação profissional é refletir sobre as práticas reais dos atores e das instituições de educação e de produção de cuidados à saúde (Santana e Christófaro 2003).

Há de se considerar também que a formação profissional é um campo de luta ideológica e política; é um daqueles domínios em que todos se sentem à vontade para emitir opiniões, de onde resulta a estranha impressão de que nunca se avança.

A efetiva integração entre os processos de ensino-aprendizagem e de produção de serviços é requisito indispensável para o desenvolvimento de competências profissionais.

A experiência na elaboração de perfis de competências para profissões ou ocupações na área de saúde é ainda tem muito a caminhar, pois envolve o embate de grupos de interesse, procedentes do setor acadêmico e de serviços ou, mais freqüentemente, das corporações profissionais, resultando nas listas constantes nos projetos de diretrizes curriculares nacionais para os diversos cursos.

Para avançar mais nessas construções de consensos, é preciso basear-se em concepções e justificativas acordadas na dinâmica da interação entre grupos sociais que estão à frente dos processos de ensino e de prática profissional.

A complexidade que envolve as relações entre os mundos do trabalho e da educação e como lidar com suas decorrências são questões presentes na agenda dos gestores de recursos humanos do SUS. A análise permanente dessa problemática tornase um exercício indispensável para o bom desempenho de suas responsabilidades, tanto que uma política específica foi criada pelo Governo Federal (Santana e Christófaro 2003).

\section{4 - Política de Educação e Desenvolvimento para o SUS.}

O Governo Federal tem como uma de suas diretrizes principais a formulação e implementação de políticas de recursos humanos para a saúde. Essa diretriz está sendo desenvolvida pela Secretaria de Gestão do Trabalho e da Educação na Saúde do Ministério da Saúde (SGETES/MS) por meio de suas várias estratégias ${ }^{6}$.

\footnotetext{
${ }^{6}$ Fonte: Ministério da Saúde. http://portal.saude.gov.br/portal/sgtes/visualizar texto.cfm?idtxt=22848 ou Boletim Informativo da Rede Unida - ano XX, n. 44 - jan a abr 2005, pág. 18.
} 
Na saúde, são várias as ações: Política Nacional de Educação Permanente como estratégia do SUS para a formação e o desenvolvimento de trabalhadores para o setor; o AprenderSUS, política direcionada para as mudanças na graduação em coerência com as diretrizes e princípios do SUS; o VER-SUS, que visa proporcionar aos estudantes diversificadas experiências do mundo de trabalho e do controle social do sistema, o MultiplicaSUS, que tem o objetivo de promover espaços de reflexão, de discussão e de troca de conhecimento com os trabalhadores da área de saúde, tornando-os sujeitos ativos e críticos - agentes de mudança- de seus processos de trabalho para o aperfeiçoamento do SUS e, recentemente (junho/2007), por meio de portaria interministerial, foi instituído no âmbito do SUS o Programa de Educação para Trabalho em saúde (PET). No seu conjunto, as políticas em desenvolvimento buscam a interação entre os segmentos da formação, da atenção, da gestão e do controle social: o quadrilátero da Educação Permanente em Saúde (EPS).

A Educação Permanente em Saúde impulsiona a transformação dos processos formativos, das práticas pedagógicas e de saúde e para a organização dos serviços, empreendendo um trabalho articulado entre o sistema de saúde, em suas várias esferas de gestão, e as instituições formadoras (Brasil 2004b).

A educação permanente requer ações no âmbito da formação técnica, de graduação e de pós-graduação, da organização do trabalho, da interação com as redes de gestão e de serviços de saúde e do controle social neste setor.

O processo de educação permanente, implementado no SUS, deve priorizar:

- as equipes que atuam na atenção básica, num trabalho de qualificação que envolverá a articulação e o diálogo entre atores e saberes da clínica, da saúde coletiva e da gestão em saúde;

- as equipes de urgência e emergência;

- as equipes de atenção e internação domiciliar;

- $\quad$ as equipes de reabilitação psicossocial;

- o pessoal necessário para prestar atenção humanizada ao parto e ao pré-natal;

- os Hospitais Universitários e de Ensino em ações que objetivam sua integração à rede do SUS na cadeia de cuidados progressivos à saúde, a revisão de seu papel no ensino e seu apoio docente e tecnológico ao desenvolvimento do sistema de saúde;

- o desenvolvimento da gestão do sistema, das ações e dos serviços de saúde; 
- ações educativas específicas resultantes de deliberação nacional, estadual intergestores, municipal ou do respectivo Conselho de Saúde.

$\mathrm{Na}$ educação permanente em saúde, não se esgotam o conceito e a noção de educação para o trabalho técnico, uma vez que ocorrem na dimensão das equipes de trabalho e da gestão do trabalho, propiciando, em sua implementação, a discussão sobre os programas e o sistema de saúde, as novidades tecnológicas ou epidemiológicas e a integralidade da atenção à saúde, os protocolos de atenção à saúde e a clínica ampliada criando, continuamente, processos de análise e de problematização.

Importante ressaltar que existem diferenças entre educação continuada e educação permanente, esta última, preconizada pelo Ministério da Saúde (Brasil 2004b).

\begin{tabular}{|c|c|c|}
\hline & Educação Continuada & Educação Permanente \\
\hline $\begin{array}{l}\text { Pressuposto } \\
\text { Pedagógico }\end{array}$ & $\begin{array}{l}\text { O "conhecimento" preside / } \\
\text { define as práticas }\end{array}$ & $\begin{array}{l}\text { As práticas são definidas } \\
\text { por múltiplos fatores } \\
\text { (conhecimento, valores, relações } \\
\text { de poder, organização do trabalho } \\
\text { etc.); a aprendizagem dos adultos } \\
\text { requer que se trabalhe com } \\
\text { elementos que "façam sentido" } \\
\text { para os sujeitos envolvidos } \\
\text { (aprendizagem significativa). }\end{array}$ \\
\hline Objetivo principal & $\begin{array}{l}\text { Atualização de conhecimentos } \\
\text { específicos. }\end{array}$ & Transformação das práticas. \\
\hline
\end{tabular}

Fonte: Ministério da Saúde.

Figura 1 - Proposta política do Ministério da Saúde

Para a implantação da Política de Educação Permanente em Saúde, tornou-se necessário que o Departamento de Gestão da Educação na Saúde (DEGES) articulasse agenda e compromissos de ação com os diversos órgãos do Ministério da Saúde (MS), com o Conselho Nacional de Saúde, com o Conselho Nacional de Secretários Estaduais de Saúde (CONASS) e com as Secretarias Estaduais de Saúde e Conselhos Estaduais de Saúde, com o Conselho Nacional de Secretários Municipais de Saúde (CONASEMS) e com as Secretarias Municipais de Saúde, e Conselhos Municipais de Saúde, com o Ministério da Educação (MEC), com as entidades de profissionais e de ensino das profissões de saúde, com as entidades estudantis e com os movimentos e práticas de educação popular em saúde, entre outros (Brasil 2004b).

Como estratégia do SUS para a formação e o desenvolvimento de trabalhadores para o setor foi criada, em 13 de fevereiro de 2004, a Portaria 198/GM/MS, que 
institui a Política Nacional de Educação Permanente em Saúde. Para a condução locorregional da política, foram criados os Pólos de Educação Permanente em Saúde (PEPS) para o SUS (Brasil 2004b).

\subsection{1 - Pólos de Educação Permanente em Saúde.}

Esses pólos constituem-se em instâncias interinstitucionais e locorregionais para a gestão colegiada da educação em serviço, possibilitando, portanto, a articulação entre gestores do SUS e instituições formadoras, objetivando adequar os processos de formação e educação permanente às necessidades do sistema.

A falta de profissionais com perfil adequado tem sido, ao lado de problemas de gestão e organização da atenção, um dos principais obstáculos para a melhoria da qualidade da atenção e para a efetividade do SUS.

\subsubsection{1 - As funções dos pólos.}

- Identificar necessidades de formação e de desenvolvimento dos trabalhadores de saúde e construir estratégias e processos que qualifiquem a atenção e a gestão em saúde e fortaleçam o controle social no setor com a perspectiva de produzir impacto positivo sobre a saúde individual e coletiva;

- Mobilizar a formação de gestores de sistemas, ações e serviços para a integração da rede de atenção como cadeia de cuidados progressivos à saúde (rede única de atenção intercomplementar e de acesso ao conjunto das necessidades de saúde individuais e coletivas);

- Propor políticas e estabelecer negociações interinstitucionais e intersetoriais orientadas pelas necessidades de formação e de desenvolvimento e pelos princípios e diretrizes do SUS, não substituindo quaisquer fóruns de formulação e decisão sobre as políticas de organização da atenção à saúde;

- Articular e estimular a transformação das práticas de saúde e de educação na saúde no conjunto do SUS e das instituições de ensino, tendo em vista a implementação das diretrizes curriculares nacionais para o conjunto dos cursos da área da saúde e a transformação de toda a rede de serviços e de gestão em rede-escola; 
- Formular políticas de formação e desenvolvimento de formadores e de formuladores de políticas, fortalecendo a capacidade docente e a capacidade de gestão do SUS em cada base locorregional;

- Estabelecer a pactuação e a negociação permanente entre os atores das ações e serviços do SUS, docentes e estudantes da área da saúde;

- Estabelecer relações cooperativas com as outras articulações locorregionais nos estados e no País (Brasil 2004b).

\subsubsection{2 - Composição dos pólos de Educação Permanente em Saúde para o SUS.}

- Gestores estaduais e municipais;

- Universidades e instituições de ensino com cursos na área da saúde, incluindo as áreas clínicas e da saúde coletiva;

- Escolas de Saúde Pública (ESP);

- Centros Formadores (CEFOR);

- Núcleos de Saúde Coletiva (NESC);

- Escolas Técnicas de Saúde do SUS (ETS-SUS);

- Hospitais de ensino;

- Estudantes da área de saúde;

- Trabalhadores de saúde;

- Conselhos Municipais e Estaduais de Saúde;

- Movimentos ligados à gestão social das políticas públicas de saúde.

A gestão da Educação Permanente em Saúde será feita por meio de Pólos de Educação Permanente em Saúde (PEPS), que são instâncias de articulação interinstitucional.

Aos PEPS compete:

- funcionar como dispositivos do Sistema Único de Saúde para promover mudanças, tanto nas práticas de saúde quanto nas práticas de educação na saúde, funcionando como rodas de debate e de construção coletiva - Rodas para a Educação Permanente em Saúde;

- trabalhar com a perspectiva de construir, nos espaços locais, microrregionais, regionais, estaduais e interestaduais, a capacidade de pensar e executar a formação 
profissional e o desenvolvimento das equipes de saúde, dos agentes sociais e dos parceiros intersetoriais e

- trabalhar com os elementos que conferem à integralidade da atenção à saúde (diretriz constitucional), forte capacidade de impacto sobre a saúde da população e que são essenciais para a superação dos limites da formação e das práticas tradicionais de saúde, quais sejam: acolhimento, vínculo entre usuários e equipes, responsabilização, desenvolvimento da autonomia dos usuários e resolutividade da atenção à saúde.

Nos Estados com vários Pólos de Educação Permanente em Saúde para o SUS, cabe à Secretaria Estadual de Saúde (SES) a iniciativa de reuni-los periodicamente para estimular a cooperação e a conjugação de esforços, a não fragmentação das propostas e a compatibilização das iniciativas com a política estadual e nacional de saúde, atendendo aos interesses e necessidade do fortalecimento do SUS e da Reforma Sanitária Brasileira e sempre respeitando as necessidades locais (Brasil 2004b).

Desde o lançamento da política de educação permanente em saúde para o SUS em 2004, foram constituídos no Brasil 96 pólos, assim distribuídos por regiões: Norte 12, Nordeste 23, Centro Oeste 09, Sudeste 27 e Sul 25.

O HRAC integra o Pólo Sudoeste Paulista, que abrange os municípios: Bauru, Botucatu, Registro e Sorocaba, por ser um hospital de ensino e prestador de serviços de saúde.

Está representado por dois profissionais da equipe interdisciplinar e outros profissionais que já se qualificaram por meio dos cursos de Formação de Tutores para Humanização da Atenção e Gestão no SUS de Formação de Facilitadores de Educação Permanente em Saúde.

Tal nível de envolvimento demonstra o interesse do HRAC no desenvolvimento de atividades relacionadas à formação, desenvolvimento profissional e educação permanente dos trabalhadores da saúde, buscando se fortalecer como uma instituição formadora, de acordo com o interesse do SUS e atendendo as necessidades da população na área de anomalias craniofaciais, mais especificamente, as fissuras labiopalatinas, assunto a ser abordado no próximo capítulo. 


\section{5 - As malformações labiopalatinas.}

\subsection{1 - Etiologia, conceituação e classificação.}

A palavra fissura, de etiologia latina, significa fenda, abertura (Silva Filho e Freitas, 2007). Com base em conceitos vigentes na etiologia das fissuras labiopalatinas, Capelozza Filho et al (1988) afirmam que as deformidades congênitas estruturais que afetam a face humana manifestam-se de diferentes formas clínicas, variando desde as fissuras labiopalatinas mais comuns ou raras, até as mais complexas malformações craniofaciais.

Essas malformações, também denominadas de fissuras ou lesões, são resultantes da falta de coalescência dos processos maxilar, mandibular e frontonasal. Assim, o desenvolvimento insuficiente de um ou mais desses processos ou a ocorrência de falhas na desintegração da superfície epitelial nas regiões de contato entre os processos resultarão na ocorrência das mais variadas fissuras.

Entre as malformações que atingem a face do ser humano, os defeitos congênitos identificados como fissuras labiopalatinas são comuns e ocorrem com uma prevalência média entre 1 e 2 indivíduos brancos para cada mil nascimentos. No Brasil, admite-se que a incidência de fissuras labiopalatinas oscila em torno de 1:650 (Silva Filho e Freitas 2007). Os autores ainda relatam que as malformações são estabelecidas precocemente na vida intra-ulterina, mais precisamente no período embrionário e no período fetal, o que significa dizer até a $12^{\mathrm{a}}$ semana gestacional.

A classificação das fissuras labiopalatinas utilizada pelo HRAC baseia-se em Spina (1972), com uma modificação proposta por Silva Filho et al (1992) e Silva Filho e Freitas (2007), especialmente na inclusão das fissuras medianas também no grupo II, como demonstrado na figura sinóptico. 


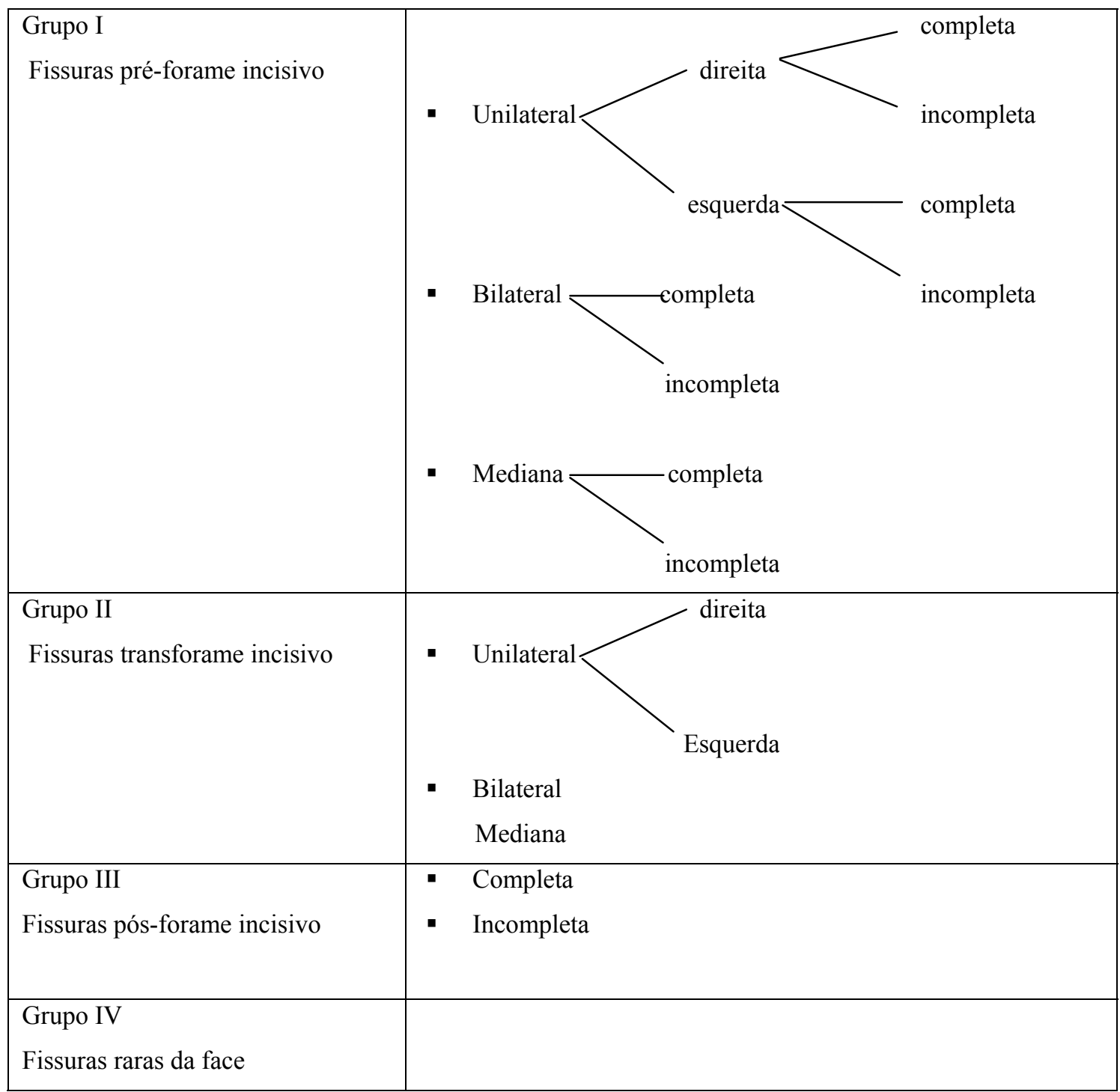

Fonte: Trindade ILK, Silva Filho OG, coordenadores. In: Fisuras labiopalatinas: uma abordagem interdisciplinar. 2007. p.21.

Figura 2 - Sinóptico

Essa classificação, simples e objetiva, fundamenta-se na teoria embriológica que reconhece os mecanismos independentes de formação das estruturas anteriores (palato primário) e posteriores (palato secundário) ao forame incisivo, ponto anatômico de referência elegido para essa categorização.

Para melhor entendimento, as fendas pré-forames são as de lábio, as pós-forame são as do palato (céu da boca) e as transforame são as que envolvem lábio, alvéolo (gengiva) e palato, e são popularmente conhecidas como lábio-leporino (fissuras labiais) e/ou goela de lobo (fissuras palatais). 
Há uma controvérsia muito grande na literatura e muito pouco se conhece sobre a etiologia das fissuras de lábio e/ou palato. Para tentar explicá-las, dois fatores são imputados: os fatores genéticos e os ambientais que podem atuar isoladamente ou associados. Contudo, a determinação dos fatores hereditários e sua comprovação são difíceis na espécie humana.

Assim, a maior parte das fissuras é ocasionada pela interação de muitos fatores genéticos e ambientais, individualmente indistinguíveis que consiste em causas multifatoriais. Essa teoria, por permitir avaliar os riscos de recorrência, é a mais aceita na literatura (Capelozza Filho et al 1988).

No entanto, independentemente das "causas", sabe-se que as fissuras labiopalatinas interferem intensamente na vida dos pacientes, desde o nascimento em virtude das alterações funcionais e estéticas, provocando transtornos psicológicos e sociais.

\subsection{2 - Aspectos estéticos funcionais e psicossociais.}

A alimentação, como fator de sobrevivência, é uma das primeiras preocupações dos pais, diante do nascimento de um filho. Essa preocupação se agrava com a presença das fissuras labiopalatinas, pelo temor frente a intercorrências como refluxo nasal do leite, engasgos, e a demora no processo da administração alimentar, que pode prejudicar o ganho ponderal (Marques et al 2007).

Segundo Marques et al (2007), a comunicação entre a cavidade oral e a nasal nas crianças com fissuras labiopalatinas pode levar a maior freqüência de infecções, desde resfriados comuns até quadros de broncopneumonia. A presença de fissura de palato pode facilitar o refluxo de alimentos e secreções, que favorece sua aspiração para a trompa de Eustaquio e uma freqüência considerável de otites por disfunção tubária, que levam a perdas auditivas. No entanto, essas infecções do ouvido médio tendem a reduzir, após a realização de cirurgias primárias (Montagnolli e Rocha 1990).

Montagnolli e Rocha (1990) ressaltam que as crianças com fissura apresentam problemas fonéticos, pois a aquisição de linguagem é um mecanismo complexo e é necessário que os órgãos envolvidos na formação dos sons estejam anatomicamente adequados. Essas crianças poderão adquirir uma fala característica decorrentes da 
chamada incompetência ou disfunção velofaríngea, o que provoca hipernasalidade (comunicação nasal-oral); além disso, a dentição irregular gera desvio na articulação.

Segundo Altmann et al (1997), os indivíduos com fissuras labiopalatinas podem apresentar as seguintes alterações fonoaudiológicas: audição, linguagem, fala, voz, órgãos fonoarticulatórios (OFA), e de leitura e escrita; a terapia fonoaudiológica pode ser direcionada para todos esses fatores concomitantemente.

De acordo com Genaro et al (2007) geralmente os distúrbios da fala repercutem negativamente junto à sociedade, e a fala é justamente um dos aspectos mais estigmatizantes no caso da fissura labiopalatina. As alterações são as mais variadas, podendo ocorrer desde uma leve distorção de algum fonema causada por deformidade dentofacial até o desenvolvimento de hipernasalidade e de mecanismos compensatórios que tornam a fala ininteligível.

Os autores ressaltam, ainda, que das alterações da fala presentes na fissura palatina, grande parte relaciona-se direta ou indiretamente à disfunção no mecanismo velofaríngeo, que pode comprometer o desenvolvimento da fala quanto aos aspectos fonético e fonológico.

Os pacientes com fissuras labiopalatinas, de modo geral, podem apresentar os seguintes distúrbios da fala: - distúrbios articulatórios do desenvolvimento, que correspondem a alterações comuns da fase de aquisição dos fonemas; - distúrbios articulatórios compensatórios, que correspondem a distúrbios do aprendizado, decorrentes de alterações estruturais, provocadas pela própria fissura palatina ou pela presença de fístulas do palato; - distúrbios obrigatórios, que correspondem a alterações decorrentes exclusivamente da disfunção velofaríngea como a hipernasalidade e a emissão de ar nasal; e adaptação compensatória relacionada a distorções na produção articulatória frente a alterações estruturais, como as deformidades dentofaciais (Genaro, et al 2007).

Segundo Gomide e Costa (2007), a ocorrência de dentes natais e neonatais na região da fenda é comum em bebês com fissuras transforame incisivo unilateral e o desenvolvimento de dentição, com a irrupção dos dentes decíduos é semelhante ao da população em geral, demonstrando atraso de irrupção no lado da fissura, sendo esse significativo apenas para o incisivo lateral superior da região da fenda, que pode irromper com atraso de até 2 anos nas fissuras labiopalatinas completas. 
Em crianças com fissuras com envolvimento do rebordo alveolar é comum a presença de dente decíduo supranumerário e/ou numerário mal posicionado adjacentes à fissura, cuja permanência é importante para preservar o tecido ósseo que se encontra deficiente nessa região. Por isso, os cuidados orientados aos pais, relativos aos procedimentos de higiene específicos para tais dentes, proporcionam sua manutenção em boas condições.

“As anomalias dentárias de forma, de número e de posição, particularmente na área da fissura, podem ter efeito deletério no desenvolvimento maxilo-mandibular e comprometem não só a estética como também as funções de mastigação, respiração, deglutição e fonação" (André et al 1997 p239).

Roxo et al (1997) ressaltam que as cirurgias visam ao restabelecimento anatômico e funcional, favorecem o equilíbrio muscular, que é o grande colaborador e orientador do crescimento do terço médio da face e da obtenção de uma fala e voz adequadas, propiciando ao paciente uma auto-imagem positiva e, conseqüentemente, melhor integração social.

O HRAC/USP objetiva não só a reabilitação estética e funcional, como também a reabilitação psicossocial do paciente e sua família. A atenção psicossocial se revela como um importante instrumento para reabilitação mais efetiva dos pacientes com fissuras labiopalatinas (Graciano et al 2007).

Segundo Amaral (1997), com relação aos aspectos psicossociais, as fissuras labiopalatinas trazem aos indivíduos contingências físicas, psicológicas, afetivas e sociais que produzem conseqüências manifestadas em algumas características comumente levantadas no grupo, como: redução de autoconceito, mais dependência dos pais, isolamento, esquiva de contatos sociais em situações novas, redução da capacidade verbal, entre outras.

Segundo Graciano et al (2007), as repercussões da doença no desenvolvimento físico e/ou psicológico do paciente, bem como o impacto psicossocial na família devem ser compreendidos pelos profissionais de saúde que compõem a equipe de atendimento.

Tal postura é efetivada no HRAC por uma equipe de profissionais que, por meio de uma ação interdisciplinar junto à pessoa com fissuras labiopalatinas, seus familiares e a comunidade, procura minimizar seus problemas, favorecendo as condições para o pleno desenvolvimento de suas capacidades físicas, psicológicas afetivas e sociais. (Graciano et al 2007). 
Os autores ressaltam, ainda que a equipe interdisciplinar deve estar atenta a todas as fases do desenvolvimento, desde o nascimento até a fase adulta, a fim de que alcance com sucesso os objetivos da tarefa de reabilitar, estimulando o envolvimento da família/paciente no processo de reabilitação que, por sua complexidade, exige esforços conjuntos para se efetivar.

\subsection{3 - As condutas terapêuticas para reabilitação das malformações labiopalatinas.}

"Reabilitação é um processo contínuo, coordenado com objetivo de restaurar o indivíduo incapacitado para ter o mais completo possível desempenho físico, mental, social, econômico e vocacional, permitindo a sua integração social" (Organização Mundial de Saúde, Associação Brasileira Beneficente de Reabilitação) (2007 p1).

A reabilitação enquanto serviço é um conjunto de ações de atenção à saúde e, portando, um componente imprescindível da promoção, prevenção e assistência às pessoas, na manifestação de sua saúde e bem-estar, bem como a sua família e comunidade (Brasil 1993, Graciano et al 2007).

O processo de reabilitação das fissuras labiopalatinas é complexo, exige técnicas avançadas e pode durar até a idade adulta; a estética facial é baseada na trilogia osso+dente+cirurgia, obtendo a reabilitação estética funcional ideal com atuação integrada da equipe (Universidade de São Paulo 1999).

O protocolo do HRAC é simples e se encontra respaldado em resultados de pesquisas que comparam experiências de outros centros de tratamento, defendendo as seguintes condutas terapêuticas (Universidade de São Paulo 2001): cirurgia primária na primeira infância (lábio a partir de 3 meses e palato de 12 meses); ausência de ortopedia maxilar precoce pré e pós cirurgias primarias; tratamento ortodôntico de preferência a partir de dentadura mista; enxerto ósseo secundário no final da dentadura mista ( 9 a 12 anos); tratamento ortodôntico corretivo; cirurgias ortognáticas, se houver necessidade, cirurgias plásticas secundárias (a partir de 6 anos).

A seqüência de tratamento de fissuras labiopalatinas preconizada pelo HRAC com a equipe interdisciplinar é ilustrada a seguir. 
Fonte: Condutas e Etapas Terapêuticas do HRAC/USP.

Figura 3 - Seqüência de tratamento das fissuras labiopalatinas 
A figura demonstra a participação das diversas áreas no processo de reabilitação efetivado pelo HRAC na forma de um trabalho desenvolvido por uma equipe interdisciplinar, em que, segundo Sampaio et al (1989 p83), estabelece-se "uma relação de reciprocidade, de mutualidade, um regime de co-propriedade, possibilitando o diálogo, onde as diversas disciplinas levam a uma interação, a uma intersubjetividade, condição para a efetivação do trabalho interdisciplinar". É, portanto, um trabalho em comum onde se considera a interação das disciplinas científicas, de seus conceitos, diretrizes, de sua metodologia e de seus procedimentos, valorizando a contribuição de cada ciência em particular.

Considerando o objetivo de nossa pesquisa, conhecimento dos serviços de reabilitação interdisciplinar no país, com ênfase nas áreas de serviço social, psicologia fonoaudiologia e odontologia ${ }^{7}$, destacamos, com base na seqüência de tratamento de fissuras labiopalatinas do HRAC, a importância desses serviços para viabilizar a reabilitação.

$\mathrm{Na}$ área de fonoaudiologia, o tratamento é essencial, constituindo-se em uma das especialidades-chaves (Shaw e Semb 2007) do processo de reabilitação ao lado das áreas de medicina e odontologia, responsabilizando-se pelos tratamentos de voz nasalizada, distúrbios orais, da audição e escrita, corrigindo hábitos e/ ou reeducando a fala.

No protocolo de atendimento fonoaudiológico, as suas condutas gerais englobam a triagem fonoaudiológica e a definição de condutas: avaliação do desenvolvimento da linguagem e função alimentares, avaliação fonoarticulatória e audiológica e encaminhamentos para avaliação ou fonoterapia. Busca-se um resultado satisfatório de comunicação com êxito total de reabilitação (fala normal) ou parcial (boa inteligibilidade e comunicação socialmente efetiva), procurando-se a satisfação do paciente com sua condição de fala.

O tratamento reabilitador na área de odontologia tem como ponto de equilíbrio a atuação da medicina e fonoaudiologia. A estética facial é baseada na trilogia osso + dente + cirurgia, com a atuação integrada da equipe, visando à reabilitação estéticofuncional ideal.

\footnotetext{
${ }^{7}$ A Organização Mundial de Saúde - OMS - considera a fonoaudiologia e odontologia (ortodontia), juntamente com cirurgia plástica, os especialistas-chaves da equipe - define as etapas do processo do reabilitador da pessoa com fissura labiopalatina.
} 
$\mathrm{Na}$ odontologia várias especialidades se interagem, de acordo com a seqüência de tratamento: odontopediatria, dentística, periodontia, ortodontia, prótese, endodontia e cirurgia maxilo mandibular (André 1997).

O serviço social e a psicologia, considerados atendimentos complementares à equipe, são fundamentais no apoio psicossocial às famílias e aos pacientes, prevenindo e/ou intervindo nas questões psicossociais, estimulando a criação de estratégias para facilitar esse duplo processo: reabilitação e inclusão.

A inclusão social consiste no processo pelo qual a sociedade se adapta para poder incluir em seu contexto as pessoas com necessidades especiais. Por outro lado, estas mesmas pessoas precisam ser preparadas para assumir seus papéis na sociedade. Será uma forma de parceria entre ambas - sociedade e pessoas especiais - visando equacionar problemas, decidindo sobre soluções e efetuando equiparação para todos (Sassaki 1997). 


\section{OBJETIVOS.}

\section{1 - Objetivo geral.}

- Mapear e caracterizar os serviços de reabilitação no Brasil utilizados pelos usuários do HRAC, diagnosticando as necessidades de capacitação dos reabilitadores nas áreas de fonoaudiologia, odontologia, psicologia e serviço social.

\section{2 - Objetivos específicos.}

- Conhecer e cadastrar os serviços de reabilitação, englobando as diferentes áreas;

- Identificar formas de articulação dos serviços/reabilitadores com órgãos locais (universidades, secretarias de saúde e outros) e HRAC;

- Levantar o perfil profissional dos reabilitadores das organizações, identificando seu nível de articulação técnico, científico e funcional com o HRAC;

- Identificar as necessidades e o interesse dos reabilitadores em participar do programa de capacitação do HRAC;

- Propor forma(s) de ampliação de intercâmbio e articulação dos serviços/reabilitadores com diferentes organizações públicas, privadas e ou do Terceiro Setor;

- Contribuir para a construção de um pólo de capacitação de reabilitadores, tendo como compromisso a humanização e qualificação da atenção. 
4 MATERIAL E MÉTODO

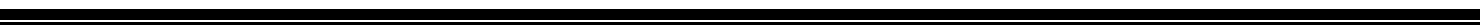




\section{MATERIAL E MÉTODO.}

Para o desenvolvimento da pesquisa optamos pelo método dialético, entendido como aquele que "pensa a relação de quantidade como uma das qualidades dos fatos e fenômenos, buscando encontrar, na parte, a compreensão e a relação como um todo e a interioridade e exterioridade como constitutivas dos fenômenos que podem ser entendidos nas determinações e transformações dadas pelos sujeitos" (Minayo 1994 $\mathrm{p} 22-3)$.

A pesquisa foi desenvolvida por meio de estudos exploratórios e descritivos. O exploratório permite ao investigador aumentar sua experiência em torno do assunto pesquisado, buscando o aprimoramento de idéias ou descobertas de intuições; esclarecer e modificar conceitos e idéias. O estudo descritivo tem como objetivo primordial a descrição das características de determinada população ou fenômeno ou o estabelecimento de relações entre variáveis (Gil 1989).

A abordagem é quanti-qualitativa, sendo a abordagem qualitativa essencialmente interpretativa e a abordagem quantitativa de natureza analítica.

Segundo Chizotti (1995), as pesquisas quantitativas provêm às mensurações de variáveis pré-estabelecidas, procurando verificar e explicar a sua influência sobre outras variáveis, mediante a análise da freqüência de incidência e de correlações estatística, fornecendo por meio de dados estatísticos condições necessárias para uma análise mais profunda dos resultados apresentados.

As pesquisas qualitativas procuram compreender as experiências que os sujeitos têm, as representações que formam e os conceitos que elaboram, partindo do princípio que todos os sujeitos são igualmente dignos de estudo, permanecem únicos e todos os seus pontos de vista são relevantes. Alem disso, a pesquisa qualitativa tem como características gerais: o fato de ser descritiva, de ter ambiente natural como fonte direta de dados e o pesquisador como instrumento-chave (Furtado 2006).

O universo deste estudo foi constituído pelos serviços de reabilitação apontados pelos pacientes/usuários incluídos no "Projeto Flórida" - um projeto interdisciplinar desenvolvido em parceria com a Universidade da Flórida, com o objetivo de investigar e 
comparar os resultados de fala e da função velofaríngea para a fala, após palatoplastia em número de 475 pacientes, procedentes de 298 municípios $^{8}$.

O "Projeto Florida" é composto por uma amostra considerada homogênea e atual representada por pacientes com fissuras labiopalatinas transforame incisivo (as que envolvem lábio, alvéolo (gengiva) e palato), que iniciaram o tratamento no HRAC em 1996, virgens de tratamento anterior, procedentes de todas as regiões do país e com acompanhamento da equipe interdisciplinar do HRAC. Por isso esse critério de escolha foi considerado, retratando as diferentes realidades vividas pelos pacientes, nos diferentes serviços (Graciano 2004).

Para alcançar os objetivos propostos, o presente estudo foi agregado em dois momentos: num primeiro momento, foi estruturado um questionário (anexo1) simplificado para ser aplicado no HRAC em pacientes agendados e/ou enviado pelo correio dentre os 475 pacientes do Projeto Florida, de modo a garantir a representatividade nos 298 municípios, identificando os serviços / reabilitadores por eles utilizados nos municípios e/ou região de origem e sua satisfação com os mesmos.

Após o pré-teste realizado no HRAC foi verificado que os pais/responsáveis não sabiam informar os endereços dos profissionais/serviços onde os filhos realizavam o tratamento. Assim, nesse primeiro momento, foi decidido que os 475 questionários fossem enviados pelo correio, para que garantir respostas mais precisas sobre os serviços/reabilitadores.

Durante o período da coleta de dados, 09 pacientes foram excluídos do projeto ${ }^{9}$. Portanto, o universo da pesquisa passou a ser de 466 (100\%).

Diante da resposta do questionário, foi possível identificar e caracterizar os 61 serviços utilizados pelos pacientes $(100 \%)$.

Num segundo momento, após a identificação desses serviços, foi enviado um questionário (anexo 2) para os respectivos serviços/reabilitadores com enfoque nas áreas de fonoaudiologia, odontologia, psicologia e serviço social, com objetivo de mapear e caracterizar os serviços de reabilitação na área das fissuras labiopalatinas utilizados pelos usuários do HRAC nas diferentes regiões do Brasil, bem como diagnosticar as necessidades de capacitação dos profissionais envolvidos.

\footnotetext{
${ }^{8}$ Fonte: Serviço de Informática Hospitalar (SIH) - HRAC/USP.

${ }^{9}$ Motivos da exclusão: atraso neuromotor, atraso de desenvolvimento (2), holoprocefalia, síndrome, tratamento em outros serviços, paradeiro desconhecido, alteração na idade cirúrgica e alteração no procedimento cirúrgico.
} 
Em ambos os casos, os questionários (anexos 1 e 2) foram enviados pelo correio com uma carta explicativa sobre a natureza da pesquisa, sua importância e data de devolução, bem como dos termos de consentimento livre e esclarecido (anexos 3 e 4). 
5 RESULTADOS

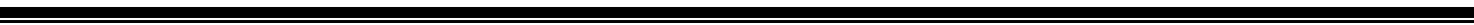




\section{RESULTADOS.}

Neste capítulo procura-se sistematizar os dados encontrados durante o processo de investigação; para tanto, os resultados a seguir serão apresentados em dois momentos distintos conforme previsto na metodologia da pesquisa. $\mathrm{O}$ primeiro momento refere-se aos resultados dos questionários encaminhados aos pacientes do "Projeto Flórida" e o segundo momento aos serviços/reabilitadores identificados pelos pacientes.

$1^{0}$ Momento - Identificação dos serviços/reabilitadores utilizados pelos pacientes do HRAC e a caracterização dos mesmos na ótica do usuário.

Do universo de 466 questionários enviados recebemos 143 respostas (31\%). Dentre estes verificamos que 91 pacientes $(63,7 \%)$ encontravam-se em tratamento na sua cidade e/ou região e $52(36,3 \%)$ não, cujos motivos serão identificados na tabela abaixo, anteriormente a caracterização dos serviços de reabilitação indicados pelos casos em tratamento.

Tabela 1 - Motivos da não realização de tratamento na cidade/região de origem

\begin{tabular}{lcc}
\hline Motivos & Freqüência & $\mathbf{( \% )}$ \\
\hline Não foi indicado pelo Hospital & 30 & 62,5 \\
Foi indicado, mas não realiza tratamento & 18 & 37,5 \\
TOTAL & $\mathbf{4 8}$ & $\mathbf{1 0 0 , 0}$ \\
\hline Sem Resposta & 04 & \\
\hline TOTAL GERAL & $\mathbf{5 2}$ & \\
\hline Indicação de tratamento X Não realização de tratamento & Freqüência & $\mathbf{( \% )}$ \\
\hline Não tem tratamento na cidade & 02 & 11,1 \\
Não tinha vaga & 02 & 11,1 \\
Não teve condições financeiras & 05 & 27,8 \\
Estava insatisfeito com o tratamento & 05 & 27,8 \\
Não tinha condições financeiras para o transporte & 01 & 5,5 \\
Outros motivos & 03 & 16,7 \\
\hline TOTAL & $\mathbf{1 8}$ & $\mathbf{1 0 0 , 0}$ \\
\hline
\end{tabular}

O maior índice $(62,5 \%)$ concentrou-se entre os que não tinham indicação de tratamento pelo HRAC para um menor índice $(37,5 \%)$ com indicação, mas, que por vários motivos apresentados na tabela 1 os mesmos não estavam realizando tratamento em sua cidade de origem ou região. Independentemente das razões, esses dados são preocupantes e sugerem uma intervenção, em razão das fissuras labiopalatinas 
interferirem intensamente na vida dos pacientes, provocando alterações funcionais e estéticas e, conseqüentemente, transtornos psicológicos e sociais.

Todas as respostas indicam a precariedade na oferta/qualidade dos serviços públicos, efetivando a exclusão do paciente na área de saúde, contrariando as prioridades do Pacto pela defesa do SUS citado na página 9.

Antes de relacionar os serviços apontados, será apresentada a figura de distribuição geográfica dos pacientes do universo e da amostra, identificando os que se encontram ou não em tratamento em sua cidade de origem ou região, bem como o número de serviços identificados pelos casos em tratamento. 


\begin{tabular}{|c|c|c|c|c|c|c|c|c|}
\hline \multicolumn{2}{|r|}{$\begin{array}{c}\text { Distribuiç̧ão por } \\
\text { Estados }\end{array}$} & \multicolumn{2}{|c|}{ Universo } & \multicolumn{5}{|c|}{ Amostra } \\
\hline \multirow{9}{*}{ 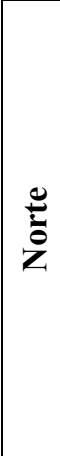 } & \multirow[t]{2}{*}{ Estados } & \multirow[t]{2}{*}{$\begin{array}{c}\mathbf{N}^{\circ}(\%) \\
\text { Pacientes }\end{array}$} & \multirow[t]{2}{*}{$\begin{array}{c}\mathbf{N}^{\circ}(\%) \\
\text { Cidades }\end{array}$} & \multirow[t]{2}{*}{$\begin{array}{c}\mathrm{N}^{0}(\%) \\
\text { Paciente }\end{array}$} & \multirow[t]{2}{*}{$\begin{array}{c}\mathbf{N}^{0}(\%) \\
\text { Cidades }\end{array}$} & \multicolumn{2}{|c|}{$\begin{array}{c}\text { Pacientes em } \\
\text { tratamento }\end{array}$} & \multirow[t]{2}{*}{ Serviços } \\
\hline & & & & & & Sim & Não & \\
\hline & Acre/AC & 01 & 01 & & & & & \\
\hline & Amapá/AP & 01 & 01 & & & & & \\
\hline & Manaus/AM & & & & & & & \\
\hline & Pará/PA & 03 & 02 & 01 & 01 & & 01 & \\
\hline & Rondônia/RO & 05 & 05 & 02 & 02 & & 02 & \\
\hline & Roraíma/RR & & & & & & & \\
\hline & Tocantins/TO & 01 & 01 & & & & & \\
\hline & TOTAL & $11(2,4)$ & $10(3,4)$ & $03(2,1)$ & $03(2,5)$ & & $03(5,7)$ & \\
\hline \multirow{8}{*}{$\begin{array}{l}\frac{0}{0} \\
\frac{8}{0} \\
\frac{0}{0} \\
Z\end{array}$} & Alagoas/AL & 01 & 01 & 00 & 00 & & & \\
\hline & Bahia/BA & 03 & 03 & 01 & 01 & & 01 & \\
\hline & Ceará/CE & 01 & 01 & & & & & \\
\hline & Maranhão/MA & & & & & & & \\
\hline & Paraíba/PB & & & & & & & \\
\hline & Pernambuco/PE & & & & & & & \\
\hline & Piauí/PI & & & & & & & \\
\hline & $\begin{array}{l}\text { Rio Grande do } \\
\text { Norte/RN }\end{array}$ & 01 & 01 & 01 & 01 & 01 & & 01 \\
\hline \multirow{5}{*}{ 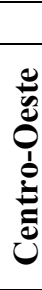 } & TOTAL & $06(1,3)$ & $06(2,1)$ & $02(1,4)$ & $02(1,7)$ & $01(1,1)$ & $01(1,9)$ & $01(1,6)$ \\
\hline & $\begin{array}{l}\text { Distrito } \\
\text { Federal/DF }\end{array}$ & 14 & 05 & 05 & 04 & 01 & 04 & 01 \\
\hline & Goiás/GO & 17 & 12 & 05 & 03 & 03 & 02 & 03 \\
\hline & Mato Grosso/MT & 12 & 10 & 03 & 03 & 03 & & 03 \\
\hline & $\begin{array}{l}\text { Mato Grosso do } \\
\text { Sul/MS }\end{array}$ & 21 & 11 & 02 & 02 & 02 & & 01 \\
\hline \multirow{5}{*}{ 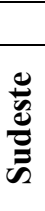 } & TOTAL & $64(13,7)$ & 38(13) & $15(10,5)$ & 12(10) & $09(9,8)$ & $06(11,5)$ & $08(13,1)$ \\
\hline & Espírito Santo/ES & 07 & 07 & 03 & 03 & 02 & 01 & 02 \\
\hline & Minas Gerais/MG & 73 & 54 & 16 & 15 & 08 & 08 & 08 \\
\hline & Rio de Janeiro/RJ & 18 & 11 & 04 & 04 & 03 & 01 & 03 \\
\hline & São Paulo/SP & 197 & 108 & 67 & 51 & 46 & 21 & 26 \\
\hline \multicolumn{2}{|r|}{ TOTAL } & $295(63,3)$ & $180(61,4)$ & $90(63,0)$ & $73(60,8)$ & 59(65) & $31(59,6)$ & $39(64,0)$ \\
\hline \multirow{3}{*}{$\bar{B}$} & Paraná/PR & 46 & 30 & 23 & 20 & 16 & 07 & 08 \\
\hline & $\begin{array}{l}\text { Rio Grande } \\
\text { Sul/RS }\end{array}$ & 19 & 10 & 05 & 04 & 04 & 01 & 03 \\
\hline & Santa Catarina/SC & 25 & 19 & 05 & 06 & 02 & 03 & 02 \\
\hline & TOTAL & $90(19,3)$ & $59(20,1)$ & $33(23,0)$ & 30(25) & $22(24,1)$ & $11(21,2)$ & $13(21,3)$ \\
\hline & TOTAL GERAL & $466(100)$ & 293(100) & 143(100) & $120(100)$ & 91(100) & $52(100)$ & 61(100) \\
\hline
\end{tabular}

Fonte: Serviço de Informática Hospitalar (SIH) - HRAC/USP.

Figura 4 - Distribuição do universo e amostra da pesquisa segundo: número de pacientes, situação de tratamento e abrangência geográfica

Houve uma concentração de pacientes pertencentes a região sudeste, tanto no universo $(63,3 \%)$ como na amostra (63\%), seguida da região sul $(19,3 \%$ e $23 \%)$. O mesmo ocorreu em termos de serviços identificados nessas regiões atingindo na sudeste um índice de $64,0 \%$ e no sul, $21,3 \%$, refletindo a realidade do Projeto Flórida e do próprio HRAC, cuja maior concentração de pacientes é destas regiões. $\mathrm{Na}$ região 
sudeste o Estado de São Paulo, se destaca de onde procede a maioria dos pacientes do HRAC, em virtude da maior proximidade deste recurso em comparação com as outras regiões.

Especificando os serviços, a figura 5, a seguir, mostra os serviços identificados pelos 91 pacientes, num total de 61, identificando localização e natureza (Postos de Saúde ou Unidades de Saúde, Centros de Atendimentos, Clínicas, Associações, Subsedes ${ }^{10}$ e Hospitais).

${ }^{10}$ As subsedes são unidades de atendimento ambulatorial mantidas pela Fundação para Estudo e Tratamento das Deformidades Crânio-Faciais (FUNCRAF) parceira do HRAC; implantadas em três regiões do Brasil, ou seja, Campo Grande/MS, Itararé/SP e Santo Bernardo do Campo/SP. 


\begin{tabular}{|c|c|c|c|}
\hline Região & Nome do Serviço & Cidade & Estado \\
\hline NORDESTE & 1. UNIVERSIDADE POTIGUÁ & Natal & $\mathrm{RN}$ \\
\hline \multirow{39}{*}{ SUDESTE $=39$} & 2. $\quad$ CENTRO DISTURBIO COMUNICAÇÃO & Taubaté & SP \\
\hline & 3. $\quad$ CLINICA & Sertãozinho & SP \\
\hline & 4. FUNCRAF & S. Bernardo Campo & SP \\
\hline & 5. $\quad$ POSTO DE SAÚDE & Jales & SP \\
\hline & 6. UNIDADE BASICA DE SAUDE & Piracicaba & SP \\
\hline & $\begin{array}{ll}\text { 7. } & \text { CLINICA/AFISFRAN } \\
\end{array}$ & S. José Bela Vista & SP \\
\hline & 8. $\quad$ APAE & Morungaba & SP \\
\hline & 9. CETREM & Paulínia & $\mathrm{SP}$ \\
\hline & 10. AAFLAP & S. José dos Campos & SP \\
\hline & 11. APAFI & Mogi das Cruzes & SP \\
\hline & 12. FUNCRAF & Itararé & $\mathrm{SP}$ \\
\hline & 13. AMBULATÓRIO DA CRIANÇA & Guarulhos & $\mathrm{SP}$ \\
\hline & 14. AFISSORE & Sorocaba & $\mathrm{SP}$ \\
\hline & 15. NADEF & Ribeirão Preto & SP \\
\hline & 16. CENTRO DE SAÚDE & Salto & $\mathrm{SP}$ \\
\hline & 17. SECRETARIA MUNICIPAL & Capivari & SP \\
\hline & 18. CENTRO VALORIZAÇÃO DA CRIANÇA & Praia Grande & SP \\
\hline & 19. NÚCLEO DE SAÚDE & Guariba & SP \\
\hline & 20. CLINICA DE FONO & Colina & SP \\
\hline & 21. CLINICA ODONTOL. ESPAÇO SORRISO & Amparo & SP \\
\hline & 22. CENTRO ATEND. NEC. ESPECIAIS & Oscar Bressani & SP \\
\hline & 23. CENTRO NEUROLOGICO DE CAMPINAS & Sumaré & SP \\
\hline & 24. AFIPP & Presidente Prudente & SP \\
\hline & 25. SECRETARIA MUNICIPAL DE SAÚDE & Botucatu & SP \\
\hline & 26. CENTRO DE SAÚDE E ODONTOLOGICO & Auriflama & SP \\
\hline & 27. CLINICA PARTICULAR & Catanduva & SP \\
\hline & 28. UFRJ & Rio de Janeiro & RJ \\
\hline & 29. CLINICA MUNICIPAL & Petropolis & RJ \\
\hline & 30. CLINICA DE FONOAUDIOLOGIA & Macaé & RJ \\
\hline & 31. CLINICA ESPAÇO SEMENTE & Belo Horizonte & MG \\
\hline & 32. FUNDO CRISTÃO & Belo Horizonte & MG \\
\hline & 33. HOSPITAL PRIVADO & S. Sebastião Paraíso & MG \\
\hline & 34. CLINICA PRIORITÁ & Ipatinga & MG \\
\hline & 35. PROGRAMA MUNICIPAL A FISSURADO & Uberlândia & MG \\
\hline & 36. UNIDADE BASICA DE SAÚDE & Brasópolis & MG \\
\hline & 37. CLINICA & Manhumirim & MG \\
\hline & 38. CENTRO DE ATENDIMENTO & Araguari & MG \\
\hline & 39. PROFIS DE VITÓRIA & Vitória & ES \\
\hline & 40. CLIMEB & Aracruz & ES \\
\hline \multirow{13}{*}{ SUL $=13$} & 41. AFIM & Maringá & PR \\
\hline & 42. CEFIL & Londrina & PR \\
\hline & 43. APOFILAB & Cascavel & PR \\
\hline & 44. CAIC - CENTRO DE ATENDIMENTO & Paranavaí & PR \\
\hline & 45. CLINICA & Guarapuava & PR \\
\hline & 46. CLINICA & Perola D'Oeste & PR \\
\hline & 47. CENTRO ATENDIMENTOEDUCACIONAL & Ribeirão do Pinhal & PR \\
\hline & 48. CAIF/HOSPITAL DO TRABALHADOR & Curitiba & PR \\
\hline & 49. SECRETARIA DE SAÚDE & Pelotas & $\mathrm{RS}$ \\
\hline & 50. CIRCULO OPERÁRIO & Caxias Do Sul & $\mathrm{RS}$ \\
\hline & 51. UNIVERS. FEDERAL SANTA MARIA & Santa Maria & $\mathrm{RS}$ \\
\hline & 52. CLINICA DE REABILITAÇÃO CRESCER & Crisciuma & $\mathrm{SC}$ \\
\hline & 53. CENTRINHO/JOINVILLE & Joinville & $\mathrm{SC}$ \\
\hline \multirow{8}{*}{$\begin{array}{c}\text { CENTRO } \\
\text { OESTE }=8\end{array}$} & 54. FUNCRAF & Campo Grande & MS \\
\hline & 55. SECRETARIA DE SAÚDE & Itauba & MT \\
\hline & 56. CLINICA ORL-PREV & Cuiaba & MT \\
\hline & 57. CENTRO REABILITAÇÃO CANARANA & Canarana & MT \\
\hline & 58. CLINICAS & Goiania & GO \\
\hline & 59. CENTRO DE SAÚDE & Uruana & GO \\
\hline & 60. CLINICA ODONTOLOGICA & Uruana & $\mathrm{GO}$ \\
\hline & 61. CENTRO EMPRESÁRIAL & Brasilia & DF \\
\hline TOTAL & 61 serviços & & \\
\hline
\end{tabular}

Figura 5 - Distribuição do universo dos serviços e abrangência geográfica 
Os serviços identificados pelos pacientes em tratamento foram caracterizados pelos mesmos, resultando na tabela que se segue.

Tabela 2 - Classificação dos serviços identificados pelos pacientes em tratamento na cidade/região de origem segundo: tipologia, natureza, áreas de atendimento e satisfação com os tratamentos

\begin{tabular}{lcc}
\hline Classificação & Freqüência & (\%) \\
\hline Natureza & 39 & 42,9 \\
\hline Público & 19 & 20,9 \\
Privado & 33 & 36,3 \\
Terceiro Setor & $\mathbf{9 1}$ & $\mathbf{1 0 0 , 0}$ \\
\hline TOTAL & & 18,7 \\
\hline Tipologia & 17 & 27,5 \\
\hline Clínica & 25 & 6,6 \\
Associação & 06 & 31,9 \\
Subsede & 29 & 15,4 \\
Prefeitura Municipal & 14 & $\mathbf{1 0 0 , 0}$ \\
Hospitais & $\mathbf{9 1}$ & 57,1 \\
\hline TOTAL & & 76,9 \\
\hline Áreas & 52 & 82,4 \\
\hline Médico & 70 & 38,5 \\
Odontologia & 75 & 36,3 \\
Fonoaudiologia & 35 & 8,8 \\
Psicologia & 33 & $\mathbf{1 0 0 , 0}$ \\
Serviço Social & 08 & \\
Outros & $\mathbf{9 1}$ & 12,1 \\
\hline TOTAL & & 87,9 \\
\hline Satisfação & 11 & $\mathbf{1 0 0 , 0}$ \\
\hline Não & 80 & \\
Sim & $\mathbf{9 1}$ & \\
\hline TOTAL & & \\
\hline
\end{tabular}

Com relação à natureza dos serviços, os mesmos foram caracterizados como Público, Privado e Terceiro Setor.

De acordo com o Ferreira (1999): público é relativo ou pertencente ou destinado ao povo, à coletividade; relativo ou pertencente ao governo de um país; que é de uso de todos; comum; conhecido de todos; que serve para todos; notório; sabido; o povo em geral; auditório; assistência, também considerado como o primeiro setor constituído por serviços mantidos pelo Estado e o privado que não é público; particular, falto, desprovido; individual; íntimo; proibido; favorito; valido ou segundo setor formado pela iniciativa privada/empresas.

De acordo com Rodrigues (1998), Terceiro Setor é a ação da sociedade se organizando, de forma espontânea ou não, para ocupar espaços deixados pelo setor 
público e buscar compensar, ou sanar, as mazelas do processo de produção do setor privado. O terceiro setor (setor social ou organizações da sociedade civil ou ainda organizações não-lucrativas) se compõe por meio das organizações privadas sem fins lucrativos voltadas para a produção de bens ou para os serviços públicos.

Os resultados mostram a diversidade da natureza dos serviços na seguinte ordem de concentração: público $42,9 \%$ - terceiro setor $36,3 \%$ e privado $20,9 \%$, evidenciando o esforço da esfera privada e do terceiro setor $(57,1 \%)$ em desenvolver políticas de atendimento a pessoas com malformação labiopalatina.

Quanto à tipologia, o maior índice foi observado nos serviços disponibilizados pelas Prefeituras Municipais (31,9\%), pois o município é o principal responsável pela saúde pública de sua população. A partir da implantação do SUS e com o Pacto pela Saúde, assinado em 2006, o gestor municipal passa a assumir imediata ou paulatinamente a plenitude da gestão das ações e serviços de saúde oferecidos em seu território. Porem, a maior parte dos municípios não tem condições de ofertar na integralidade os serviços de saúde e, para que o sistema funcione, é necessário que haja uma estratégia regional de atendimento (parceria entre estado e municípios) para corrigir essas distorções de acesso (Brasil 2006).

Esse dado revela a escassez de serviços públicos para atender a demanda, exigindo do Serviço Social do HRAC uma constante mobilização de recursos comunitários, entre eles, organizações do Terceiro Setor, que se compõe por meio das organizações privadas sem fins lucrativos, definidas na LEI No 10.406 do Código Civil (as associações; as sociedades; as fundações; as organizações religiosas; os partidos políticos) (Brasil 2007c).

Um exemplo a ser considerado são as Associações de Pais e Pacientes com Fissuras pertencentes ao Terceiro Setor que atendem 27,5\% dos pacientes, garantindo além da assistência social, o atendimento na área da saúde/reabilitação.

Dentre os atendimentos da saúde e reabilitação destacam-se as áreas de fonoaudiologia $(82,4 \%)$ e odontologia $(76,9 \%)$, considerados como especialistas-chave na definição das etapas do tratamento reabilitador na área das fissuras labiopalatinas, que podem e devem ser oferecidas nas cidades/região de origem.

No entanto não basta apenas oferecer o(s) serviço(s); é necessário estar preparada para a prestação dos serviços e, também, para o atendimento das necessidades 
dos indivíduos, nas dimensões biológicas, psicológicas e sociais, a partir do conhecimento teórico e técnico de cada profissional.

A definição de qualidade de Ovretveit (1996), citado por Serapioni (2006 p. 220), "identifica três dimensões que correspondem aos principais atores que agem no âmbito dos serviços de saúde: qualidade avaliada pelo usuário, qualidade profissional e qualidade gerencia”. Questionados sobre a qualidade dos serviços prestados, os pacientes, na sua maioria $(87,9 \%)$, declararam-se satisfeitos, como mostra a tabela 2 , sendo a satisfação uma das facetas da qualidade.

A figura a seguir especifica esses recursos cadastrados no HRAC que além da prestação de serviços, caracterizam-se como apoio ao paciente e família para o processo de reabilitação, estabelecendo uma interface da saúde com a assistência social.

Além desses serviços há um outro recurso de apoio a reabilitação com o qual algumas cidades contam: pais coordenadores, considerados agentes multiplicadores do HRAC nas diferentes regiões do país. Esses agentes são pais e ou pacientes adultos que representam o Hospital e os pacientes de suas respectivas cidades, defendendo interesses comuns, especialmente os relacionados à reabilitação.

Esses agentes, no desempenho de suas funções básicas de apoio, divulgação, mobilização e organização, passam a manter contatos com vários segmentos da sociedade. 


\begin{tabular}{|c|c|c|c|c|c|c|c|c|}
\hline \multicolumn{2}{|c|}{$\begin{array}{l}\text { Distribuição por } \\
\text { Região/Estados }\end{array}$} & \multicolumn{4}{|c|}{ Amostra } & \multicolumn{2}{|c|}{$\begin{array}{l}\text { Participação na } \\
\text { associação }\end{array}$} & \multirow{2}{*}{$\begin{array}{c}\text { Sem } \\
\text { Associa- } \\
\text { ção na } \\
\text { cidade }\end{array}$} \\
\hline \multirow{2}{*}{$\begin{array}{l}0 \\
\stackrel{0}{0} \\
0 \\
0 \\
\vdots \\
Z\end{array}$} & Estados & Coord. & Assoc. & Núcleo & Outros & $\begin{array}{c}\text { Pacientes } \\
\text { com } \\
\text { associação } \\
\text { na cidade }\end{array}$ & $\begin{array}{l}\text { Pacientes } \\
\text { participant } \\
\text { es de } \\
\text { associação }\end{array}$ & \\
\hline & $\begin{array}{r}\text { Rio Grande do } \\
\text { Norte/RN }\end{array}$ & & & & & & & 01 \\
\hline & TOTAL & & & & & & & $01(1,9)$ \\
\hline \multirow{4}{*}{ 它䓌 } & Distrito Federal/DF & 01 & 01 & & & 01 & & 01 \\
\hline & Goiás/GO & 01 & 01 & & & 01 & & 03 \\
\hline & Mato Grosso/MT & 01 & 00 & & & & & 03 \\
\hline & $\begin{array}{r}\text { Mato Grosso } \\
\text { Sul/MS }\end{array}$ & 01 & 01 & & 01 & 02 & 02 & \\
\hline \multicolumn{2}{|r|}{ TOTAL } & $04(8,2)$ & $03(17,6)$ & & $01(20)$ & $04(9,3)$ & $02(5,3)$ & $07(13,1)$ \\
\hline \multirow{4}{*}{$\begin{array}{l}\frac{0}{0} \\
\frac{0}{0} \\
\tilde{D}\end{array}$} & Espírito Santo/ES & 02 & 01 & & & 01 & 01 & 01 \\
\hline & Minas Gerais/MG & 05 & 01 & & & & & 08 \\
\hline & Rio de Janeiro/RJ & 04 & & & & & & 03 \\
\hline & São Paulo/SP & 24 & 07 & & 02 & 22 & 22 & 24 \\
\hline \multicolumn{2}{|r|}{ TOTAL } & $35(71,4)$ & $09(47,4)$ & & $02(40)$ & $23(53,5)$ & $23(60,5)$ & $36(68,0)$ \\
\hline \multirow{3}{*}{$\bar{B}$} & Paraná/PR & 04 & 04 & 03 & 01 & 15 & 12 & 04 \\
\hline & Rio Grande Sul/RS & 03 & & & & & & 04 \\
\hline & Santa Catarina/SC & 03 & 01 & & 01 & 01 & 01 & 01 \\
\hline \multicolumn{2}{|r|}{ TOTAL } & $10(20,4)$ & $05(29,4)$ & $03(100)$ & $02(40)$ & $16(37,2)$ & $13(34,2)$ & $09(17,0)$ \\
\hline & TOTAL GERAL & 49(100) & $17(100)$ & 03(100) & $05(100)$ & 43(100) & $38(100)$ & $53(100)$ \\
\hline
\end{tabular}

Figura 6 - Recursos comunitários de apoio à reabilitação na cidade/região dos pacientes cadastrados no HRAC e sua participação em associações

Identificamos, a partir dos pacientes da amostra (91, procedentes de 74 cidades), 49 cidades com pais-coordenadores $(66,2 \%)$, portanto, um índice considerável, com garantia do apoio ao processo de reabilitação nas suas especificidades.

O programa de pais coordenadores implantado pelo Serviço Social do HRAC em 1981, conta atualmente (dezembro de 2006) com 473 agentes no país e potencial de cobertura a 3.671 casos ( $56 \%$ do universo de casos em tratamento).

Segundo Graciano (1988), num estudo sobre as dimensões da atuação dos paiscoordenadores as estratégias utilizadas pelo Serviço Social do HRAC, buscando estimular formas de representação e organização popular e engajando esses pais que de clientes são transformados em agentes multiplicadores. Aos pais coordenadores, é possível uma atuação imediata logo após o nascimento da criança portadora de fissura para apoio, orientação e encaminhamento ao tratamento, bem como o acompanhamento do tratamento prevenindo e/ou intervindo em casos irregulares.

Sabemos, porém, que o caminho percorrido tantos pelos pacientes como pelos coordenadores para o acesso aos diferentes recursos comunitários revela que para se ter os direitos assegurados são necessários lutas e conquistas (Bordin 2001). 
A existência das associações de pais e pessoas com fissuras labiopalatinas é uma realidade em muitas cidades.

Em um estudo sobre o processo histórico de associações de pais e portadores de lesões labiopalatinas no país, Graciano (1996) destaca que a organização desse segmento da sociedade civil vem construindo diferentes espaços de luta e tem como eixo central a questão da solidariedade em função de um problema comum - as fissuras labiopalatinas.

Esse processo de organização social é um exemplo de luta pela conquista de direitos garantidos pela Constituição, numa sociedade em fase de construção da democracia. O número de associações, até dezembro de 2006, era de $43^{11}$.

Considerando os municípios de procedência dos pacientes (52), constatamos que 17 contam com associações (39,6\%), abrangendo 43 pacientes (47,2\%). Desse pacientes, a participação é de $88,3 \%$.

Os 57 municípios restantes (77,0\%) não contam com essa organização, justificando assim a não participação dos pais 58,3\%.

No Brasil, o índice geral de filiação em associações voluntárias é de 52\%, abrangendo as de bairros, de moradores, religiosas, filantrópicas e esportiva e cultural (Arretch 1999).

Considerando que as Associações garantem a representatividade de diversos grupos, faz-se necessário não só o incentivo na criação de associações, como também para a participação dos pais e pacientes - no estudo o índice apontado foi de 88,3\%.

Essas associações além de oportunizar o conhecimento sobre as fissuras e seu processo de reabilitação, é também uma forma, enquanto sociedade civil organizada, de pressionar os poderes públicos para a implantação de serviços próprios para a assistência as pessoas com fissuras labiopalatinas, influindo na criação de políticas públicas de saúde e reabilitação.

Arretch (1999) considera que a participação em associações civis - seja qual for sua natureza - geraria sociedades fortes cuja capacidade de pressão geraria governos fortes, os quais, por sua vez, seriam categorizados por sua capacidade de instruir e manter políticas públicas de qualidade.

A partir de 2004, foi criada, com apoio de um programa de políticas públicas, a Rede Nacional de Associações de Pais e Portadores de Lesões Labiopalatais

\footnotetext{
${ }^{11}$ Fonte: Serviço Social de Projetos Comunitários - HRAC/USP.
} 
denominada REDE PROFIS cuja finalidade principal é congregar, integrar, representar e defender os interesses institucionais de suas associadas, colaborando com o desenvolvimento da solidariedade social (Bauru 2004).

Quanto aos núcleos regionais, considerados centros de atendimento ambulatoriais de apoio ao processo de reabilitação do HRAC, normalmente com as áreas de medicina, odontologia, fonoaudiologia, psicologia e serviço social, incluindo as fases pré e pós-cirúrgicas dando o suporte para o seguimento do tratamento.

Os dados da pesquisa evidenciam a existência de 03 núcleos regionais na amostra situados em Londrina, Maringá e Cascavel todos do Estado do Paraná.

Esses núcleos geralmente contam com a parceria/convênios das Prefeituras Municipais e ou Secretarias de Estados (Saúde, Educação, Assistência Social), cabendo ao HRAC colaborar na formação de recursos humanos. No Brasil, contamos com 12 núcleos regionais, distribuídos em diferentes regiões devidamente cadastradas no HRAC.

$\mathrm{Na}$ categoria outros, temos as subsedes e os hospitais credenciados pelo Ministério da Saúde em Alta Complexidade, conforme portaria 62 de 19 de abril de 1994.

As subsedes são unidades de atendimento ambulatorial mantidas pela Fundação para Estudo e Tratamento das Deformidades Crânio-Faciais (FUNCRAF) parceira do HRAC; implantadas em três regiões do Brasil, ou seja, Campo Grande/MS, Itararé/SP e Santo Bernardo do Campo/SP. Contando com 23.808 pacientes matriculados (dezembro de 2006). Dessas subsedes, (100\%) se faz presente em municípios da amostra.

$\mathrm{Na}$ categoria hospitais credenciados encontramos dois serviços situados nas cidades de Joinville/SC - Hospital Regional Hans Dieter Schmidt e Curitiba/PR Hospital do Trabalhador. Ambos os hospitais contam com apoio de núcleos e associações.

O programa de descentralização dos serviços do HRAC no país prevê o apoio e/ou criação de núcleos de atendimentos, subsedes e de associações buscando facilitar o acesso dos pacientes a recursos nos municípios e/ou regiões de origem, minimizando dificuldades geográficas, financeiras e sociais, além de aliviar a demanda do HRAC.

Ressaltam Roque et al (2001) que diante dessa diversidade de recursos é necessário destacar que o HRAC conta com uma rede de recursos comunitários, de 
forma articulada e integrada de apoio ao processo de reabilitação, garantindo o acesso ao tratamento e sua continuidade enquanto direito de cidadania.

Esse aparato institucional fortalece o trabalho extra muros, facilitando o desenvolvimento de parcerias que buscam solidariedade neste novo milênio, empenhando-se em construir uma ponte entre vivência de problemas e a efetivação da reabilitação. Sua efetivação se traduz em serviços de reabilitação em busca da universalização dos direitos sociais.

Os resultados apresentados neste primeiro momento foram procedimentos preliminares e necessários para chegarmos ao $2^{\circ}$ momento e propriamente ao objetivo do estudo: de conhecer e cadastrar esses serviços de reabilitação, englobando as diferentes áreas (fonoaudiologia, odontologia, psicologia e serviço social).

\section{$2^{\circ}$ Momento - Caracterização dos serviços reabilitadores identificados pelos pacientes do HRAC.}

De acordo com os 91 pacientes que realizam tratamentos em sua cidade ou região, foram identificados $61(100 \%)$ serviços para os quais foram enviados os questionários. Desses, recebemos resposta de 21 (34,4\%), compreendendo 19 cidades, 08 Estados e 03 regiões, como mostra a figura a seguir.

5.1 - Conhecimento e cadastramento dos serviços de reabilitação englobando as diferentes áreas (fonoaudiologia, odontologia, psicologia e serviço social). 


\begin{tabular}{|c|c|c|}
\hline Serviços & Cidade & Estado \\
\hline $\begin{array}{l}\text { AFIM - Associação de Apoio ao Fissurado Labiopalatal de } \\
\text { Maringá }\end{array}$ & Maringá & PR \\
\hline $\begin{array}{l}\text { CEFIL - Centro de Apoio e Reabilitação aos Portadores de } \\
\text { Fissuras Labiopalatal de Londrina e Região }\end{array}$ & Londrina & PR \\
\hline APOFILAB - Associação dos Fissurados de Cascavel & Cascavel & PR \\
\hline Centrinho Prefeito Luis Gomes /Hospital & Joinville & $\mathrm{SC}$ \\
\hline Círculo Operário Pró-Face & Caxias do Sul & $\mathrm{RS}$ \\
\hline APAE Morungaba & Morungaba & SP \\
\hline $\begin{array}{l}\text { FUNCRAF - Fundação para Estudo e Tratamento das } \\
\text { Deformidades Craniofaciais }\end{array}$ & $\begin{array}{l}\text { São Bernardo do } \\
\text { Campo }\end{array}$ & SP \\
\hline Associação dos Fissurados de Franca - AFISFRAN & Franca & SP \\
\hline $\begin{array}{l}\text { AFIPP - Associação de Apoio ao Fissurado Labiopalatal } \\
\text { de Presidente Prudente }\end{array}$ & Pres. Prudente & SP \\
\hline $\begin{array}{l}\text { FUNCRAF- Fundação para Estudo e Tratamento das } \\
\text { Deformidades Craniofaciais }\end{array}$ & Itararé & SP \\
\hline $\begin{array}{l}\text { APAFI - Associação de Pais e Amigos dos Portadores de } \\
\text { Fissuras Labiopalatais de Mogi das Cruzes }\end{array}$ & M. das Cruzes & SP \\
\hline AAFLAP- Associação de Apoio aos Fissurados & São José dos & SP \\
\hline Labiopalatais & Campos & \\
\hline Núcleo de Saúde Mental de Guariba & Guariba & SP \\
\hline $\begin{array}{l}\text { CETREIM - Centro de Terapia e Reabilitação Integrada } \\
\text { Municipal }\end{array}$ & Campinas & SP \\
\hline Secretaria Municipal de Saúde de Brasópolis & Brasópolis & MG \\
\hline Consultório Odontológico de Brasópolis & Brasópolis & MG \\
\hline $\begin{array}{l}\text { Programa de Atendimento ao Portador de Lesões } \\
\text { Labionalatais - Prefeitura Municinal de Uberlândia }\end{array}$ & Uberlândia & MG \\
\hline HD Ensinos Odontológicos/Ortopedia Funcional & Uberlândia & MG \\
\hline PROFIS-Vitória & Vitória & ES \\
\hline Centro de Reabilitação de Canarana & Canarana & MT \\
\hline $\begin{array}{l}\text { FUNCRAF - Fundação para Estudo e Tratamento das } \\
\text { Deformidades Craniofaciais }\end{array}$ & Campo Grande & MS \\
\hline Total de Serviços $=21$ & 19 cidades & 8 Estac \\
\hline
\end{tabular}

\section{Figura 7 - Distribuição dos serviços segundo cidade e Estado}

Estes serviços foram caracterizados segundo as respostas dos diretores, coordenadores e profissionais responsáveis pelas instituições que prestam atendimentos aos pacientes, conforme tabela 3 . 
Tabela 3 - Caracterização dos serviços identificados segundo: finalidades, natureza, áreas de atendimento, elegibilidade e instrumento de avaliação da satisfação dos usuários

\begin{tabular}{lcc}
\hline Caracterização & Freqüência & $\mathbf{( \% )}$ \\
\hline Natureza & & \\
\hline Público & 06 & 28,6 \\
Privado & 03 & 14,2 \\
Terceiro Setor & 12 & 57,2 \\
\hline TOTAL & $\mathbf{2 1}$ & $\mathbf{1 0 0 , 0}$ \\
\hline Finalidade & & \\
\hline Serviços de saúde e reabilitação & 09 & 42,9 \\
Serviços de saúde/reabilitação e assistência social & 12 & 57,1 \\
\hline TOTAL & $\mathbf{2 1}$ & $\mathbf{1 0 0 , 0}$ \\
\hline Áreas & & \\
\hline Medicina & 14 & 66,7 \\
Odontologia & 15 & 71,4 \\
Fonoaudiologia & 19 & 90,4 \\
Psicologia & 18 & 85,7 \\
Serviço Social & 15 & 71,4 \\
Outros & 13 & 61,9 \\
\hline TOTAL & $\mathbf{2 1}$ & $\mathbf{1 0 0 , 0}$ \\
\hline Elegibilidade & & \\
\hline Fissura lábio-palatal/ Encaminhamentos de profissionais da saúde & 19 & 100,0 \\
TOTAL & 19 & \\
\hline Sem resposta & 02 & $\mathbf{1 0 0 , 0}$ \\
\hline TOTAL GERAL & $\mathbf{2 1}$ & \\
\hline Instrumentos de avaliação & & \\
\hline Não & 11 & 55,0 \\
Sim & 9 & 45,0 \\
TOTAL & 20 & $\mathbf{1 0 0 , 0}$ \\
\hline Sem resposta & 01 & \\
\hline TOTAL GERAL & $\mathbf{2 1}$ & \\
\hline & &
\end{tabular}

A Constituição Federal, em seu art. 199, § $1^{\circ} 17$ (Brasil 1988) e a Lei Orgânica da Saúde (Brasil 1990), em seu art. 2518, prevêem que as entidades filantrópicas e as sem fins lucrativos têm preferência para participar de forma complementar no Sistema Único de Saúde, proporcionando a participação da sociedade civil na promoção de políticas sociais e abrindo novos espaços de atuação das organizações sociais.

Os serviços, em sua maioria $(57,2 \%)$, pertencem ao Terceiro Setor, seguidos dos serviços públicos $(28,6 \%)$, prestando não só reabilitação $(42,9 \%)$, mas a reabilitação em conjunto com assistência social $(57,1 \%)$.

A presença de diferentes áreas demonstra o interesse da reabilitação global dos pacientes. Dentre os serviços prestados a maioria conta com profissionais nas áreas de fonoaudiologia $(90,4 \%)$ e psicologia $(85,7 \%)$, seguidas das de odontologia, serviço 
social, $(71,4 \%)$ medicina e outros, com $61,9 \%$. As áreas citadas em outros foram: Nutrição, Enfermagem, Direito e Pedagogia.

Tais serviços têm como critério de elegibilidade, a presença de fissura labiopalatal mediante encaminhamento de profissionais da área da saúde (100,0\%).

“A avaliação é, em especial, parte fundamental no planejamento e na gestão do sistema de saúde. Um sistema de avaliação efetivo deve reordenar a execução das ações e serviços, redimensionados de forma a contemplar as necessidades de seu público, dando maior racionalidade ao uso dos recursos" (Brasil 2004a p5).

A avaliação é um dever ético e as organizações que atuam na esfera pública precisam apresentar à sociedade os resultados de sua ação, serem transparentes, uma vez que se espera desta eficiência, eficácia e equidade na prestação de serviços de interesse do cidadão.

No que se refere aos instrumentos de avaliação (tabela 3), 42,9\% responderam ocorrer especialmente por meio de questionários, caixa de sugestão, Serviço de Atendimento ao Consumidor (SAC), 0800 e reuniões.

Segundo Serapioni (2006) o assunto da satisfação dos usuários foi bastante explorado nos últimos 15 anos, mas ainda são poucas as avaliações de qualidades mais abrangentes, que envolvem a participação de diferentes atores na produção da saúde.

Ressalta que ainda existe uma multiplicidade de linguagens, práxis e métodos de avaliação da qualidade que dificultam o desenvolvimento de estratégias de integração, resultado das resistências das organizações profissionais (dos técnicos, dos gerentes, etc.) que continuam promovendo abordagens da qualidade muito especializadas e setoriais.

\section{2 - Identificação das formas de articulação/parceria dos serviços/ reabilitadores com órgãos locais (universidade, secretaria de saúde e outros).}

A palavra parceria (Ferreira 1999) significa reunião de pessoas para um fim de interesse comum, que é o entendimento corrente tanto na mídia como nas referencias utilizada em conversas cotidianas. Pode significar ainda convênio ou acordo.

Segundo Di Pietro (2006) citado por Brasil (2007c p.12), “o convênio pode ser definido como forma de ajuste entre Poder Público e entidades públicas ou privadas, 
para a realização de objetivos de interesse comum, mediante mútua colaboração, todos os partícipes querem a mesma coisa".

Para Meirelles (2003) citado por Brasil (2007c p12), “convênio é acordo onde os partícipes têm interesses comuns e coincidentes. Por essa razão, no convênio, a posição jurídica dos signatários é uma só, idêntica para todos, podendo haver apenas diversificação na cooperação de cada um, segundo suas possibilidades para a consecução do objetivo comum, desejado por todos. Assim, a realização de um convênio confere às entidades conveniadas a condição de parceira do Poder Público".

"O convênio pode ser utilizado para regular a relação com entidades privadas sem fins lucrativos, entidades filantrópicas e, também, com entidades públicas quando houver o interesse mútuo em promover a saúde da população. Em razão do disposto no art. 199, §11 da Constituição Federal, entidades privadas sem fins lucrativos, entidades filantrópicas têm prioridade na participação complementar na rede pública de saúde" (Brasil 2007c p13).

Tabela 4 - Articulação dos serviços/reabilitadores com outros órgãos locais e com o Hospital de Reabilitação de Anomalias Craniofaciais

\begin{tabular}{lcc}
\hline Parcerias / Convênios & Freqüência & $\mathbf{( \% )}$ \\
\hline Não & 02 & 9,5 \\
Sim & 19 & 90,5 \\
TOTAL & $\mathbf{2 1}$ & $\mathbf{1 0 0 , 0}$ \\
\hline Órgãos & & \\
\hline Universidade & 09 & 42,8 \\
Pref. Municipal (Secretaria de Saúde) & 13 & 61,9 \\
Associação & 09 & 42,9 \\
HRAC & 14 & 66,7 \\
Outros & 07 & 33,3 \\
\hline TOTAL & $\mathbf{2 1}$ & $\mathbf{1 0 0 , 0}$ \\
\hline
\end{tabular}

A maioria dos serviços (90,5\%) estabeleceu parcerias/convênios, 66,7\% com o próprio $\mathrm{HRAC}^{12}, 61,9 \%$ com as Prefeituras Municipais por meio da Secretaria de Saúde. Tais parcerias com o setor público garantem legitimidade e o cumprimento de

\footnotetext{
12 Os convênios com o HRAC devem ser encaminhados para a Universidade de São Paulo por meio de minuta de convênio que celebra a cooperação acadêmica na área de interesse, conforme plano de trabalho em anexo - na minuta - que, a partir de então, passa a ser parte integrante do instrumento.
} 
exigências legais e também recursos físicos e humanos. Além disso, a parceria com o HRAC tem viabilizado o apoio técnico e científico para as áreas afins.

Diante do interesse do HRAC no atendimento dos pacientes na cidade/região de origem, houve o questionamento sobre o nível de articulação dos serviços/reabilitadores, como demonstrado na tabela 5 .

Tabela 5 - Formas de articulação dos serviços/reabilitadores com o Hospital de Reabilitação de Anomalias Craniofaciais

\begin{tabular}{lcc}
\hline Conhecimento do HRAC & Freqüência & $(\mathbf{\% )}$ \\
\hline Não & 06 & 28,6 \\
Sim & 15 & 71,4 \\
\hline TOTAL & $\mathbf{2 1}$ & $\mathbf{1 0 0 , 0}$ \\
\hline Formas de articulação & & \\
\hline Visita & 11 & 52,3 \\
Estágio & 03 & 14,2 \\
Cursos & 11 & 52,3 \\
Internet & 05 & 23,8 \\
Outros & 07 & 33,3 \\
\hline TOTAL & $\mathbf{2 1}$ & $\mathbf{1 0 0 , 0}$ \\
\hline Interesse em conhecer o HRAC & & 100,0 \\
\hline Sim & 06 & $\mathbf{1 0 0 , 0}$ \\
\hline TOTAL & $\mathbf{1 3}$ & \\
\hline
\end{tabular}

Dos $(28,6 \%)$ que não conhecem o HRAC, a totalidade tem interesse em conhecer. Já a maioria dos responsáveis pelos serviços $(71,4 \%)$ revela conhecê-lo por meio de cursos e visitas (52,3\%), o que demonstra, por um lado, o empenho do HRAC como formador de recursos humanos e, por outro, o interesse dos serviços no desenvolvimento técnico-científico (formação/capacitação) e/ou mesmo em colaborar como agentes multiplicadores.

A direção do HRAC se preocupa constantemente em manter sua equipe atualizada e, também, em formar recursos humanos, promovendo cursos e eventos que possibilitam a incrementação de novos conhecimentos.

Um exemplo concreto dessa disposição é o Curso de Anomalias Congênitas Labiopalatais, que acontece desde 1984, com a participação de profissionais e estudantes de todo o Brasil. Esse curso pode ser considerado como um pré-requisito para o entendimento das anomalias craniofaciais e conhecimento da estrutura do HRAC/USP - indispensável para a formação dos alunos de graduação (estágio) e de pós-graduação. 
Por seu conteúdo, ele tem se consolidado como determinante para que os profissionais do país compreendam o tratamento nesta área e, principalmente, entendam a necessidade de uma reabilitação integral e de caráter interdisciplinar; configura-se como um início de capacitação para todas as especialidades.

Capacitar é qualificar a pessoa para determinado trabalho, é tornar habilitado para o desempenho de uma função (Sena 2007).

A importância da capacitação/formação profissional para a vida das pessoas, encontra-se na possibilidade de acesso às oportunidades de trabalho, que por sua vez, têm suas características modificadas a cada dia.

A capacitação não só dá condições para o exercício de determinadas profissões como também objetiva preparar o profissional para o mundo do trabalho, oferecendo a oportunidade de uma melhor adaptação ao mercado competitivo, uma vez que a pessoa deverá estar pronta, com hábitos e atitudes condizentes às exigências desse mercado.

$\mathrm{Na}$ perspectiva do trabalho na sociedade do conhecimento, a criatividade e a disposição para capacitação permanente serão requeridas e valorizadas, motivo pelo qual os serviços foram questionados quanto a programas/projetos de capacitação.

Tabela 6 - Desenvolvimento institucional de programas/projetos de capacitação profissional (humanização, qualidade e outros)

\begin{tabular}{lcc}
\hline Programas/Projetos de capacitação & Freqüência & (\%) \\
\hline Sim & 13 & 65 \\
Não & 07 & 35 \\
TOTAL & $\mathbf{2 0}$ & $\mathbf{1 0 0 , 0}$ \\
\hline Sem resposta & 01 & \\
\hline TOTAL GERAL & $\mathbf{2 1}$ & \\
\hline
\end{tabular}

Os dados revelam que $65 \%$ dos serviços desenvolvem programas/projetos de capacitação em suas instituições para seus profissionais ou mesmo favorecem a participação dos mesmos em programas desenvolvidos fora da instituição.

Com relação à capacitação na própria instituição, vários temas foram desenvolvidos: saúde pública; reabilitação das fissuras labiopalatinas; gestão social, rede de proteção social e inclusão social.

Além desses programas/projetos de capacitação, os temas humanização e qualidade foram enfatizados como mostra a tabela seguinte. 
Tabela 7 - Outros cursos de capacitação profissional

\begin{tabular}{lcc}
\hline Cursos & Freqüência & $\mathbf{( \% )}$ \\
\hline Humanização & 11 & 52,3 \\
Qualidade & 11 & 52,3 \\
Outros & 02 & 14,2 \\
\hline TOTAL & $\mathbf{2 1}$ & $\mathbf{1 0 0 , 0}$ \\
\hline
\end{tabular}

A exemplo do HRAC a maioria dos serviços (61,9\%) desenvolve programas/projetos de capacitação profissional, principalmente no que se refere a questão da humanização e qualidade, temas esses prioritários para um bom atendimento na área da saúde preconizado pelo Ministério da Saúde por meio de suas políticas: educação permanente e humanização.

“O setor da Saúde é responsável pela maior política brasileira de inclusão social. O SUS já provocou profundas mudanças nas práticas de saúde, mas ainda não é o bastante. Para que novas mudanças ocorram, é preciso haver também profundas transformações na formação e no desenvolvimento dos profissionais da área. A idéia é usar a educação permanente para melhorar a formação e, conseqüentemente, fortalecer o SUS. A educação permanente possibilita, ao mesmo tempo, o desenvolvimento pessoal daqueles que trabalham na Saúde e o desenvolvimento das instituições. Além disso, ela reforça a relação das ações de formação com a gestão do sistema e dos serviços, com o trabalho da atenção à saúde e com o controle social” (Brasil 2005 p5).

Área como a da Saúde, não funciona sozinha - sua eficácia é fortemente influenciada pela qualidade do fator humano e do relacionamento que se estabelece entre profissionais e usuários no processo de atendimento.

Para tanto, é necessário cuidar dos próprios profissionais da área da saúde, constituindo equipes de trabalho saudáveis e, por isso mesmo, capazes de promover a humanização do serviço, estender-se, também, à formação educacional dos profissionais de saúde. É no processo de formação que se firmam valores e atitudes de respeito à vida humana, indispensáveis à consolidação e à sustentação de uma nova cultura de atendimento à saúde.

Cabe à Secretaria de Gestão do Trabalho e da Educação na Saúde e ao Ministério da Saúde, ao lado das Secretarias Estaduais e Municipais de Saúde, mostrarem caminhos para a formação de novos profissionais de saúde, aperfeiçoando o pessoal que já está no SUS e o cuidado para que haja profissionais de saúde 
comprometidos e em quantidade suficiente em todos os pontos do País, para garantir a equidade também na qualidade e humanização do atendimento (Brasil 2005).

\section{3 - Perfil profissional dos reabilitadores das organizações identificando sua procedência, seu nível de articulação técnico, científico e funcional com o HRAC.}

Inicialmente, faremos uma caracterização dos profissionais envolvidos no presente estudo anteriormente à apresentação do perfil do profissional dos reabilitadores.

A Classificação Brasileira de Ocupações (CBO), (Brasil 2007e), é o documento normalizador do reconhecimento, da nomeação e da codificação dos títulos e conteúdos das ocupações do mercado de trabalho brasileiro. É ao mesmo tempo uma classificação enumtierava e descritiva. $\mathrm{Na} \mathrm{CBO}$, as ocupações foram agregadas por nível de competência e simulares nas atividades executadas, comportando dez conjuntos. A CBO classifica as ocupações do estudo nos grandes grupos $(\mathrm{GG}-2)$ que agrega os empregos compondo as profissões científicas e das artes de nível superior.

GG - 2 - PROFISSIONAIS DAS CIÊNCIAS E DAS ARTES - Compreende as ocupações cujas atividades principais requerem para seu desempenho conhecimentos profissionais de alto nível e experiência em matéria de ciências físicas, biológicas, sociais e humanas. Incluído também pessoal das artes e desportos, cujo exercício profissional requer alto nível de competência como, por exemplo, maestro, músicos, entre outros. Este grande grupo compreende: pesquisadores e profissionais policientíficos; profissionais das ciências exatas, físicas e da engenharia; profissionais das ciências biológicas, da saúde e afins; profissionais do ensino; profissionais das ciências jurídicas; profissionais das ciências sociais e humanas; comunicadores, artistas e religiosos.

\section{Fonoaudiólogo - Descrição sumária.}

Atendem pacientes e clientes para prevenção, habilitação e reabilitação de pessoas utilizando protocolos e procedimentos específicos de fonoaudiologia. Tratam de

pacientes e clientes; efetuam avaliação e diagnóstico fonoaudiológico; orientam pacientes, clientes, familiares, cuidadores e responsáveis; desenvolvem programas de 
prevenção, promoção da saúde e qualidade de vida; exercem atividades administrativas, de ensino e pesquisa; administram recursos humanos, materiais e financeiros.

\section{Odontologia - Descrição sumária.}

Atendem e orientam pacientes e executam tratamento odontológico, realizando, entre outras atividades, radiografias e ajuste oclusal, aplicação de anestesia, extração de dentes, tratamento de doenças gengivais e canais, cirurgias bucomaxilofaciais, implantes, tratamentos estéticos e de reabilitação oral, confecção de prótese oral e extraoral. Diagnosticam e avaliam pacientes e planejam tratamento. Realizam auditorias e perícias odontológicas, administram local e condições de trabalho, adotando medidas de precaução universal de biossegurança. Podem desenvolver pesquisas na prática odontológica e integrar comissões de normatização do exercício da profissão.

\section{Psicologia - Descrição sumária.}

Estudam, pesquisam e avaliam o desenvolvimento emocional e os processos mentais e sociais de indivíduos, grupos e instituições, com a finalidade de análise, tratamento, orientação e educação; diagnosticam e avaliam distúrbios emocionais e mentais e de adaptação social, elucidando conflitos e questões e acompanhando o(s) paciente(s) durante o processo de tratamento ou cura; investigam os fatores inconscientes do comportamento individual e grupal, tornando-os conscientes; desenvolvem pesquisas experimentais, teóricas e clínicas e coordenam equipes e atividades de área e afins.

\section{Serviço Social - Descrição sumária.}

Prestam serviços sociais, orientando indivíduos, famílias, comunidade e instituições sobre direitos e deveres (normas, códigos e legislação), serviços e recursos sociais e programas de educação; planejam, coordenam e avaliam planos, programas e projetos sociais em diferentes áreas de atuação profissional (seguridade, educação, trabalho, jurídica, habitação e outras), atuando nas esferas pública e privada; orientam e monitoram ações em desenvolvimento relacionadas à economia doméstica, nas áreas de habitação, vestuário e têxteis, desenvolvimento humano, economia familiar, educação do consumidor, alimentação e saúde; desempenham tarefas administrativas e articulam recursos financeiros disponíveis. 
As profissões também são regulamentadas por leis ${ }^{13}$ : Fonoaudiologia - Lei $n^{\circ}$ 6.965, de 9 de dezembro de 1981. (Dispõe sobre a regulamentação da Profissão de Fonoaudiólogo, e determina outras providências); Odontologia - Lei $\mathrm{n}^{\mathrm{o}} 5.081$, de 24/08/1966 (Regula o Exercício da Odontologia); Psicologia - Lei $\mathrm{n}^{\mathrm{o}} 4.119$, de 27/08/1962 (Dispõe sobre os cursos de formação em Psicologia e regulamenta a profissão de Psicólogo) e Serviço Social - Lei nº 8.662/93 (Dispõe sobre a profissão de Assistente Social e dá outras providências).

De acordo com Brasil (2005 p.9), "no campo da Educação na Saúde, a grande maioria dos cursos técnicos, universitários, de pós-graduação e as residências formam profissionais distantes das necessidades de saúde da população e de organização do sistema. Além disso, enquanto em algumas regiões do País há uma grande oferta de cursos de formação na área da Saúde, em outras eles quase não existem. Para completar, temos muitos educadores e orientadores de serviços que estão desatualizados e precisam aprender novos modos de ensinar".

Competência profissional como resposta às várias circunstâncias relativas à prática profissional, inclui capacidades, atividades e contextos, tratando da combinação de conhecimentos, destrezas, experiências e qualidades pessoais usadas efetiva e apropriadamente em atos individuais e coletivos.

Neste sentido, um processo de formação para desenvolver competências profissionais deve se ocupar da esquematização de fatores de aprendizagem críticos, reflexivos, significativos e participativos. (Brasil 2007f)

Nestas perspectivas houve o interesse em traçar o perfil dos reabilitadores, que atendem os pacientes, totalizando 72 profissionais (100,0\%) distribuídos por área: 24 fonoaudiólogos (33,3\%), 12 psicólogos (16,7\%), 19 dentistas (26,4\%) e 17 assistentes sociais $(23,6 \%)$ procedentes de 09 Estados e 3 Regiões, como mostra a tabela a seguir.

\footnotetext{
${ }^{13}$ Fonte: Câmara de Regulação do Trabalho em Saúde - Ministério da Saúde, 2006.
} 
Tabela 8 - Perfil dos reabilitadores segundo procedência

\begin{tabular}{|c|c|c|c|c|c|c|}
\hline & Procedência & 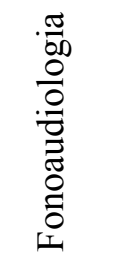 & $\begin{array}{l}\frac{\pi}{00} \\
\frac{0}{0} \\
\frac{0}{0} \\
0\end{array}$ & $\begin{array}{l}\frac{\pi}{00} \\
\frac{0}{0} \\
\frac{0}{0} \\
\frac{0}{0} \\
0\end{array}$ & 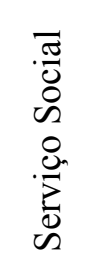 & 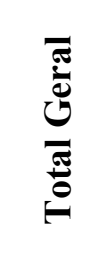 \\
\hline \multirow{4}{*}{ 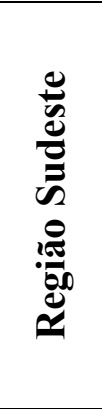 } & $\begin{array}{l}\text { São Paulo: } 13 \text { cidades - Campinas, Itararé, } \\
\text { Franca, Guariba, Jales, Mogi das Cruzes, } \\
\text { Morungaba, Oscar Bressani, Paulínia, Presidente } \\
\text { Prudente, São Bernardo do Campo, São José dos } \\
\text { Campos e Sorocaba. }\end{array}$ & $\begin{array}{c}15 \\
62,5 \%\end{array}$ & $\begin{array}{c}06 \\
50,0 \%\end{array}$ & $\begin{array}{c}08 \\
42,1 \%\end{array}$ & $\begin{array}{c}07 \\
41,2 \%\end{array}$ & $\begin{array}{c}36 \\
50,0 \%\end{array}$ \\
\hline & $\begin{array}{l}\text { Minas Gerais: } 03 \text { cidades - Brasópolis, } \\
\text { Manhumirim e Uberlândia }\end{array}$ & $\begin{array}{c}03 \\
12,5 \%\end{array}$ & $\begin{array}{c}02 \\
16,7 \%\end{array}$ & $\begin{array}{c}02 \\
10,5 \%\end{array}$ & $\begin{array}{c}03 \\
17,6 \%\end{array}$ & $\begin{array}{c}10 \\
13,8 \%\end{array}$ \\
\hline & Espírito Santo: 01 cidade - Vitória & & & $\begin{array}{c}02 \\
10,5 \%\end{array}$ & $\begin{array}{c}01 \\
5,9 \%\end{array}$ & $\begin{array}{c}03 \\
4,2 \%\end{array}$ \\
\hline & Total & 18 & 08 & 12 & 11 & 49 \\
\hline \multirow{5}{*}{ 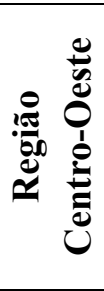 } & Goiás: 01 cidade Uruana & & & $\begin{array}{c}02 \\
10,5 \% \\
\end{array}$ & & $\begin{array}{c}02 \\
2,8 \%\end{array}$ \\
\hline & Mato Grosso: 01 cidade -Canarana. & $\begin{array}{c}01 \\
4,2 \%\end{array}$ & & & & $\begin{array}{c}01 \\
1,4 \%\end{array}$ \\
\hline & Mato Grosso do Sul: 01 cidade - Campo & & & 01 & 01 & $\mathbf{0 2}$ \\
\hline & Grande $^{14}$ & & & $5,3 \%$ & $5,9 \%$ & $2,8 \%$ \\
\hline & Total & 01 & & 03 & 01 & 05 \\
\hline \multirow{5}{*}{ 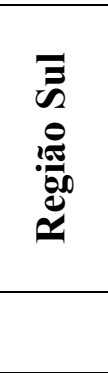 } & $\begin{array}{l}\text { Paraná: } 03 \text { cidades - Londrina, Maringá, } \\
\text { Cascavel }\end{array}$ & $\begin{array}{c}05 \\
20,8 \% \\
\end{array}$ & $\begin{array}{c}03 \\
25,0 \% \\
\end{array}$ & $\begin{array}{c}03 \\
15,8 \% \\
\end{array}$ & $\begin{array}{c}03 \\
17,6 \% \\
\end{array}$ & $\begin{array}{c}14 \\
19,4 \%\end{array}$ \\
\hline & Santa Catarina: 01 cidade - Joinville & & $\begin{array}{c}01 \\
8,3 \%\end{array}$ & $\begin{array}{c}01 \\
5,3 \% \\
\end{array}$ & $\begin{array}{c}01 \\
5,9 \% \\
\end{array}$ & $\begin{array}{c}03 \\
4,2 \% \\
\end{array}$ \\
\hline & Rio Grande do Sul: 01 cidade - Caxias do Sul & & & & $\begin{array}{c}01 \\
5,9 \%\end{array}$ & $\begin{array}{c}01 \\
1,4 \%\end{array}$ \\
\hline & Total & 05 & 04 & 04 & 05 & 18 \\
\hline & Total $=09$ Estados -25 cidades & 24 & 12 & 19 & 17 & $\begin{array}{c}72 \\
100,0\end{array}$ \\
\hline
\end{tabular}

Assim como em outras categorias, o maior índice de profissionais foi constatado na região sudeste (68\%), mais especificamente, no estado de São Paulo (50\%), seguida da região sul (25\%), com predominância dos recursos do estado do Paraná (19,4\%).

14 A subsede FUNCRAF de Campo Grande, na época da pesquisa, estava em fase de contratação de profissionais das áreas de fonoaudiologia e psicologia. 
Tabela 9 - Perfil dos reabilitadores segundo: formação, experiência e desenvolvimento profissional

\begin{tabular}{|c|c|c|c|c|c|c|c|c|c|}
\hline \multicolumn{10}{|c|}{ Área /Ano de graduação } \\
\hline & $\begin{array}{c}1970 \text { a } \\
1980\end{array}$ & $\begin{array}{c}1981 \text { a } \\
1990\end{array}$ & $\begin{array}{c}1991 \text { a } \\
2000\end{array}$ & $\begin{array}{c}2001 \text { a } \\
2006\end{array}$ & $\begin{array}{c}\text { Sub } \\
\text { Total }\end{array}$ & $(\%)$ & $\begin{array}{l}\text { Sem } \\
\text { resp }\end{array}$ & & $\begin{array}{l}\text { Total } \\
\text { Geral }\end{array}$ \\
\hline \multirow{3}{*}{ Fonoaudiologia } & & 06 & 12 & 05 & 23 & & 01 & & 24 \\
\hline & - & $(26,1 \%)$ & $(52,2 \%)$ & $(21,7 \%)$ & & 100,0 & & & \\
\hline & & 02 & 06 & 04 & 12 & & - & & 12 \\
\hline \multirow[t]{2}{*}{ Psicologia } & - & $(16,7 \%)$ & $(50,0 \%)$ & $(33,3 \%)$ & & 100,0 & & & \\
\hline & 02 & 04 & 09 & 04 & 19 & & - & & 19 \\
\hline \multirow[t]{2}{*}{ Odontologia } & $(10,5 \%)$ & $(21,0 \%)$ & $(47,5 \%)$ & $(21,0 \%)$ & & 100,0 & & & \\
\hline & $\begin{array}{c}02 \\
(12,5 \%)\end{array}$ & $\begin{array}{c}06 \\
(37,5 \%)\end{array}$ & $\begin{array}{c}06 \\
(37,5 \%)\end{array}$ & $\begin{array}{c}02 \\
(12,5 \%)\end{array}$ & 16 & 100,0 & 01 & & 17 \\
\hline TOTAL & $04(5,7)$ & $18(25,7)$ & $33(47,2)$ & $15(21,4)$ & 70 & 100,0 & $\mathbf{0 2}$ & & 72 \\
\hline \multicolumn{10}{|c|}{ Área/Tempo de experiência } \\
\hline & $\begin{array}{c}01 \text { a } 05 \\
\text { anos }\end{array}$ & $\begin{array}{c}06 \text { a } 10 \\
\text { anos }\end{array}$ & $\begin{array}{c}11 \text { a } 15 \\
\text { anos }\end{array}$ & $\begin{array}{c}+ \text { de } 15 \\
\text { anos }\end{array}$ & $\begin{array}{c}\text { Sub } \\
\text { Total }\end{array}$ & $(\%)$ & $\begin{array}{l}\text { Sem } \\
\text { resp }\end{array}$ & & $\begin{array}{l}\text { Total } \\
\text { Geral }\end{array}$ \\
\hline \multirow{2}{*}{ Fonoaudiologia } & $\begin{array}{c}06 \\
(26,1 \%)\end{array}$ & $\begin{array}{c}08 \\
(34,8 \%)\end{array}$ & $\begin{array}{c}05 \\
(21,7 \%)\end{array}$ & $\begin{array}{c}04 \\
(17,4 \%)\end{array}$ & 23 & 100,0 & 01 & & 24 \\
\hline & $\begin{array}{c}04 \\
(33,3 \%)\end{array}$ & $\begin{array}{c}06 \\
(50,0 \%)\end{array}$ & - & $\begin{array}{c}02 \\
(16,7 \%)\end{array}$ & 12 & 100,0 & - & & 12 \\
\hline \multirow[t]{2}{*}{ Odontologia } & $\begin{array}{c}04 \\
(21,0 \%)\end{array}$ & $\begin{array}{c}05 \\
(26,3 \%)\end{array}$ & $\begin{array}{c}03 \\
(15,8 \%)\end{array}$ & $\begin{array}{c}0 \\
7(36,9 \%)\end{array}$ & 19 & 100,0 & - & & 19 \\
\hline & $\begin{array}{c}02 \\
(12,5 \%)\end{array}$ & $\begin{array}{c}05 \\
(31,2 \%)\end{array}$ & $\begin{array}{c}02 \\
(12,5 \%)\end{array}$ & $\begin{array}{c}07 \\
(43,8 \%) \\
\end{array}$ & 16 & 100,0 & 01 & & 17 \\
\hline TOTAL & $16(22,8)$ & $24(34,3)$ & $10(14,3)$ & $20(28,6)$ & 70 & 100,0 & $\mathbf{0 2}$ & & 72 \\
\hline \multicolumn{10}{|c|}{ Áreas/experiência na área da Fissura Labiopalatina } \\
\hline & \multicolumn{2}{|l|}{ sim } & $(\%)$ & \multicolumn{2}{|c|}{ não } & \multicolumn{2}{|c|}{$(\%)$} & \multicolumn{2}{|c|}{ Total Geral } \\
\hline Fonoaudiologia & \multicolumn{2}{|l|}{22} & 30,6 & \multicolumn{2}{|c|}{02} & \multicolumn{2}{|c|}{2,7} & \multicolumn{2}{|c|}{$24(33,3 \%)$} \\
\hline Psicologia & \multicolumn{2}{|l|}{11} & 15,3 & \multicolumn{2}{|r|}{01} & \multicolumn{2}{|c|}{1,4} & \multicolumn{2}{|c|}{$12(16,7 \%)$} \\
\hline Odontologia & \multicolumn{2}{|l|}{17} & 23,6 & \multicolumn{2}{|c|}{02} & \multicolumn{2}{|c|}{2,8} & \multicolumn{2}{|c|}{$19(26,4 \%)$} \\
\hline Serviço Social & 15 & & 20,8 & & 02 & 2, & 8 & $17(2$ & $23,6 \%)$ \\
\hline TOTAL & 65 & & 90,3 & & 07 & 9, &, 7 & $72(10$ & $00,0 \%)$ \\
\hline Área/Tempo c & experiên & a na áre & Fissur & Labiopala & tina & & & & \\
\hline & $\begin{array}{c}06 \text { meses } \\
\text { a } 1 \text { ano }\end{array}$ & $\begin{array}{c}02 \text { a } 05 \\
\text { anos }\end{array}$ & $\begin{array}{c}06 \text { a } 10 \\
\text { anos }\end{array}$ & $\begin{array}{c}11 \text { a } 15 \\
\text { anos }\end{array}$ & $\begin{array}{c}+ \text { de } 15 \\
\text { anos }\end{array}$ & $\begin{array}{c}\text { Sub } \\
\text { Total }\end{array}$ & $(\%)$ & $\begin{array}{l}\text { Sem } \\
\text { resp }\end{array}$ & $\begin{array}{l}\text { Total } \\
\text { Geral }\end{array}$ \\
\hline Fonoaudiologia & $\begin{array}{c}04 \\
(20,0 \%)\end{array}$ & $\begin{array}{c}07 \\
(35,0 \%)\end{array}$ & $\begin{array}{c}04 \\
(20,0 \%)\end{array}$ & $\begin{array}{c}05 \\
(25,0 \%)\end{array}$ & - & 20 & 100,0 & 04 & 24 \\
\hline Psicologia & $\begin{array}{c}01 \\
(9,0 \%)\end{array}$ & $\begin{array}{c}05 \\
(45,5 \%)\end{array}$ & $\begin{array}{c}05 \\
(45,5 \%)\end{array}$ & - & - & 11 & 100,0 & 01 & 12 \\
\hline Odontologia & $\begin{array}{c}03 \\
(20,0 \%)\end{array}$ & $\begin{array}{c}06 \\
(40,0 \%)\end{array}$ & $\begin{array}{c}04 \\
(26,6 \%)\end{array}$ & $\begin{array}{c}01 \\
(6,7 \%)\end{array}$ & $\begin{array}{c}01 \\
(6,7 \%)\end{array}$ & 15 & 100,0 & 04 & 19 \\
\hline Serviço Social & $\begin{array}{c}04 \\
(26,6 \%) \\
\end{array}$ & $\begin{array}{c}05 \\
(33,4 \%) \\
\end{array}$ & $\begin{array}{c}03 \\
(20 \%) \\
\end{array}$ & $\begin{array}{c}01 \\
(6,7 \%) \\
\end{array}$ & $\begin{array}{c}02 \\
(13,3 \%) \\
\end{array}$ & 15 & 100,0 & 02 & 17 \\
\hline TOTAL & $\begin{array}{c}12 \\
(19,7 \%) \\
\end{array}$ & $\begin{array}{c}23 \\
(37,7 \%) \\
\end{array}$ & $\begin{array}{c}16 \\
(26,2 \%) \\
\end{array}$ & $\begin{array}{c}07 \\
(11,5 \%) \\
\end{array}$ & $\begin{array}{c}03 \\
(4,9 \%) \\
\end{array}$ & 61 & 100,0 & 11 & 72 \\
\hline Área /Cursos re & alizados & & & & & & & & \\
\hline & Malf & or-mação & $(\%)$ & outros & $(\%)$ & $\begin{array}{c}\text { Sub } \\
\text { Total } \\
\end{array}$ & $(\%)$ & $\begin{array}{l}\text { Sem } \\
\text { resp. }\end{array}$ & $\begin{array}{l}\text { Total } \\
\text { Geral } \\
\end{array}$ \\
\hline Fonoaudiologia & & 10 & 62,5 & 06 & 37,5 & 16 & 100,0 & 10 & 26 \\
\hline Psicologia & & 03 & 60,0 & 02 & 40,0 & 05 & 100,0 & 07 & 12 \\
\hline Odontologia & & 11 & 91,7 & 01 & 8,3 & 12 & 100,0 & 07 & 19 \\
\hline Serviço Social & & 07 & 70,0 & 03 & 30,0 & 10 & 100,0 & 07 & 17 \\
\hline TOTAL & & 31 & 72,1 & 12 & 27,9 & 43 & 100,0 & 31 & 74 \\
\hline
\end{tabular}




\begin{tabular}{|c|c|c|c|c|c|c|c|c|c|c|c|c|}
\hline \multicolumn{13}{|c|}{ Área /Pós Graduação } \\
\hline & 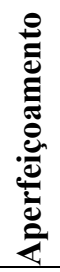 & $(\%)$ & 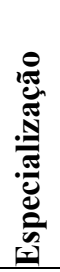 & $(\%)$ & 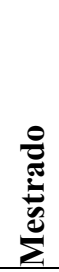 & $(\%)$ & 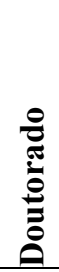 & $(\%)$ & 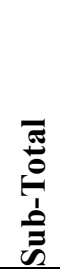 & $(\%)$ & 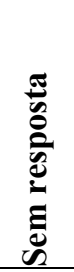 & 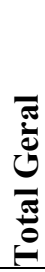 \\
\hline Fonoaudiologia & 02 & 9,1 & 18 & 81,8 & 02 & 9,1 & & & 22 & 100,0 & 02 & 24 \\
\hline Psicologia & 01 & 10,0 & 09 & 90,0 & & & & & 10 & 100,0 & 02 & 12 \\
\hline Odontologia & 03 & 16,7 & 11 & 61,1 & 03 & 16,7 & 01 & 5,5 & 18 & 100,0 & 01 & 19 \\
\hline Serviço Social & 01 & 7,1 & 13 & 92,9 & & & & & 14 & 100,0 & 03 & 17 \\
\hline TOTAL & 07 & 10,9 & 51 & 79,6 & 05 & 7,8 & 01 & 1,6 & 64 & 100,0 & 08 & 72 \\
\hline
\end{tabular}

Os dados revelaram de modo geral que a maioria dos profissionais se graduou na década de $90(47,2 \%)$ contando com mais de 06 anos (34,3\%) de experiência profissional e $90,3 \%$ com experiência em fissuras labiopalatinas, num período de dois a cinco anos $(37,7 \%)$.

Outro dado relevante nessa categoria é que a totalidade dos profissionais já realizou algum curso de pós-graduação, a maioria $(79,6 \%)$ em nível de especialização.

Além da pós-graduação, outros cursos foram apontados; na área das malformações o índice alcançado foi de 72,1\%. Essa freqüência a cursos em geral revela uma tendência atual de busca de reciclagem na qualificação profissional, de acordo com as exigências do mercado.

Especificando o perfil por área:

Fonoaudiologia: a maioria graduou-se na década de 90 (52,2\%), o tempo de experiência profissional variou de seis a dez anos (34,8\%) e de um a cinco anos (26,1\%). Com relação à experiência na área de fissuras labiopalatinas 30,6 \% dos profissionais relataram ter, por um período de dois a cinco anos (35,0\%) seguido de 11 a 15 anos $(25,0 \%)$ e $20 \%$ de seis meses a um ano de experiência. No item referente aos cursos de Pós-Graduação, a maioria dos profissionais $(81,8 \%)$ tem especialização, nas áreas de motricidade oral, distúrbios da linguagem e educação especial. Cursos latu sensu - mestrado em saúde pública foi relatado por $9,1 \%$ dos profissionais. O curso de malformação foi realizado por $62,5 \%$ dos profissionais. Os cursos realizados extra HRAC referem-se a: Congresso Brasileiro de Fissura Lábio Palatal em Curitiba/PR, Avaliação e Terapia com Portador de Fissura Lábio Palatal - CEFAC-SP (37,5\%). 
Psicologia: 50\% dos profissionais graduaram-se na década de 90 e 33,3\% na década de 2000. Com relação ao tempo de experiência profissional, 50\% possuem de 06 a 10 anos e 33,3\% com um a cinco anos. Especificamente a experiência na área das fissuras labiopalatinas apenas 15,3\% dos profissionais possuem sendo o tempo de experiência de $45,5 \%$ o mesmo índice para os tempos de dois a cinco anos e de seis a dez anos. A maioria dos profissionais $(90,0 \%)$ tem especialização nas áreas de Psicomotricidade, Psicopedagogia, Psicologia Hospitalar e Saúde da Família, revelando assim, a preocupação com o desenvolvimento profissional. Com relação ao curso de malformação, $60 \%$ dos profissionais já haviam realizado e quanto aos cursos extra HRAC, os profissionais citaram os do Centro de Atendimento Integral ao Fissurado Lábio Palatal (CAIF), na área de psicologia - Congresso - I Simpósio de psicologia: Faces e Interfaces, na Universidade do Sagrado Coração de Jesus (USC-Bauru) e Simpósio da Sociedade Brasileira de Pesquisa e Assistência para Reabilitação Craniofacial (SOBRAPAR) em Campinas (40\%).

Odontologia: 47,5\% dos profissionais graduaram-se na década de 90, seguidos da década de 80 e 2000 com mesmos índices $(21,0 \%)$. A experiência profissional foi evidenciada por $36,9 \%$ dos profissionais com mais de 15 anos seguidos de seis a dez anos (26,3\%). A experiência na área de fissura labiopalatina foi citada por 23,6\% e, destes ,40\% com tempo de dois a cinco anos. Com relação à pós-graduação, $61,1 \%$ realizaram cursos de especialização em Dentística Restauradora, Endodontia e Saúde Coletiva. O curso de malformação foi realizado pela maioria dos profissionais $(91,7 \%)$ superando as demais áreas. Apenas um profissional (8,3\%) citou um curso extra HRAC promovido pelo Centro de Atendimento Integral ao Fissurado Lábio Palatal (CAIF).

Serviço Social: coincidentemente, $37,5 \%$ dos profissionais graduaram-se na década de 80 e $37,5 \%$ na década de 90 . O tempo de experiência profissional citado é de mais de 15 anos para $43,8 \%$ e de com seis a dez anos para $31,2 \%$ dos assistentes sociais. Com relação à experiência na área da fissura lábiopalatina verificamos que 20,8\% a vivenciaram por período de dois a cinco anos $(37,7 \%)$ e de $26,6 \%$ entre seis meses a um ano. A maioria dos profissionais (92,9\%) tinha especialização em política social e projetos sociais, Saúde Pública e Serviço Social na área da Saúde. Verificamos também na área que o curso de malformação foi realizado por 70\% dos profissionais e os cursos extra HRAC foram realizados no CAIF em Curitiba/PR por 30,0\% dos assistentes sociais. 
Em síntese, os dados apresentados na tabela 9 referente ao perfil dos reabilitadores, segundo formação, experiência e desenvolvimento profissional, observamos que todos os profissionais possuem experiência profissional; as áreas de psicologia e fonoaudiologia $(50 \%$ e $34,8 \%)$ possuem tempo de experiência profissional de seis a dez anos e as áreas de serviço social e odontologia (43,8\%e 36\%) com mais de 15 anos de experiência. Quanto à experiência profissional na área das fissuras labiopalatinas, verificamos que a área de a fonoaudiologia é a que possui maior experiência $(30,6 \%)$ e houve unanimidade entre as áreas para o tempo de experiência na área das fissuras labiopalatinas de dois a cinco anos. Esse dado revela que apesar dos profissionais possuírem experiência profissional com mais de seis anos a experiência na área das fissuras labiopalatinas é pequena. Quanto ao curso de malformação o índice maior foi para a área de odontologia $91,7 \%$ e o menor índice para psicologia $60,0 \%$.

Tabela 10 - Perfil dos profissionais segundo vínculo com o serviço

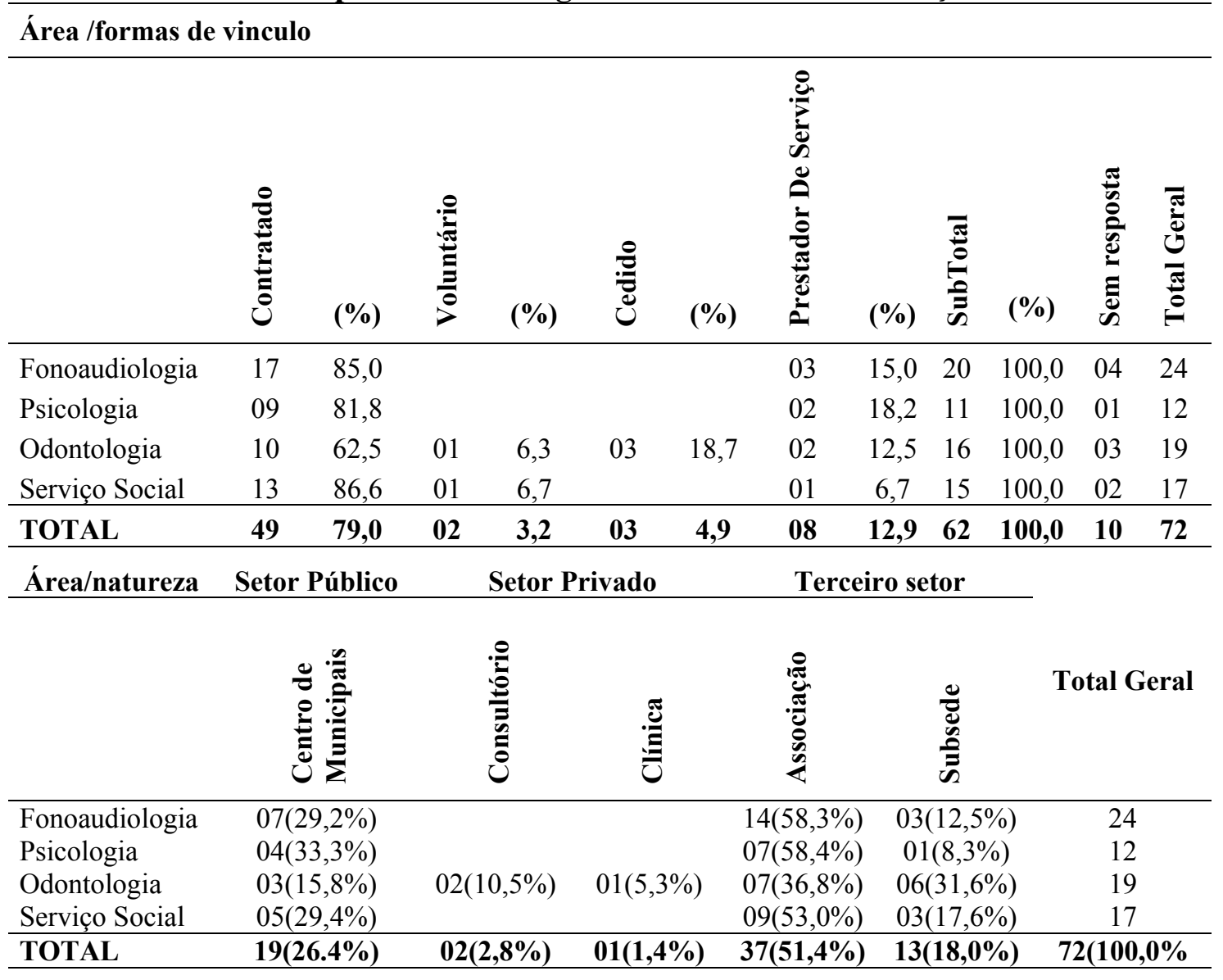


Com relação ao vínculo com os serviços 79,0\% dos profissionais são contratados e 12,9\% são prestadores de serviços. Esse vínculo, em todas as áreas, alcançou um maior índice nas Associações (51,4\%). Especificando por área:

Fonoaudiologia: no item referente ao vinculo com o serviço que $85 \%$ dos profissionais estão contratados e $15 \%$ estão como prestadores de serviços, sendo que 58,3\% dos profissionais estão trabalhando em associações de pais e pacientes com fissura labiopalatinas, considerados como de terceiro setor e $29,2 \%$ nos centros, unidades básicas de saúde, caráter público.

Psicologia: $81,2 \%$ dos profissionais estão contratados e 18,2\% estão como prestadores de serviços, um índice significante $(58,4 \%)$ estão trabalhando nas associações de pais e pacientes com fissura labiopalitanas pertencentes ao terceiro setor e 33,3\% estão nos serviços públicos.

Odontologia: dos profissionais, $62,5 \%$ são contratados e 18,7 são cedidos de outros órgãos parceiros para atendimentos aos pacientes. Verificamos que 36,8\% trabalham nas associações de pais e pacientes com fissura labiopalatinas e 31,6\% nas subsedes da FUNCRAF, ambas pertencentes ao terceiro setor.

Serviço Social: quanto ao vínculo, observamos que $86,6 \%$ são contratados e 6,7 \% são prestadores de serviços e 6,7\% são voluntários. Destes profissionais, 53\% trabalham nas associações de pais e pacientes com fissura labiopalatinas - terceiro setor e 29,4\% nas redes publicas.

De modo geral o perfil dos profissionais segundo vínculo com o serviço conforme apresentado na tabela 10 à maioria dos profissionais encontram-se contratado e com índices altos para as áreas de serviço social, fonoaudiologia, e psicologia respectivamente $86,6 \%, 85,0 \%$ e $81,8 \%$. Na área de odontologia esse dado é de $62,5 \%$.

Outro dado importante é a de trabalhadores como prestadores de serviço sendo que a área de psicologia possui o maior índice, ou seja, 18,2\% e o mais baixo é do serviço social $(6,7 \%)$. Os profissionais cedidos encontram-se apenas na odontologia $(18,7 \%)$ e os voluntários apresentam-se em baixo índice nas áreas de serviço social $(6,7 \%)$ e na odontologia $(6,3 \%)$. Verificamos que o maior índice encontrado entre os profissionais que trabalham em centros ou unidades básicas de saúde pertencentes ao setor público, o maior índice é o da área de psicologia 33,3\%, seguido do serviço social $29,4 \%$ e fonoaudiologia $29,2 \%$, tendo a odontologia é o menor índice de $15,8 \%$ nesta categoria. 
Nos serviços de caráter privado apenas a odontologia faz referencia sendo 10,5\% para consultório e 5,3\% em clinicas de atendimentos. Para os serviços pertencentes ao terceiro setor, verificamos que as associações de pais possuem o maior índice de profissionais trabalhando, sendo nas áreas de psicologia e fonoaudiologia 58,4 e 58,3\% e a odontologia com o menor índice $36,8 \%$. Ao contrario encontramos nas subsedes FUNCRAF onde a área de odontologia é a que possui maior índice de 31,6\% para o menor índice o da psicologia com $8,3 \%$.

Segundo Okumura (2007p1), "apesar de sermos carentes em cultura social, o terceiro setor já emprega $2 \%$ da população nacional, o que corresponde a mais de um milhão de pessoas". É crescente o número de profissionais que começam a ver o Terceiro Setor como uma opção efetiva de carreira, apesar de oferecer uma remuneração cerca de $15 \%$ a menos do setor privado, a motivação de se trabalhar em uma entidade sem fins lucrativos é bem maior. A justificativa é o fato de trabalharem movidos por seus ideais, e também de conviverem num ambiente mais agradável de trabalho, onde o espírito de equipe é essencial para o bom funcionamento da instituição. Ao contrário do setor privado, o Terceiro Setor busca algo além do simples lucro, procura atingir metas, transformar realidades, lutar por alguma causa social ou ecológica e este, talvez, seja o atrativo principal para que vários empresários conceituados estejam migrando para esse "novo" setor (Okumura 2007).

Tabela 11 - Perfil dos profissionais segundo facilidades para intercâmbio

\begin{tabular}{|c|c|c|c|c|c|c|c|c|c|c|}
\hline \multicolumn{11}{|c|}{ Área/ Acesso à Internet } \\
\hline & Sim & & (\%) & \multicolumn{2}{|c|}{ Não } & $(\%)$ & \multicolumn{3}{|c|}{ Total Geral } & $(\%)$ \\
\hline Fonoaudiologia & 21 & & 87,5 & \multicolumn{2}{|c|}{03} & 12,5 & & 24 & \multicolumn{2}{|r|}{100,0} \\
\hline Psicologia & 12 & & 100,0 & & & & & 12 & \multirow{2}{*}{\multicolumn{2}{|c|}{100,0}} \\
\hline Odontologia & 19 & & 100,0 & \multirow{2}{*}{\multicolumn{2}{|c|}{01}} & & & 19 & & \\
\hline Serviço Social & 16 & & 94,1 & & & 5,9 & & 17 & \multicolumn{2}{|c|}{100,0} \\
\hline TOTAL & 68 & & $(94,4)$ & \multicolumn{2}{|c|}{04} & $(5,6)$ & & 72 & & 100,0 \\
\hline \multicolumn{11}{|c|}{ Área /Curso de Línguas } \\
\hline & 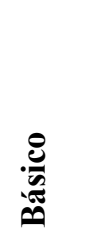 & $(\%)$ & 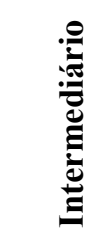 & $(\%)$ & 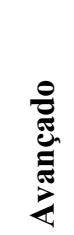 & $(\%)$ & $\begin{array}{l}\overline{\tilde{J}} \\
\hat{\theta} \\
\hat{\bar{E}} \\
0\end{array}$ & $(\%)$ & 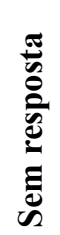 & $\begin{array}{l}\bar{\pi} \\
\overline{0} \\
\overline{0} \\
\overline{0}\end{array}$ \\
\hline Fonoaudiologia & 14 & 63,6 & 06 & 27,3 & 02 & 9,1 & 22 & 100,0 & 02 & 24 \\
\hline Psicologia & 10 & 90,9 & 01 & 9,1 & & & 11 & 100,0 & 01 & 12 \\
\hline Odontologia & 06 & 40,0 & 06 & 40,0 & 03 & 20,0 & 15 & 100,0 & 04 & 19 \\
\hline Serviço Social & 09 & 90,0 & & & 01 & 10,0 & 10 & 100,0 & 07 & 17 \\
\hline TOTAL & 39 & 67,2 & 13 & 22,4 & 06 & 10,4 & 58 & 100,0 & 14 & 72 \\
\hline
\end{tabular}


De acordo com Reis (2007), os conhecimentos básicos exigidos, além de sua própria atividade profissional, são línguas (especialmente inglês e espanhol), informática e cada vez mais qualidade. A ampla troca de informações internacionais que já está sendo possível com o acesso às redes de informação, como a Internet, é mais revolucionária do que foi a invenção da imprensa. Estar de fora da era da informação é perder oportunidades, é perder poder. Não saber informática equivale a ser um analfabeto.

O acesso a Internet está ao alcance da maioria $(94,4 \%)$ e todos freqüentaram ou freqüentam algum curso de línguas, mesmo que em nível básico (67,2\%).

Especificando o perfil por áreas:

Fonoaudiologia - a maioria dos profissionais (87,5\%) tem acesso à internet e 63,6\% dos profissionais têm conhecimento de outra(s) língua(s) em nível básico $(63,6 \%)$ seguido do intermediário $(27,3 \%)$.

Psicologia - a totalidade dos profissionais tem acesso à internet e 90,9\% têm conhecimento de outra(s) língua(s) em nível básico seguido de 9,1\% em nível intermediário.

Odontologia - a totalidade dos profissionais tem acesso à internet e $40 \%$ freqüentaram ou freqüentam curso de línguas em nível básico e intermediário e $20 \%$ no nível avançado.

Serviço Social - o acesso à internet é citado por $94,1 \%$ e os cursos de línguas, $90,0 \%$ possuem em nível básico e 10\% no nível avançado.

A tabela 11 demonstra o perfil dos profissionais segundo facilidades para intercâmbio, sendo a facilidade referenciada pela maioria dos profissionais de todas as áreas, a totalidade de acesso nas áreas de psicologia e odontologia e, as áreas de fonoaudiologia e serviço social, os índices foram de $87,5 \%$ e $94,1 \%$ respectivamente.

Para os cursos de línguas observamos que, em nível básico, as áreas de psicologia e serviço social atingiram um maior índice, ou seja, 90,9\% e 90,0\% respectivamente, as áreas de fonoaudiologia e odontologia, 63,6\% e 40,0\%. Quanto ao nível intermediário o maior índice $40 \%$ ficou com a área odontologia seguida das áreas de fonoaudiologia e psicologia respectivamente $27,3 \%$ e 9,1\%. No nível avançado encontramos também na área de odontologia com o maior índice (20\%), seguido do serviço social $(10 \%)$ e fonoaudiologia $(9,1 \%)$. Com esse manancial de conhecimentos e experiência, dentro e fora da área da fissura labiopalatinas a maioria dos profissionais 
conhece o HRAC e a(s) forma(s) de articulação com os recursos serão conhecidos na tabela que se segue.

Tabela 12 - Perfil dos reabilitadores segundo articulação técnico-cientifico e funcional com o HRAC

\begin{tabular}{|c|c|c|c|c|c|c|c|c|c|c|c|c|c|c|}
\hline \multicolumn{15}{|c|}{ Área/Conhecimento do HRAC } \\
\hline & \multicolumn{2}{|c|}{ Sim } & \multicolumn{3}{|c|}{$(\%)$} & \multicolumn{2}{|c|}{ Não } & \multicolumn{2}{|c|}{$(\%)$} & \multicolumn{3}{|c|}{ Total Geral } & \multicolumn{2}{|c|}{$(\%)$} \\
\hline Fonoaudiologia & \multicolumn{2}{|c|}{21} & \multicolumn{3}{|c|}{87,5} & \multicolumn{2}{|l|}{03} & \multicolumn{2}{|c|}{12,5} & \multicolumn{3}{|c|}{24} & \multicolumn{2}{|c|}{100,0} \\
\hline Psicologia & \multicolumn{2}{|c|}{08} & \multicolumn{3}{|c|}{66,7} & \multicolumn{2}{|l|}{04} & \multicolumn{2}{|c|}{33,3} & \multicolumn{3}{|c|}{12} & \multicolumn{2}{|c|}{100,0} \\
\hline Odontologia & \multicolumn{2}{|c|}{13} & \multicolumn{2}{|r|}{68,4} & & \multicolumn{2}{|l|}{06} & \multicolumn{2}{|c|}{31,6} & \multicolumn{3}{|c|}{19} & \multicolumn{2}{|c|}{100,0} \\
\hline Serviço Social & \multicolumn{2}{|c|}{13} & \multicolumn{2}{|r|}{76,5} & & \multicolumn{2}{|l|}{04} & \multicolumn{2}{|c|}{23,5} & \multicolumn{3}{|c|}{17} & \multicolumn{2}{|c|}{100,0} \\
\hline TOTAL & 5 & & & 76,4 & & 17 & & & 3,6 & & 72 & & & \\
\hline Área /Meios de & onhec & imen & & & & & & & & & & & & \\
\hline & : & $(\%)$ & 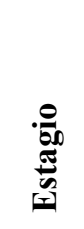 & $(\%)$ & $\underset{ٍ}{\mathscr{E}}$ & $(\%)$ & 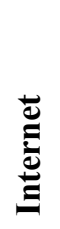 & $(\%)$ & $\stackrel{\mathscr{E}}{E}$ & $(\%)$ & 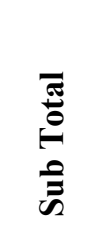 & $(\%)$ & 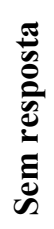 & $\begin{array}{l}\bar{T} \\
\frac{\pi}{0} \\
\frac{\pi}{0}\end{array}$ \\
\hline Fonoaudiologia & 12 & 46,1 & 04 & 15,3 & 13 & 50,0 & 04 & 15,3 & & & 26 & 100,0 & 03 & 24 \\
\hline Psicologia & 04 & 57,1 & & & 03 & 42,8 & 02 & 28,5 & 01 & 14,2 & 07 & 100,0 & 04 & 12 \\
\hline Odontologia & 03 & 16,6 & 05 & 27,7 & 10 & 55,5 & 01 & 5,5 & 01 & 5,5 & 18 & 100,0 & 05 & 19 \\
\hline Serviço Social & 05 & 27,7 & 03 & 16,6 & 10 & 55,5 & 03 & 16,6 & 01 & 5,5 & 18 & 100,0 & 04 & 17 \\
\hline TOTAL & 24 & 61,5 & 12 & 30,7 & 36 & 92,3 & 10 & 25,6 & $\mathbf{0 3}$ & 7,6 & 69 & 100,0 & 13 & 72 \\
\hline Área /Estágios & alizad & & & & & & & & & & & & & \\
\hline & HRA & & $(\%)$ & & utros & $(0$ & о) & $\begin{array}{l}\text { Sul } \\
\text { Tot }\end{array}$ & & $(\%)$ & & $\begin{array}{l}\text { Sem } \\
\text { esposta }\end{array}$ & & $\begin{array}{l}\text { otal } \\
\text { eral }\end{array}$ \\
\hline Fonoaudiologia & 04 & & 44,4 & & 06 & 60 &, 0 & 10 & & 100,0 & & 14 & & 24 \\
\hline Psicologia & & & 0,0 & & 01 & 10 & 0,0 & 01 & & 100,0 & & 11 & & 12 \\
\hline Odontologia & 05 & & 55,5 & & 04 & 44 &, 5 & 09 & & 100,0 & & 10 & & 19 \\
\hline Serviço Social & 03 & & 100,0 & & & & 0 & 03 & & 100,0 & & 14 & & 17 \\
\hline TOTAL & 12 & & 52,2 & & 11 & & 8 & 23 & & 100,0 & & 49 & & 72 \\
\hline
\end{tabular}

Área /Contato com profissionais do HRAC

\begin{tabular}{lcccccc}
\hline & Sim & $\mathbf{( \% )}$ & Não & $\mathbf{( \% )}$ & Total Geral & $\mathbf{( \% )}$ \\
\hline Fonoaudiologia & 22 & 91,7 & 02 & 8,3 & 24 & 100,0 \\
Psicologia & 05 & 41,7 & 07 & 58,3 & 12 & 100,0 \\
Odontologia & 13 & 68,4 & 06 & 31,6 & 19 & 100,0 \\
Serviço Social & 15 & 88,3 & 02 & 11,7 & 17 & 100,0 \\
\hline TOTAL & $\mathbf{5 5}$ & $\mathbf{7 6 , 4}$ & $\mathbf{1 7}$ & $\mathbf{2 3 , 6}$ & $\mathbf{7 2}$ & $\mathbf{1 0 0 , 0}$ \\
\hline
\end{tabular}

Área /Formas de contato

\begin{tabular}{|c|c|c|c|c|c|c|c|c|c|c|c|c|c|c|}
\hline & 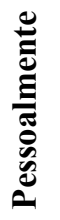 & $(\%)$ & $\underset{\tilde{U}}{\tilde{J}}$ & $(\%)$ & 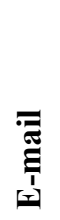 & $(\%)$ & 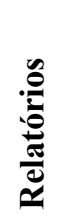 & $(\%)$ & 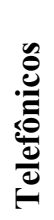 & $(\%)$ & 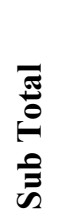 & $(\%)$ & 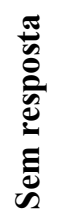 & 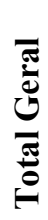 \\
\hline Fonoaudiologia & 07 & 25,0 & 05 & 17,9 & 03 & 10,7 & 05 & 17,9 & 08 & 28,5 & 28 & 100,0 & 02 & 30 \\
\hline Psicologia & 01 & 16,7 & & & & & 02 & 33,3 & 03 & 50,0 & 06 & 100,0 & 07 & 13 \\
\hline Odontologia & 07 & 30,5 & 06 & 26,1 & 05 & 21,7 & & & 05 & 21,7 & 23 & 100,0 & 05 & 28 \\
\hline Serviço Social & 06 & 26,1 & 03 & 13,0 & 02 & 8,7 & 02 & 8,7 & 10 & 43,5 & 23 & 100,0 & 02 & 17 \\
\hline TOTAL & 21 & 26,2 & 14 & 17,5 & 10 & 12,5 & 09 & 11,2 & 26 & 32,5 & 36 & 100,0 & 16 & 72 \\
\hline
\end{tabular}


Observamos que a maioria dos profissionais (76,4\%) das diferentes áreas conhece o HRAC; especialmente $(92,3 \%)$ por meio de cursos e por meio de visita $(61,5)$. Dentre os mesmos, três profissionais que conhecem o HRAC não só como profissional, mas como pacientes e também como avó de paciente (assistente social, psicólogo e dentista).

Estágios na área das malformações foram realizados por $32,0 \%$ dos profissionais; entre esses $47,8 \%$ em outras instituições e $52,2 \%$ no próprio HRAC.

Uma outra forma de articulação é revelada por meio dos contatos com os profissionais do HRAC, o que ocorre com $76,4 \%$ dos profissionais, seja por telefone $(72,2 \%)$ ou pessoalmente $(58,3 \%)$.

$\mathrm{Na}$ área da fonoaudiologia em relação aos estágios, verificamos que $44,4 \%$ dos profissionais realizaram estágio no HRAC e 60,6\% em outros serviços: Hospital das Clínicas de Ribeirão Preto, Casa do Menino Excepcional - Betinho, Pontifícia Universidade Católica do Paraná, Universidade Federal de São Paulo - UNIFESP, Universidade Estadual Paulista - UNESP- Marilia e Hospital Defeitos da Face em São Paulo. Os contatos profissionais com o HRAC são mantidos por 91,7\% de diferentes formas: por meio de telefone $47,0 \%$, cartas e pessoalmente $41,2 \%$, dentre outros.

Dos profissionais da área de psicologia apenas $8,3 \%$ informou que realizou estágio na área da fissura labiopalatal e com a equipe internacional "Operation Smile" 2005 - Fortaleza por 10 dias. E com relação aos contatos com profissionais do HRAC, verificamos que apenas $41,7 \%$ o fazem e por meio de carta $(85,7)$ e contatos telefônicos (71,4\%). Acreditamos que essa forma de articulação possa ser ampliada.

Para os profissionais de odontologia 55,5\% realizou estágios no HRAC e 44,5\% em outras instituições, $68,4 \%$ revelaram que conhecem o HRAC por meio de realização de cursos $(55,5 \%)$ e mantém contatos com profissionais da área pessoalmente $(100 \%)$.

Os Assistentes Sociais revelam que apenas 16,6\% realizaram estágio na área da fissura labiopalatal e no HRAC 100,0\% (quando do estágio de Graduação e também estágio de prática no curso de especialização), (75,0\%) possuem contato com profissionais da área pessoalmente.

"Os novos perfis profissionais privilegiam a criatividade, a interatividade, a flexibilidade e o aprendizado contínuo. Além disso, os novos profissionais devem ser capazes de operacionalizar seu conhecimento de modo integrado às suas aptidões e vivências culturais" (Silva e Cunha 2002 p 81). 
Com relação aos programas de capacitação os profissionais foram questionados e a tabela 13 que se segue, mostra sua participação em programas/projetos.

Tabela 13 - Participação em programas e projetos de humanização e qualidade

\begin{tabular}{|c|c|c|c|c|c|c|c|c|}
\hline \multicolumn{9}{|c|}{ Áreas/Participação } \\
\hline & Sim & $(\%)$ & \multicolumn{2}{|r|}{ Não } & $(\%)$ & Sub total & Sem resp. & Total Geral \\
\hline Fonoaudiologia & 02 & 20,0 & \multicolumn{2}{|r|}{08} & 80,0 & 10 & 14 & 24 \\
\hline Psicologia & 03 & 75,0 & \multicolumn{2}{|r|}{01} & 25,0 & 04 & 08 & 12 \\
\hline Odontologia & 01 & 33,3 & \multicolumn{2}{|r|}{02} & 66,7 & 03 & 16 & 19 \\
\hline Serviço Social & 03 & 60,0 & \multicolumn{2}{|r|}{02} & 40,0 & 05 & 12 & 17 \\
\hline TOTAL & 09 & 40,9 & \multicolumn{2}{|r|}{13} & $\mathbf{5 9 , 1}$ & 22 & 50 & 72 \\
\hline \multicolumn{9}{|c|}{ Áreas/Realizou Curso de humanização } \\
\hline & Sim & $(\%)$ & Não & $(\%)$ & Sub total & $(\%)$ & Sem resp. & Total Geral \\
\hline Fonoaudiologia & 05 & 31,2 & 11 & 68,8 & 16 & 100,0 & 08 & 24 \\
\hline Psicologia & 02 & 18,2 & 09 & 81,8 & 11 & 100,0 & 01 & 12 \\
\hline Odontologia & 05 & 41,7 & 07 & 58,3 & 12 & 100,0 & 07 & 19 \\
\hline Serviço Social & 03 & 23,0 & 10 & 77,0 & 13 & 100,0 & 04 & 17 \\
\hline TOTAL & 15 & 28,9 & 37 & 71,1 & 52 & 100,0 & 20 & 72 \\
\hline \multicolumn{9}{|c|}{ Áreas/Realizou Curso de qualidade } \\
\hline & Sim & $(\%)$ & Não & $(\%)$ & Sub total & $(\%)$ & Sem resp. & Total Geral \\
\hline Fonoaudiologia & 04 & 25,0 & 12 & 75,0 & 16 & 100,0 & 08 & 24 \\
\hline Psicologia & 01 & 10,0 & 09 & 90,0 & 10 & 100,0 & 02 & 12 \\
\hline Odontologia & 03 & 27,3 & 08 & 72,7 & 11 & 100,0 & 08 & 19 \\
\hline Serviço Social & 03 & 23,0 & 10 & 77,0 & 13 & 100,0 & 04 & 17 \\
\hline TOTAL & 11 & 22,0 & 39 & 78,0 & 50 & 100,0 & 22 & 72 \\
\hline \multicolumn{9}{|c|}{ Áreas/Realizou Curso de política de saúde } \\
\hline & Sim & $(\%)$ & Não & $(\%)$ & Sub total & $(\%)$ & Sem resp. & Total Geral \\
\hline Fonoaudiologia & 03 & 18,7 & 13 & 81,3 & 16 & 100,0 & 08 & 24 \\
\hline Psicologia & 03 & 27,3 & 08 & 72,7 & 11 & 100,0 & 01 & 12 \\
\hline Odontologia & 06 & 50,0 & 06 & 50,0 & 12 & 100,0 & 07 & 19 \\
\hline Serviço Social & 06 & 46,2 & 07 & 53,8 & 13 & 100,0 & 04 & 17 \\
\hline TOTAL & 18 & 34,6 & 34 & 65,4 & 52 & 100,0 & 20 & 72 \\
\hline \multicolumn{9}{|c|}{ Áreas/Curso sobre o SUS } \\
\hline & Sim & $(\%)$ & Não & $(\%)$ & Sub total & $(\%)$ & Sem resp. & Total Geral \\
\hline Fonoaudiologia & 02 & 12,5 & 14 & 87,5 & 16 & 100,0 & 08 & 24 \\
\hline Psicologia & 01 & 9,0 & 10 & 91,0 & 11 & 100,0 & 01 & 12 \\
\hline Odontologia & 07 & 58,3 & 05 & 41,7 & 12 & 100,0 & 07 & 19 \\
\hline Serviço Social & 05 & 41,7 & 07 & 58,3 & 12 & 100,0 & 05 & 17 \\
\hline TOTAL & 15 & 29,4 & 36 & 70,6 & 51 & 100,0 & 21 & 72 \\
\hline \multicolumn{9}{|c|}{ Áreas/Outros cursos } \\
\hline & Sim & $(\%)$ & Não & $(\%)$ & Sub total & $(\%)$ & Sem resp. & Total Geral \\
\hline Fonoaudiologia & 04 & 22,2 & 14 & 77,8 & 18 & 100,0 & 06 & 24 \\
\hline Psicologia & & & 11 & 100,0 & 11 & 100,0 & 01 & 12 \\
\hline Odontologia & & & 11 & 100,0 & 11 & 100,0 & 08 & 19 \\
\hline Serviço Social & 04 & 36,4 & 07 & 63,6 & 11 & 100,0 & 06 & 17 \\
\hline TOTAL & 08 & 15,7 & 43 & 84,3 & 51 & 100,0 & 21 & 52 \\
\hline
\end{tabular}

A tabela revelou um índice de $40,9 \%$ de participação dos profissionais em programas/projetos (humanização e qualidade). 
Em outros cursos os índices de participação foram baixos, como: política de saúde (34,6\%); SUS $(29,4 \%)$ e outras temáticas $(15,7 \%)$.

Especificamente na área de fonoaudiologia verificamos que apenas $20,0 \%$ dos profissionais têm participado de programas/projetos e citam o programa da saúde do trabalhador. Os dados revelam que a realização de cursos de humanização, foram apenas de $31,2 \%$, para os cursos de qualidade $25,0 \%$, de políticas de saúde $18,7 \%$, sobre o SUS $12,5 \%$, e outros cursos o índice foi de $22,2 \%$ com enfoque em saúde pública, área de fonoaudiologia, terapia, ensino e musicalização de crianças.

$\mathrm{Na}$ área da psicologia encontramos o maior índice de participação de profissionais em programas de humanização e qualidade $(75,0 \%)$. Em relação à realização de cursos de humanização $(18,2 \%)$, de qualidade $(10 \%)$, políticas públicas $(27,3 \%)$, e o SUS $(9 \%)$.

$\mathrm{Na}$ área de odontologia, apenas $33,3 \%$ dos profissionais participam em programas/projetos, verificamos o alto índice de realização em cursos de humanização (41,7\%), qualidade (27,3\%), políticas de saúde (50,0\%) e SUS (58,3\%). A área de odontologia nessa questão superou as demais áreas.

$\mathrm{Na}$ área social verificamos que $60,0 \%$ participaram de programas/projetos. Com relação ao curso de humanização, apenas 23,0\% dos Assistentes Sociais realizaram e quanto aos demais observamos: curso de qualidade $(23,0 \%)$, de política de saúde $(46,2 \%)$, SUS $(41,7 \%)$ e outros cursos $(36,4 \%)$ como: Previdência Social e Sistema Único de Assistência Social, Centro de Referencia de Assistência Social SUAS/CRAS, Política Social e Gestão Institucional/Capacitação no trabalho com família e Educação em Saúde Pública e Serviço Social hospitalar e de Saúde. Esses dados revelam um índice baixo de participação nesses cursos prioritários para o Serviço Social, além dos observados na especialização.

Segundo Silva e Cunha (2002 p77) "Na perspectiva do trabalho na sociedade do conhecimento, a criatividade e a disposição para capacitação permanente serão requeridas e valorizadas".

O interesse dos profissionais na atualização de conhecimentos revela uma preocupação com a prática que tem fundamento, uma vez que em seu cotidiano a demanda é diversificada e desafiadora, de acordo com relato dos 72 profissionais $(100 \%)$ que responderam esse item. 
De acordo com as respostas dos profissionais, houve a necessidade de solicitar contribuição dos profissionais das áreas (fonoaudiologia, odontologia e psicologia).

Tabela 14 - Diagnóstico dos problemas apresentados pelos pacientes

\begin{tabular}{|c|c|c|}
\hline Área de fonoaudiologia & Freqüência & $(\%)$ \\
\hline Fala & 21 & 91,3 \\
\hline Alimentação Respiração & 09 & 39,1 \\
\hline Audição & 06 & 26,1 \\
\hline Linguagem & 03 & 13,1 \\
\hline Outros & 11 & 47,8 \\
\hline TOTAL & 23 & 100,0 \\
\hline Sem resposta & 01 & \\
\hline TOTAL Geral & 24 & \\
\hline Área de Psicologia & Freqüência & $(\%)$ \\
\hline Relativos a dinâmica familiar & 10 & 90,9 \\
\hline Emocionais & 09 & 81,8 \\
\hline Aceitação e Inclusão Social & 06 & 54,5 \\
\hline TOTAL & 11 & 100,0 \\
\hline Sem resposta & $\mathbf{0 1}$ & \\
\hline TOTAL Geral & 12 & \\
\hline Área de odontologia & Freqüência & $(\%)$ \\
\hline Prevenção e controle da cárie dentária & 06 & 40,0 \\
\hline Alterações odontológicas e ortodônticas & 11 & 73,3 \\
\hline $\begin{array}{l}\text { Motivacionais e sócio-econômicos para acompanhamento de } \\
\text { tratamento }\end{array}$ & 05 & 33,3 \\
\hline Outros & 04 & 26,6 \\
\hline TOTAL & 15 & 100,0 \\
\hline Sem resposta & 04 & \\
\hline TOTAL Geral & 19 & \\
\hline Área de Serviço Social & Freqüência & $(\%)$ \\
\hline Insuficiência de Serviços Sociais prestados pela esfera pública & 07 & 53,8 \\
\hline Ausência de compromisso com o tratamento & 08 & 61,5 \\
\hline Vulnerabilidade Social & 03 & 12,0 \\
\hline Intercâmbio entre profissionais restritos & 01 & 7,7 \\
\hline TOTAL & 13 & 100,0 \\
\hline Sem Resposta & 04 & \\
\hline TOTAL Geral & 17 & \\
\hline
\end{tabular}

Especificamente na área de fonoaudiologia, os profissionais diagnosticaram várias alterações que foram categorizadas com a orientação de um fonoaudiólogo em ordem de ocorrências da seguinte forma:

- Fala $(91,3 \%)$ : alterações fonoarticulatorias posterior à cirurgia; distúrbio de fala; disfonia, dificuldade que o paciente tem de automatizar fonemas alterados, DAC'S, desvios fonológicos, ressonância hipernasal, hipernasalidade, alterações na nasalidade, alterações na fala, voz, voz com EAN, hipernasal com algumas distorções.

- Alimentação e Respiração (39,1\%): dificuldade de alimentação, funções de sucção e deglutição, deglutição, funções respiratórias, mastigação, deglutição antes da cirurgia. 
- Audição (26,1\%): alterações auditivas, deficiência auditiva, otites (acaba DA); DA condutiva por otite.

- Linguagem (13,0\%): atraso na aquisição e desenvolvimento de linguagem.

- Outros (47,8\%): distúrbios de aprendizagem, não têm formação para atendê-los, distúrbio de leitura e escrita, envolvimento da família e paciente no processo de reabilitação terapêutica, demora do agendamento de cirurgias e segmento ortodôntico no município.

$\mathrm{Na}$ área da psicologia os profissionais relataram as principais situações apresentadas para o atendimento dos pacientes e da mesma forma contamos com apoio de um psicólogo na categorização dos principais problemas diagnosticados que foram estabelecidos por ordem de dificuldades:

- Dinâmica familiar (90,9\%): o processo de aceitação do filho; falta de adesão da família no tratamento; falta de conscientização; falta de capacitação.

- Emocionais (81,8\%): o sentir-se diferente; baixa auto-estima; auto - imagem; negativa; insegurança afetiva; agressividade; timidez; sentimento de menos valia; auto-aceitação.

- A aceitação e inclusão social (54,5 \%): preocupação do paciente e ou família em fazer a cirurgia para que o "problema não seja mais visto"; o medo da rejeição; preconceitos sociais; problemas sócio-emocionais - socialização; busca de direitos; dificuldade da fala; dificulta a inserção social.

$\mathrm{Na}$ área odontológica os principais problemas foram categorizados com apoio de um profissional da área, o qual classificou como:

- Prevenção e controle da cárie dentária (40,0\%): prevenção, controle de placa, cárie dentária;

- Alterações odontológicas e ortodônticas (73,3\%): estética-função (ortodontia), mordida aberta, mordida cruzada, agenesia, terceiro molares incluso, discrepância antero/posterior, problemas ortodônticos, má-formação dental;

- Motivacionais e sócio-econômicos para acompanhamento de tratamento $(33,3 \%)$ : falta de cooperação dos pacientes e assiduidade no tratamento, desmotivação por parte de alguns pacientes, dificuldade de locomoção para o tratamento;

- Outros (26,60\%): falta de conhecimento e até receio em atender paciente com fissura, perda óssea, dificuldades na moldagem, higiene e criança traumatizada com ambiente hospitalar. 
$\mathrm{Na}$ área do Serviço Social os profissionais identificaram as seguintes questões:

- Insuficiência de serviços sociais pela esfera pública $(53,8 \%)$ : acesso ao tratamento em razão da dificuldade para adquirir o Tratamento Fora do Domicilio TFD, recursos para hospedagem em Bauru, inclusão do paciente no mercado de trabalho.

- Ausência de compromisso com o tratamento (61,5\%): falta de compromisso dos pacientes com o tratamento; dificuldade dos pacientes em conciliar trabalho e tratamento, assiduidade ao processo terapêutico.

- Vulnerabilidade social (12,0\%): vulnerabilidade social.

- Intercâmbio entre profissionais "restrito" (7,7\%): falta de intercâmbio entre os profissionais.

De acordo com a tabela 14 , os dados revelam que a totalidade dos profissionais reconheceu problemas em suas áreas específicas.

Diante de todos os diagnósticos apresentados no geral, o índice de dificuldades em atender o paciente foi de $25,0 \%$, no entanto se verificarmos por área, o nível de dificuldade maior ocorreu entre os fonoaudiólogos $(59,0 \%)$, o que sugere uma medida urgente, no sentido de estabelecer estratégias como um primeiro passo na criação do pólo de capacitação.

Tabela 15 - Ocorrência e especificação das principais dificuldades para o atendimento do paciente

\begin{tabular}{lcccccccc}
\hline \multicolumn{1}{l}{ Áreas/Apresenta dificuldades em atender pacientes com fissura } \\
\hline & Sim & $\mathbf{( \% )}$ & Não & $\mathbf{( \% )}$ & Sub Total & $\mathbf{( \% )}$ & Sem resp. & Total Geral \\
\hline Fonoaudiologia & 13 & 59,0 & 09 & 41,0 & 22 & 100,0 & 02 & 24 \\
Psicologia & 03 & 25,0 & 09 & 75,0 & 12 & 100,0 & & 12 \\
Odontologia & & 0,0 & 19 & 100,0 & 19 & 100,0 & & 19 \\
Serviço Social & 01 & 6,6 & 14 & 93,4 & 15 & 100,0 & 02 & 17 \\
\hline TOTAL & $\mathbf{1 7}$ & $\mathbf{2 5}$ & $\mathbf{5 1}$ & $\mathbf{7 5}$ & $\mathbf{6 8}$ & $\mathbf{1 0 0 , 0}$ & $\mathbf{0 4}$ & $\mathbf{7 2}$ \\
\hline
\end{tabular}

Os profissionais da área de fonoaudiologia apresentaram em ordem de dificuldades as seguintes categorizações:

- Tipo de alteração (53,8\%): insuficiência Velofaringea IVF; DAC'S; limitações dos casos funcional e anatômicos; Reabilitação das funções estomatognaticas em geral; quando há deficiência auditiva associada a fissura e entender a fala do fissurado.

- Falta de capacitação (38,4\%): necessita de atualização quanto a prática fonoaudiologica; pouca experiência; falta de capacitação; material específico não adquirido. 
- Motivação continuidade (30,7\%): iniciar terapia em adolescentes - por falta de motivação; motivação dos pais (resultados mais demorados); continuidade na terapia por parte dos pacientes; realização de exercícios em casa.

- Duração terapia (23,0\%): o tempo que ficam em terapia; em alguns casos quando mesmo com conhecimento não consigo evoluir a terapia; alta - qual o limite terapêutico em alguns casos.

Na área da psicologia com relação às dificuldades em atender o paciente com fissura labiopalatina, $72,7 \%$ afirmaram não encontrar dificuldades para $25,0 \%$ com dificuldades tanto na compreensão da fala dos pacientes como na ausência de ações que priorizam a prevenção de problemas psicossociais.

$\mathrm{Na}$ área de serviço social, apenas um assistente social (6,6\%) relatou dificuldades em atender casos de deformidades craniofaciais diversas.

$\mathrm{Na}$ área de odontologia não houve incidência de dificuldades no atendimento ao paciente.

Com relação ao desenvolvimento de programas/atividades/ações, os profissionais relatam estar trabalhando de acordo com as especificidades das áreas, conforme demonstra a tabela 16 .

Tabela 16 - Principais programas/atividades/ações

\begin{tabular}{lcc}
\hline Fonoaudiologia/programas/atividades/ações & Freqü̂ncia & $\mathbf{\%}$ \\
\hline Terapia & 14 & 82,3 \\
Diagnóstico & 14 & 82,3 \\
Atendimento Precoce & 05 & 29,4 \\
Orientação Cuidadores & 06 & 35,3 \\
TOTAL & $\mathbf{1 7}$ & $\mathbf{1 0 0 , 0}$ \\
\hline Sem resposta & $\mathbf{0 7}$ & \\
\hline TOTAL GERAL & $\mathbf{2 4}$ & 100,0 \\
\hline Psicologia/Programas/atividades/ações & & 70,0 \\
\hline Abordagem terapêutica & 10 & 20,0 \\
Apoio Familiar & 07 & 10,0 \\
Suporte à equipe & 02 & $\mathbf{1 0 0 , 0}$ \\
Acompanhamento Escolar & 01 & \\
TOTAL & $\mathbf{1 0}$ & $\mathbf{0 1}$ \\
\hline Sem resposta & $\mathbf{1 1}$ & 93,3 \\
\hline TOTAL GERAL & & 40,0 \\
\hline Odontologia/Programas/Atividades/Ações & 14 & 40,0 \\
\hline Preventivos, de motivação e reforço & 06 & 40,0 \\
Avaliação inicial e controle de tratamento & 06 & $\mathbf{1 0 0 , 0}$ \\
Curativos odontológicos & 06 & \\
Ortodônticos & $\mathbf{1 5}$ & $\mathbf{0 4}$ \\
TOTAL & $\mathbf{1 9}$ & \\
\hline Sem resposta & & \\
\hline TOTAL GERAL & & \\
\hline
\end{tabular}




\begin{tabular}{llc} 
Continuação & & \\
\hline Serviço Social Programas/atividades/ações & 81,2 \\
\hline $\begin{array}{l}\text { Apoio e orientações sociais: família, escola, trabalho e outros } \\
\text { Encaminhamentos, parcerias e ou orientações sobre recursos }\end{array}$ & 13 & 68,7 \\
institucionais & & 37,5 \\
$\begin{array}{l}\text { Elaboração, implementação, coordenação, execução e avaliação } \\
\text { de planos, programas e projetos }\end{array}$ & 06 & 12,5 \\
Assessoria institucional referente à área social & 02 & $\mathbf{1 0 0 , 0}$ \\
TOTAL & $\mathbf{1 6}$ & \\
\hline Sem resposta & $\mathbf{0 1}$ & $\mathbf{1 8}$ \\
\hline TOTAL GERAL & $\mathbf{1 8}$ \\
\hline
\end{tabular}

Os profissionais especificaram os programas/atividades/ações desenvolvidos, de acordo com cada área. Na fonoaudiologia, foram categorizados na seguinte ordem:

- Terapia (82,3\%): adequação funções estomatognáticas; adequação direção fluxo ar; adequação de ponto e modo articulatório; trabalho com ênfase na hipernasalidade com direcionamento do fluxo aérea para cavidade oral; tratamento; terapia; atendimento individualizado; atendimentos terapêuticos.

- Diagnóstico (82,3\%): acompanhamento clínico; atendimentos ambulatoriais; avaliação fonoaudiologica; diagnóstico; avaliação audiológica; encaminhamentos para profissionais necessários e centro de referência; reavaliação.

- Atendimento precoce $(29,4 \%)$ : atendimento precoce a bebê fissurado; estimulação global (dois a quatro anos com atraso no desenvolvimento neuropsicomotor e terapia); caso novo; atendimento precoce; estimulação global.

- Orientação a cuidadores (35,3\%): orientação à família desde nascimento; grupo de bebes e terapia; orientação aos pais; orientação.

$\mathrm{Na}$ área da psicologia, os programas/atividades/ações foram categorizados em:

- Abordagem terapêutica (100\%): atendimento individual; acompanhamento do desenvolvimento dos bebês; grupo de mães; apoio familiar; atendimento clínico individual; psicoterapia de grupo e individual; orientações; atendimento pré e pósoperatório; terapia semanal e grupo de arte-terapia.

- Apoio familiar ( 70\%): visitas domiciliares; visita à maternidade; palestra na sala de espera; funcionamento da brinquedoteca.

- Acompanhamento escolar (20\%): orientações a professores

- Suporte à equipe (10\%): auxilia a equipe; reunião mensal com os demais psicólogos da entidade.

$\mathrm{Na}$ área odontológica, os programas foram destacados e categorizados em: 
- Preventivos, de motivação e reforço (93,3\%): programa preventivo do bebê ao adulto; orientação aos pais e pacientes; motivação e reforço da importância da odontologia no tratamento do paciente com fissura labiopalatina; orientação de higiene; odontologia preventiva e curativa; programa de prevenção com escovação supervisionada; orientação da alimentação; controle de cárie; ações preventivas (selantes);

- Avaliação inicial e controle de tratamento (40,0\%): avaliação de caso novo; exame clínico e controle;

- Curativos odontológicos (40,0\%): ações curativas (restaurações); tratamento de clínica geral e dentística.

- Ortodônticos (40,0\%): análise radiográfica/modelos, ortodontia fixa e removível, programas de placas ortopédicas.

No Serviço Social, os assistentes sociais identificaram os programas/ atividades/ações desenvolvidas e foram categorizados como:

- Apoio e orientações sociais: família, escola, trabalho e outros $(81,2 \%)$ : atendimento a casos novos para acolhimento; acompanhamento através do atendimento individual e familiar; plantão social; rotinas pré e pós-cirurgias; repasse de informações; orientação na maternidade; apoio psicossocial; acompanhamento desde do nascimento até a fase de conclusão de tratamento; atendimento precoce; estimulação global; atendimento terapêutico; estudo socioeconômico.

- Encaminhamentos, parcerias e/ou orientações sobre recursos institucionais (68,7\%): encaminhamentos, intercâmbio com central de agendamento; manter uma rede de comunicação entre profissionais para planejamento de tratamento.

- Elaboração, implementação, coordenação, execução e avaliação de planos, programas e projetos $(37,5 \%)$ : programas sociais, programas de geração de renda (inclusão produtiva e capacitação profissional); Coordenação de projetos sociais em diversos segmentos; Elaboração de projetos.

- Assessoria institucional referente à área social (12,5\%): assessoria institucional.

No aspecto relacionado com os recursos terapêuticos os profissionais informaram que os utilizam no desenvolvimento de suas atividades como podemos verificar na tabela abaixo. 
Tabela 17 - Recursos terapêuticos

\begin{tabular}{|c|c|c|}
\hline Fonoaudiologia/Recursos terapêuticos & Freqüência & $(\%)$ \\
\hline Estratégias Terapêuticas & 07 & 46,7 \\
\hline Materiais & 13 & 86,7 \\
\hline Equipamento & 02 & 13,3 \\
\hline Outros & 09 & 60,0 \\
\hline TOTAL & 15 & 100,0 \\
\hline Sem resposta & 09 & \\
\hline TOTAL GERAL & 24 & \\
\hline \multicolumn{3}{|l|}{ Psicologia/Recursos terapêuticos } \\
\hline Psicodiagnóstico & 02 & 18,1 \\
\hline Psicoterapêuticos & 11 & 100,0 \\
\hline Encaminhamentos & 02 & 18,1 \\
\hline Materiais & 04 & 36,3 \\
\hline TOTAL & 11 & 100,0 \\
\hline Sem resposta & $\mathbf{0 1}$ & \\
\hline TOTAL GERAL & 12 & \\
\hline \multicolumn{3}{|l|}{ Odontologia/Recursos terapêuticos } \\
\hline Diagnóstico & 09 & 69,2 \\
\hline Prevenção & 07 & 53,8 \\
\hline Curativo & 07 & 53,8 \\
\hline Documentação ortodôntica & 03 & 23,0 \\
\hline outros & 01 & 7,7 \\
\hline TOTAL & 13 & 100,0 \\
\hline Sem resposta & 06 & \\
\hline TOTAL GERAL & 19 & \\
\hline \multicolumn{3}{|l|}{ Serviço Social/Recursos Terapêuticos } \\
\hline Assessoria à equipe & 02 & 20,0 \\
\hline Orientação social individual, grupos e população & 06 & 60,0 \\
\hline Identificação de recursos e encaminhamentos para diferentes serviços & 03 & 30,0 \\
\hline Apoio e acompanhamento psicossocial & 03 & 30,0 \\
\hline Estudo socioeconômico para fins de benefícios e serviços & 03 & 30,0 \\
\hline Relatórios sociais & 04 & 40,0 \\
\hline TOTAL & 10 & 100,0 \\
\hline Sem resposta & $\mathbf{0 7}$ & \\
\hline TOTAL GERAL & 17 & \\
\hline
\end{tabular}

Os recursos terapêuticos apresentados pelos profissionais da área da fonoaudiologia também foram categorizados em:

- Estratégias terapêuticas (46,7\%): aquisição do ponto articulatório; automatização do fonema; direcionamento do fluxo aéreo para cavidade oral com remo de ar e com pistas auditivas e visuais; massagens; manobras e exercícios de motricidade oral; técnicas fonoaudiologicas usualmente utilizadas e aprendidas na graduação.

- Materiais (86,7\%): espelhos milimetrados; garote; remo de ar; objetos de sopro existentes e/ou criados em terapia para auxílio de percepção e visualização; recursos táteis, visuais auditivos e cinestésico; espelho de glatzem; scape-scope; materiais pedagógicos; materiais lúdicos, didáticos e pedagógicos; vela; teste escape; materiais para mioterapia; material de terapia fonoaudiologica. 
- Equipamento (13,3\%): audiômetro; imitanciômetro.

- Outros (60,0\%): terapias individuais; Protocolo de avaliação.

Para o atendimento dos pacientes foram informados os seguintes recursos terapêuticos utilizados pelos profissionais da área de psicologia que foram categorizados em:

- Psicodiagnóstico (18,1\%): teste psicológico

- Psicoterapêutico (100,0\%): ludoterapia para crianças; abordagem psicanalítica para adultos; dinâmicas; acompanhamento psicológico; técnicas psicológicas; acompanhamento psicológico; esculta terapêutica; terapia de apoio; análise do discurso; técnicas voltadas para autoconhecimento; abordagem sistêmica.

- Encaminhamentos (18,1\%): encaminhamento - neurologista e/ou psiquiatra; encaminhamento interno e externo.

- Materiais utilizados (36,3\%): brinquedos; material escolar (sulfite, lápis, etc.); jogos; materiais gráficos/lúdicos e material pedagógico.

$\mathrm{Na}$ área de odontologia, os profissionais identificaram os seguintes recursos terapêuticos:

- Diagnóstico $(69,2 \%)$;

- Prevenção (53,8\%): preventivo, aplicação de selante e profilaxia;

- Curativo (53,8\%): restauração em resina composta e amálgama;

- Documentação ortodôntica (23,0\%): aparelhos ortopédicos e funcionais;

- Outros (7,7\%): material odontológico de primeira linha.

Os profissionais de serviço social informaram diferentes recursos terapêuticos categorizados em:

- Assessoria à equipe $(20,0 \%)$;

- Orientação social individual, grupos e população $(60,0 \%)$ : abordagem individual e grupal, entrevistas, reuniões, visitas domiciliares;

- Identificação de recursos e encaminhamentos para diferentes serviços na defesa de direitos de cidadania (30,0\%): organização de benefícios;

- Apoio e acompanhamento psicossocial (30,0\%): escuta, encontros, seguimento de casos;

- Acompanhamento do processo de reabilitação (30,0\%): acesso e continuidade; estudo sócio-econômico para fins de benefícios e serviços (30,0\%); (estudo e estudo sócio-econômico); 
- Relatórios sociais (40,0\%): perícias e pareceres.

Conhecendo os principais problemas diagnosticados no atendimento dos pacientes do HRAC, as dificuldades enfrentadas pelos profissionais para o desenvolvimento da prática com os pacientes, os principais programas/atividades/ações voltados para área da fissura e os recursos terapêuticos utilizados, conseguimos visualizar um panorama geral da estrutura do atendimento dispensado aos pacientes do HRAC.

Esse panorama sugere o questionamento sobre a necessidade e/ou expectativa de capacitação na área das fissuras para qualidade do atendimento que seria um agente transformador das práticas e da própria instituição, de acordo com as demandas.

Essa capacitação seria via utilização de novas tecnologias (pólos de educação permanente em saúde, teleeducação, e outras), na busca de soluções criativas, para a melhoria permanente da qualidade e humanização do atendimento.

De acordo com a política proposta pelo Ministério da Saúde, a Educação Permanente em Saúde (Portaria $n^{\circ}$ 198, de 13 de fevereiro de 2004) será construída em cada locorregião do País e realizada por meio dos Pólos de Educação Permanente em Saúde.

Esses Pólos são instâncias colegiadas que servem para a articulação, o diálogo, a negociação e a pactuação interinstitucional. São espaços onde atores de diversas origens poderão se encontrar e pensar juntos as questões da Educação Permanente em Saúde, como em uma mesa de negociação. (Brasil 2004b).

Os Pólos de Educação Permanente em Saúde sejam rodas para a gestão da Educação Permanente em Saúde. Nessas rodas, pessoas que realizam as ações e os serviços do SUS e pessoas que pensam a formação em saúde poderão dialogar livremente. Todos juntos, interagindo, poderão identificar as necessidades e construir as estratégias e as políticas no campo da formação e do desenvolvimento, na busca de melhorar a qualidade da gestão, aperfeiçoar a atenção integral à saúde, popularizar o conceito ampliado de saúde e fortalecer o controle social (Brasil 2005).

Os Pólos funcionam como a parte do SUS responsável pela mudança tanto das práticas de saúde quanto das ações de educação na saúde. Serão rodas de debate e de construção coletiva. 
Á partir de 2004 após aprovação da portaria 198 começaram a constituir os pólos de educação nos municípios. O número de Pólos de Educação Permanente em Saúde, no Brasil, é de 96, como mostra a figura a seguir.

\begin{tabular}{|c|c|c|}
\hline \multicolumn{2}{|c|}{ Regiões/Estados } & Número de PEPS \\
\hline \multirow{7}{*}{$\begin{array}{l}\frac{1}{2} \\
\frac{1}{0} \\
Z\end{array}$} & Acre & 1 \\
\hline & Amazonas & 1 \\
\hline & Amapá & 1 \\
\hline & Pará & 6 \\
\hline & Rondônia & 1 \\
\hline & Roraima & 1 \\
\hline & Tocantins & 1 \\
\hline & TOTAL & 12 \\
\hline \multirow{9}{*}{ 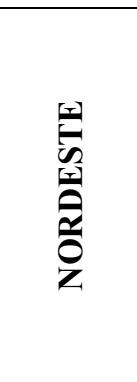 } & Alagoas & 1 \\
\hline & Bahia & 7 \\
\hline & Ceará & 4 \\
\hline & Maranhão & 2 \\
\hline & Paraíba & 1 \\
\hline & Pernambuco & 5 \\
\hline & Piauí & 1 \\
\hline & Rio Grande do Norte & 1 \\
\hline & Sergipe & 1 \\
\hline \multicolumn{2}{|r|}{ TOTAL } & 23 \\
\hline \multirow{4}{*}{ 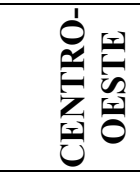 } & Distrito Federal & 1 \\
\hline & Goiás & 5 \\
\hline & Mato Grosso & 2 \\
\hline & Mato Grosso do Sul & 1 \\
\hline \multicolumn{2}{|r|}{ TOTAL } & 9 \\
\hline \multirow{4}{*}{ 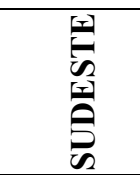 } & Espírito Santo & 1 \\
\hline & Minas Gerais & 13 \\
\hline & Rio de Janeiro & 5 \\
\hline & São Paulo & 8 \\
\hline \multicolumn{2}{|r|}{ TOTAL } & 27 \\
\hline \multirow{3}{*}{$\vec{\infty}$} & Paraná & 6 \\
\hline & Rio Grande do Sul & 7 \\
\hline & Santa Catarina & 12 \\
\hline & TOTAL & 96 \\
\hline
\end{tabular}

Fonte: Ministério da Saúde.

Figura 8 - Número de Pólos de Educação Permanente em Saúde (PEPS), por região e estados

Com relação a esses pólos, os profissionais foram questionados quanto ao conhecimento de sua existência, conhecimento do pólo na sua cidade e sua participação. 
Tabela 18 - Existência, dos Pólos de Educação na cidade

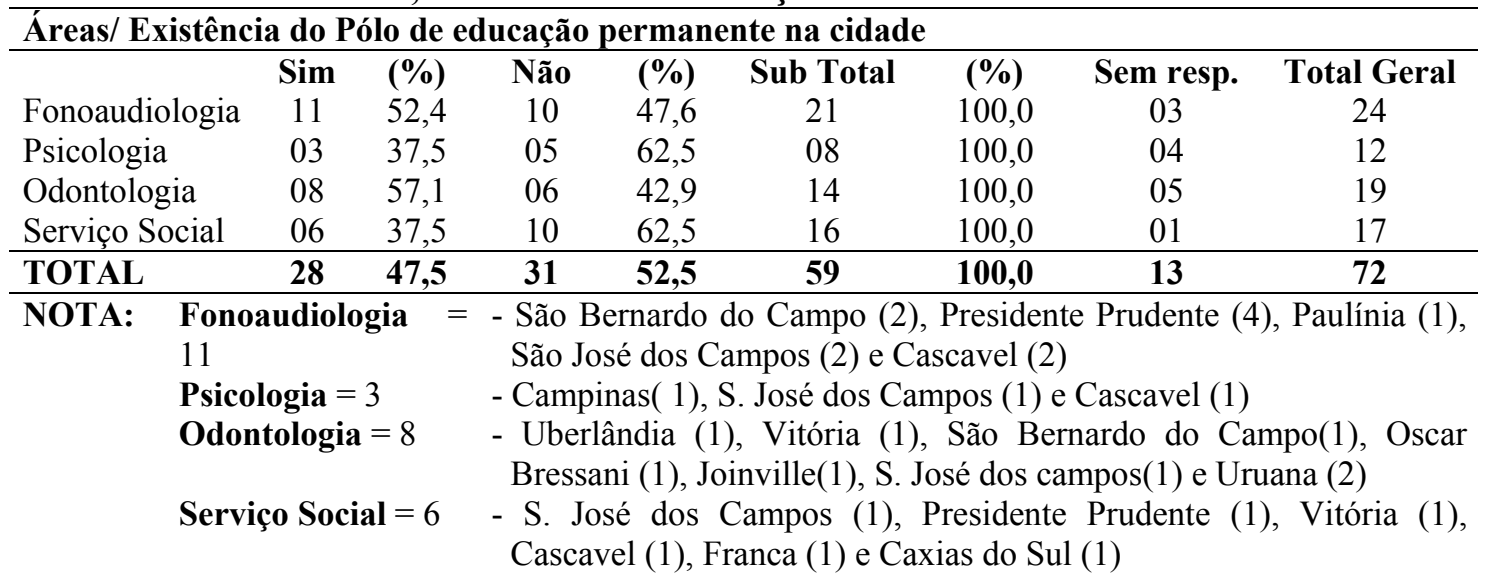

Conforme os dados apresentados, 47,5\% dos profissionais, informaram a existência do pólo de educação permanente, em sua cidade/região. Como os pólos foram constituídos a partir de 2004, acreditamos que seja necessário maior divulgação dos mesmos, pois os "Pólos buscam a integralidade da atenção à saúde por meio do fortalecimento dos elementos dessa diretriz do SUS: o acolhimento de todos os usuários; a produção de vínculo entre eles e a equipe de saúde local; a responsabilização das equipes com a saúde individual e coletiva; o desenvolvimento da autonomia dos usuários, que devem ser protagonistas no processo de cuidado e não meros objetos nas mãos dos profissionais; e a resolutividade da atenção à saúde, que representa a capacidade de resolver com qualidade os problemas de saúde detectados em cada caso" (Brasil 2005 p.18). "Outra importante função dos Pólos é descobrir formas de aproximar as escolas dos serviços de saúde, possibilitando que professores e estudantes vivenciem o cotidiano dos processos de organização dos serviços de cuidado e atenção à saúde da população" (Brasil 2005 p. 19). 
Tabela 19 - Conhecimento do Pólo de educação permanente na cidade

\begin{tabular}{|c|c|c|c|c|c|c|c|}
\hline \multicolumn{8}{|c|}{ Áreas/Conhece o pólo de educação permanente na cidade } \\
\hline & Sim & $(\%)$ & Não & $(\%)$ & Sub Total & Sem resp. & Total Geral \\
\hline Fonoaudióloga & 01 & 11,1 & 08 & 88,9 & 09 & 02 & 11 \\
\hline Psicologia & 01 & 33,3 & 02 & 66,7 & 03 & - & 03 \\
\hline Odontologia & 04 & 57,1 & 03 & 42,9 & 07 & 01 & 08 \\
\hline Serviço Social & 02 & 33,3 & 04 & 66,7 & 06 & - & 06 \\
\hline TOTAL & 08 & 32,0 & 17 & 68,0 & 25 & 03 & 28 \\
\hline \multicolumn{8}{|c|}{ Áreas/Participa no pólo de educação permanente } \\
\hline & Sim & $(\%)$ & Não & $(\%)$ & Sub Total & Sem resp. & Total Geral \\
\hline Fonoaudiologia & & & 11 & 100,0 & 11 & & 11 \\
\hline Psicologia & & & 03 & 100,0 & 03 & & 03 \\
\hline Odontologia & 03 & 42,9 & 04 & 57,1 & 07 & 01 & 08 \\
\hline Serviço Social & & & 06 & 100,0 & 06 & & 06 \\
\hline TOTAL & 03 & 11,1 & 24 & 88,9 & 27 & 01 & 28 \\
\hline
\end{tabular}

Apenas 32,0\% o conhecem e somente 11,1\% participam. Observamos que a área de odontologia é que tem maior índice de conhecimento $(57,1 \%)$ e de participação (42,9\%) nos pólos de educação permanente do SUS especialmente com relação aos programas de capacitação em saúde da família, câncer bucal, curso na área da saúde pública e também cursos de amamentação.

De acordo com os dados extraídos da pesquisa, verificamos que os profissionais identificaram problemas na sua prática profissional com paciente, que em sua maioria demonstraram necessidade e interesse na criação de um pólo de capacitação, como mostra a tabela a seguir.

\section{4 - Identificação das necessidades e interesse dos reabilitadores em participar do programa de capacitação do HRAC.}

Tabela 20 - Necessidade e interesse na criação do pólo de capacitação

\begin{tabular}{lcccccccc}
\hline \multicolumn{7}{l}{ Interesse na criação do pólo de capacitação } \\
\hline \multicolumn{1}{c}{ Sim } & $\mathbf{( \% )}$ & Não & $\mathbf{( \% )}$ & Sub Total & $\mathbf{( \% )}$ & Sem resp. & Total Geral \\
\hline Fonoaudiologia & 20 & 100,0 & & & 20 & 100,0 & 04 & 24 \\
Psicologia & 09 & 90,0 & 01 & 10,0 & 10 & 100,0 & 02 & 12 \\
Odontologia & 14 & 93,3 & 01 & 6,7 & 15 & 100,0 & 04 & 19 \\
Serviço Social & 16 & 100,0 & - & & 16 & 100,0 & 01 & 17 \\
\hline TOTAL & $\mathbf{5 9}$ & $\mathbf{9 5 , 4}$ & $\mathbf{0 2}$ & $\mathbf{4 , 6}$ & $\mathbf{6 1}$ & $\mathbf{1 0 0 , 0}$ & $\mathbf{1 1}$ & $\mathbf{7 2}$ \\
\hline
\end{tabular}

Com relação à criação de um pólo de capacitação no HRAC, 95,4\% demonstraram interesse e necessidades de participarem de cursos de capacitação para reabilitadores e sugeriram vários temas que foram agrupados por áreas: 


\section{Fonoaudiologia}

- Fonoterapia - reabilitação fonoaudiologica; terapia fono; atualizações terapêuticas do tratamento dos pacientes com fissura labiopalatina; atuação prática com fisssura labiopalatina; intervenções fonoaudiológicas no atendimento aos pacientes com fissura labiopalatina; atendimento aos pacientes com fissura labiopalatina: técnicas; novas estratégias terapêuticas; reabilitação de adultos, pós faringo; avaliação e tratamento da fala do paciente com fissura labiopalatina.

- Bebês e alimentação - técnica de alimentação; todo e qualquer curso para instrumentalizar atendimento e orientação a bebês e crianças em início e desenvolvimento de linguagem, fonoterapia, avaliação e atualização.

- Audição - curso sobre deficiência auditiva associada a fissura labiopalatina, reabilitação.

- Outros - família na reabilitação; qualquer tema, sempre é necessário obter novos conhecimentos; instrumentalização técnica, atualização na área.

\section{Psicologia}

- Psicologia clínica;

- O desenvolvimento emocional da criança nos seus primeiros anos de vida relacionando as intervenções cirúrgicas de fissura labiopalatina;

- Diagnóstico precoce e orientação de pais;

- Quais principais (se há) conseqüências psicológicas ou características cognitivas comuns em pessoas que nasceram com fissura labiopalatina;

- A dinâmica familiar do indivíduo com fissura labiopalatina;

- Quaisquer temas voltados à psicologia e ao tratamento da pessoa com fissura.

\section{Odontologia}

- Odontologia: condicionamento psicológico em pacientes especiais, atendimento de pacientes com fissura labiopalatina no posto de saúde (unidade básica), dentística restauradora em odontopediatria;

- Ortodontia: ortodontia para pacientes com fissura, ortodontia estética;

- Atualização na odontologia em geral.

\section{Serviço Social}

- Diagnóstico precoce e orientação familiar;

- Atualização na área do serviço social e reabilitação da pessoa com físsura labiopalatina; 
- Curso para elaboração de projetos sociais;

- Legislação de saúde - Tratamento Fora do Domicílio (TFD);

- Envolvimento da família e paciente como tratamento;

- O serviço social no processo de reabilitação, interdisciplinaridade.

Alguns profissionais de todas as áreas se manifestaram sobre a criação do Pólo de Capacitação no HRAC/USP, emitindo opiniões e comentários, abordando conhecimento da área, intercâmbio entre profissionais, formação recursos humanos e qualidade do atendimento. Alguns depoimentos foram destacados por área.

Fonoaudiologia - Opiniões e Comentários:

"Seria ótimo, pois nesta cidade os profissionais desconhecem a área da fissura e encaminham os pacientes para APAFI (Associação de Pais e Amigos dos Portadores de Fissuras Labiopalatais de Mogi das Cruzes)”.

"Oportunidade para novos conhecimentos, experiências com equipe de referência no atendimento aos portadores de fissura".

“Acho uma excelente idéia, pois o centrinho realiza um trabalho ótimo, mas nem sempre as instituições têm capacitação de dar continuidade”.

"Ótimo, pois irá contribuir para atualização profissional discussão de casos e troca de informações com outros profissionais”.

"Acho excelente. Dessa forma mais profissionais poderão trabalhar com modelo que já deu certo e assim só tem a acrescentar aos profissionais e aos pacientes atendidos".

"Muito interessante, para melhor capacitação do profissional e melhor desempenho com o paciente”.

"Seria uma atitude excelente para quem atende o fissurado fora do HRAC".

"Excelente!! Pois nos daria maior suporte e melhoraria a qualidade do nosso atendimento".

"Acho importantíssima, pois a formação no curso de graduação é insuficiente para o bom atendimento a estes pacientes. Aqui no interior, o acesso a curso é difícil e ficamos limitados e, principalmente, aflitos frente às dificuldades que enfrentamos.

"Bastante significativo, pois alem de acrescentar conhecimento ocorre intercâmbio com demais profissionais”. 
“Acho muito bom, uma vez que na nossa cidade e região não temos profissionais especializados para atender essa patologia, pela falta de informação sobre fissuras".

"Ótima iniciativa desde que seja observado a realidade das associações, sendo em sua maioria mantidas com recursos financeiros limitados, garantindo apenas manutenção das atividades, bem como a questão dos profissionais que independente de prestadores de serviços ou voluntários possuem seus consultórios, clinicas ou atividades paralelas da instituição”.

"Uma ajuda muito importante e uma iniciativa primordial".

"Gostaria de ter maior acesso às informações, se possível de estar atualizada, de manter maior contato com HRAC, mesmo que por e-mail”.

"Gostaria de associar a possibilidade de visita ao HRAC, cursos teóricos e práticos".

\section{Psicologia - Opiniões e Comentários:}

“Ótima iniciativa desde que seja observada a realidade das associações, sendo em sua maioria mantidas com recursos financeiros limitados, garantindo apenas manutenção das atividades, bem como a questão dos profissionais que independente de prestadores se serviços ou voluntários possuem seus consultórios, clinicas ou atividades paralelas da instituição”.

"Boa, porque é a possibilidade dos profissionais possuírem capacitação adequada para seu trabalho".

"Excelente, pois dessa forma o atendimento poderia ser ampliado a profissionais que trabalham nesta área”.

"Penso ser de extrema importância a fim de capacitar, instrumentalizar os profissionais que atuam nesta área".

"Importância para apoiar, planejar, organizar e desenvolver atividades inerentes à capacitação, qualificação e formação de recursos humanos".

"Será de grande importância para todos profissionais da área da saúde”.

"Considero de extrema importância uma vez que muitos profissionais não têm conhecimento especifico de fissura e as melhores técnicas de intervenção”.

"Bom devido contribuir para maior capacitação e trocas profissionais relacionados com fissura". 
"Acredito ser muito importante com vistas a capacitação profissional”.

"O Centrinho de Joinville surgiu da necessidade de descentralização de Bauru, porém, nunca senti uma boa vontade de Bauru em nos instrumentalizarmos”.

"O pólo favorecerá a ampliação dos conteúdos e conhecimentos sobre a fissura labiopalatina".

"Que o hospital esteja mais aberto a receber as Associações em caráter permanente. Os profissionais do HRAC encaminham o paciente porém não dão suporte necessário”.

"Sinto de outros centros um interesse maior em traçar experiências e construir uma teoria para o paciente fissurado. Não confio nessa iniciativa”.

Odontologia - Opiniões e Comentários:

"Deve ser criado".

"De grande importância pois precisamos estar sempre renovando e atualizando novos conhecimentos".

"Ótima idéia pois a minha região é precária em referência para Anomalias Craniofaciais”.

"Seria muito interessante, pois provavelmente tornaria-se uma referencia especifica nesta área”.

"Seria ótimo, pois seria um centro para a capacitação de profissionais que estão interessados no tratamento de paciente com fissura labiopalatina”.

“A criação de um pólo de capacitação seria muito bom para a região pois facilitaria a vida dos pacientes, visto que em Jales há vários pacientes com fissura labiopalatina”.

"Ótima idéia visto que é necessária a reciclagem dos profissionais”.

"Ótima iniciativa desde que seja observada a realidade das associações, sendo em sua maioria mantidas com recursos financeiros limitados, garantindo apenas manutenção das atividades, bem como a questão dos profissionais que independentemente de prestadores se serviços ou voluntários possuem seus consultórios, clinicas ou atividades paralelas da instituição”.

“Acho bastante necessário”.

"A iniciativa tem relevante importância profissional e social”. 
Serviço Social - Opiniões e Comentários:

"Ótima iniciativa desde que seja observada a realidade das associações, sendo em sua maioria mantidas com recursos financeiros limitados, garantindo apenas manutenção das atividades, bem como a questão dos profissionais que independente de prestadores se serviços ou voluntários possuem seus consultórios, clinicas ou atividades paralelas da instituição”.

"Ótima, tendo em vista a necessidade de reciclagem profissional”.

"Muito importante pois ainda há muito desconhecimento deste tipo de deficiência considero de extrema importância, uma vez que muitos profissionais não tem conhecimento especifico de fissura e as melhores técnicas de intervenção”.

"Será ótimo pois irá contribuir para o constante aperfeiçoamento de nossa prática profissional”.

"Por ser o Centrinho um centro de excelência a nível nacional, isto é um ponto a favor. A criação deste centro seria muito boa, em virtude do apoio as instituições”.

"Acho muito importante para a ampliação do conhecimento nessa área".

"Sinto falta da parceria institucional. Existe apoio de alguns profissionais. Não existe nenhum diferencial ou investimento nos serviços organizados fora de Bauru”. "Que os profissionais da FUNCRAF tenham acesso aos cursos de capacitação, no caso da criação do pólo de capacitação”.

"Que o Hospital esteja mais aberto para receber as associações em caráter permanente. Os profissionais do HRAC encaminham, porém não dão suporte necessário”.

\section{Sugestões das áreas:}

"Sugiro que este curso seja realizado em breve e se houver condições de ser em nossa cidade para que várias pessoas participem seria fundamental”.

(Fonoaudiologia)

"Sugerimos que os profissionais que atuam há mais de 10 anos em instituições como AFIM (Associação de Apoio ao Fissurado de Maringá) fossem cadastrados no Hospital e posteriormente serem avaliados quanto ao interesse em realizarem cursos de especialização/residência no centrinho através de incentivos do próprio hospital". (Odontologia) 
"Espero que o pólo realize encontros regionais visando facilitar o acesso dos profissionais". (Serviço Social)

O que foi exposto pelos profissionais ratifica a necessidade de iniciativas para a ampliação das formas de intercâmbio e articulação dos serviços/reabilitadores com diferentes organizações públicas, privadas e ou do Terceiro Setor.

\section{5 -Ampliação das formas de intercâmbio e articulação dos serviços/reabilitadores com diferentes organizações públicas, privadas e ou do Terceiro Setor.}

A USP, por meio do HRAC, mantém diferentes formas de intercâmbio e articulação de seus serviços, especialmente com os profissionais que participaram do programa de formação de recursos humanos. Dentre esses programas, destacamos os formados nos diferentes cursos, desde 1996, em nível de aperfeiçoamento e especialização, totalizando 612 alunos, além de 66 de mestrado e 27 de doutorado. No ano de 2006, o HRAC contava com 202 alunos matriculados, deles, 32 estagiários, seis alunos de residência médica, oito de aprimoramento, 114 de especialização, 22 de doutorado e 20 de mestrado. Esses alunos são considerados agentes multiplicadores da filosofia do HRAC, em âmbito nacional e, até mesmo, internacional.

Esses cursos, voltados à área da reabilitação das fissuras labiopalatinas, propiciam a construção de conhecimentos mediante pesquisas e publicações. No ano de 2006, foram publicados 34 artigos em periódicos nacionais (19) e internacionais (15), além de publicações em anais (25), capítulos de livro (2), monografias (31), dissertação de mestrado (7) e tese de doutorado (7), bem como 138 pesquisas cadastradas no Comitê de Ética em Pesquisa do HRAC/USP. Entre as pesquisas, destacam-se duas desenvolvidas em conjunto com universidades americanas, com financiamento do Nacional Institute of Health - NIH.

Além destes cursos lato sensu ou stricto sensu, o HRAC mantém, desde 1984, o Curso de Anomalias Craniofaciais com objetivo de colaborar na formação e/ou aprimoramento profissional. 
No Brasil existem 175 hospitais de ensino ${ }^{15}$ registrados pelo Ministério da Saúde no Cadastro Nacional de Estabelecimentos de Saúde (CNES) Brasil (2007g), destes, 55 com serviços especializados na área de malformações craniofaciais e malformações labiopalatina (Bucomaxilofacial), 21 associados na Associação Brasileira de Hospitais Universitários e de Ensino (ABRHUE) ${ }^{16}$ e 19 participantes da Rede Universitária de Telemedicina (RUTE) ${ }^{17}$. Entendemos que o HRAC, considerado como hospital de ensino poderia ampliar suas formas de intercâmbio e articulação com estes hospitais, participando da RUTE, desenvolvendo programas de capacitação de recursos humanos.

Dentre os 55 hospitais de ensino citados (atendimento na área da fissura lábiopalatina), oito estão cadastrados pelo Ministério da Saúde como estabelecimentos de Saúde credenciados de Alta Complexidade pelo Ministério da Saúde de acordo com portara 62 na área da fissura labiopalatina, como mostra a figura a seguir.

\footnotetext{
${ }^{15}$ Hospitais de Ensino instituições hospitalares públicas ou privadas certificadas pelos Min. da Saúde e da Educação como de atenção à saúde. São espaços de referência da atenção à saúde para a alta complexidade, formação de profíssionais de saúde e para o desenvolvimento técnico e científico da saúde. ${ }^{16}$ Associação Brasileira de Hospitais Universitários e de Ensino é uma sociedade civil sem fins lucrativos, com personalidade jurídica de direito privado, que congrega, por seus Diretores, os Hospitais de Ensino, qualquer que seja sua natureza jurídica.

${ }^{17}$ A Rede Universitária de Telemedicina é uma iniciativa do Ministério da Ciência e Tecnologia, apoiada pela Financiadora de Estudos e Projetos (FINEP) e pela Associação Brasileira de Hospitais Universitários (ABRAHUE) e coordenada pela Rede Nacional de Ensino e Pesquisa (RNP), que visa a apoiar o aprimoramento de projetos em telemedicina já existentes e incentivar o surgimento de futuros trabalhos interinstitucionais. (site: http://rute.rnp.br/)
} 


\begin{tabular}{|c|c|c|c|c|c|}
\hline \multicolumn{2}{|c|}{ Região/Estado } & Hospitais de Ensino & ABRAHUE & RUTE & $\mathbf{A C}$ \\
\hline \multirow{12}{*}{ 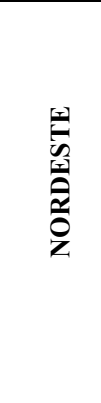 } & $\mathrm{BA}$ & Hospital Geral Roberto Santos - Salvador & & & \\
\hline & BA & Hospital Santo Antonio - Salvador & & & $\mathrm{X}$ \\
\hline & $\mathrm{CE}$ & HIAS Hospital Infantil Albert Sabin - Fortaleza & & & \\
\hline & $\mathrm{CE}$ & HDF Hospital Geral de Fortaleza & $\mathrm{X}$ & & \\
\hline & $\mathrm{CE}$ & Hospital Universitário Walter Cantidio - Fortaleza & $\mathrm{X}$ & $\mathrm{X}$ & \\
\hline & PB & Hospital Universitário Lauro Wanderley - João Pessoa & $\mathrm{X}$ & $\mathrm{X}$ & \\
\hline & $\mathrm{PB}$ & Hospital Universitário Alcides Carneiro UFCG - Campina Grande & $\mathrm{X}$ & $\mathrm{X}$ & \\
\hline & $\mathrm{PE}$ & Hospital das Clinicas - Recife & $\mathrm{X}$ & $\mathrm{X}$ & \\
\hline & $\mathrm{PE}$ & Hospital da Restauração - Recife & & & \\
\hline & $\mathrm{PE}$ & IMIP - Instituto Materno Infantil de Pernambuco - Recife & & & $\mathrm{X}$ \\
\hline & $\mathrm{RN}$ & Maternidade Escola Januário Cicco - Natal & $\mathrm{X}$ & $\mathrm{X}$ & \\
\hline & SE & Hospital Universitário - Aracaju & & $\mathrm{X}$ & \\
\hline \multirow{9}{*}{ 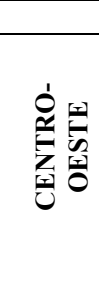 } & & TOTAL & 06 & 06 & $\mathbf{0 2}$ \\
\hline & DF & Hospital Universitário de Brasília & $\mathrm{X}$ & $\mathrm{X}$ & \\
\hline & $\mathrm{DF}$ & HBDF Hospital de Base do Distrito Federal & & & \\
\hline & DF & HRAN - Hospital Regional da Asa Norte - Brasília & & & \\
\hline & GO & Hospital das Clinicas - Goiânia & $\mathrm{X}$ & $\mathrm{X}$ & \\
\hline & MS & Santa Casa - Campo Grande & & & \\
\hline & MS & Hospital Universitário Maria Aparecida Pedrossian - C. Grande & $\mathrm{X}$ & $\mathrm{X}$ & \\
\hline & MT & Hospital Geral Universitário - Cuiabá & & & \\
\hline & MT & Hospital Universitário Julio Muller - Cuiabá & $\mathrm{X}$ & $\mathrm{X}$ & \\
\hline \multirow{23}{*}{ 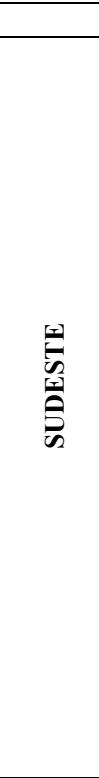 } & & TOTAL & 04 & 04 & $\mathbf{0}$ \\
\hline & MG & Santa Casa de Belo Horizonte & & & \\
\hline & MG & Hospital das Clinicas Samuel Libanio - Pouso Alegre & & & \\
\hline & MG & Hospital de Clinicas de Uberlândia & $\mathrm{X}$ & $\mathrm{X}$ & \\
\hline & MG & Hospital Universitário Alzira Velano - Alfenas & & & $\mathrm{X}$ \\
\hline & MG & Hospital das Clinicas da UFMG - Belo Horizonte & $\mathrm{X}$ & & \\
\hline & MG & Hospital da Baleia - Belo Horizonte & & & $\mathrm{X}$ \\
\hline & RJ & HGNI - Hospital Geral de Nova Iguaçú & & & \\
\hline & RJ & MS INTO Instituto Nacional De Traumato Ortopedia - R. Janeiro & & & \\
\hline & RJ & Hospital Universitário Sul Fluminense - Vassouras & & & \\
\hline & RJ & Hospital Universitário Antonio Pedro - Niterói & $\mathrm{X}$ & $\mathrm{X}$ & \\
\hline & SP & Hospital Municipal Dr Mario Gatti - Campinas & & & \\
\hline & $\mathrm{SP}$ & Santa Casa de Limeira & & & \\
\hline & SP & Hospital Das Clinicas FAEPA - Ribeirão Preto & & & \\
\hline & SP & Santa Casa de Ribeirão Preto & $\mathrm{X}$ & & \\
\hline & SP & Hospital Santa Marcelina - São Paulo & & & \\
\hline & SP & Hospital São Paulo Unidade I - São Paulo & & $\mathrm{X}$ & \\
\hline & $\mathrm{SP}$ & Hospital das Clinicas Unidade Clinico Cirúrgico - São Paulo & & & \\
\hline & SP & HC da FMUSP Hospital das Clinicas - São Paulo & $\mathrm{X}$ & $\mathrm{X}$ & \\
\hline & SP & Santa Casa de São Paulo Hospital Central - São Paulo & & & \\
\hline & $\mathrm{SP}$ & Hospital Universitário São Francisco Bragança Paulista & & & \\
\hline & SP & Hospital das Clinicas de Botucatu & $\mathrm{X}$ & & \\
\hline & SP & Hospital de Reabilitação de Anomalias Craniofaciais - Bauru & $\mathrm{X}$ & & $\mathrm{X}$ \\
\hline \multirow{14}{*}{ s } & & TOTAL & 07 & 04 & $\mathbf{0 3}$ \\
\hline & PR & Hospital de Clinicas - Curitiba & $\mathrm{X}$ & $\mathrm{X}$ & \\
\hline & $\mathrm{PR}$ & Hospital do Trabalhador-Curitiba & $\mathrm{X}$ & & $\mathrm{X}$ \\
\hline & PR & Hospital Universitário Evangélico de Curitiba & & & \\
\hline & $\mathrm{PR}$ & Hospital Infantil Pequeno Príncipe - Curitiba & & & \\
\hline & PR & Hospital Universitário Cajuru - Curitiba & & & \\
\hline & RS & Irmandade Santa Casa de Misericórdia de Porto Alegre & & $\mathrm{X}$ & \\
\hline & RS & Hospital de Clinicas - Porto Alegre & & $\mathrm{X}$ & \\
\hline & RS & Hospital Nossa Senhora da Conceição SA - Porto Alegre & & & $\mathrm{X}$ \\
\hline & RS & Hospital Cristo Redentor SA - Porto Alegre & & & \\
\hline & RS & Hospital São Lucas da PUCRS - Porto Alegre & & & \\
\hline & RS & Hospital Universitário Dr. Miguel Riet Correa Jr - Rio Grande & $\mathrm{X}$ & $\mathrm{X}$ & \\
\hline & $\mathrm{SC}$ & Hospital Infantil Joana de Gusmão - Florianópolis & $\mathrm{X}$ & & $\mathrm{X}$ \\
\hline & $\mathrm{SC}$ & Hospital Universitário UFSC - Florianópolis & & $\mathrm{X}$ & \\
\hline \multirow{2}{*}{\multicolumn{2}{|c|}{ TOTAL GERAI }} & TOTAL & 04 & 05 & $\mathbf{0 3}$ \\
\hline & & 55 & $\begin{array}{c}\mathbf{2 1} \\
(38 \%)\end{array}$ & $\begin{array}{c}19 \\
(36 \%)\end{array}$ & $\begin{array}{c}\mathbf{0 8} \\
(15 \%)\end{array}$ \\
\hline
\end{tabular}

Fontes: ABRAHUE - Associação Brasileira de Hospitais Universitários de Ensino RUTE - Rede Universitária de Telemedicina

AC -Alta Complexidade na área de fissura labiopalatina

CNES - Cadastro Nacional de Estabelecimentos de Saúde

Figura - 9 Hospitais de Ensino que atendem malformação labiopalatal (buco maxilo-facial) e/ou malformações craniofaciais 
O HRAC foi o proponente e o primeiro serviço especializado do Estado de São Paulo, cadastrado pelo Ministério da Saúde como hospital de Alta Complexidade na área das fissuras labiopalatinas, de acordo com a Portaria 62 de 19 de abril de 1994, tendo incluído a SOBRAPAR.

Atualmente (julho/2007), existem 20 estabelecimentos de saúde credenciados pelo Ministério da Saúde de acordo com a portaria n 62 de 1994 distribuídos conforme figura a seguir:

\begin{tabular}{|rl|c|c|}
\hline \multicolumn{2}{|l|}{ Estabelecimentos credenciados } & Estado & Cidade \\
\hline 1. & Obras Sociais Irmã Dulce & BA & Salvador \\
\hline 2. & Assoc.das Pioneiras Sociais SARAH & DF & Brasília \\
\hline 3. & Fund. Ensino Tecnologia Alfenas Universidade Alzira Velano & MG & Alfenas \\
\hline 4. & Fundação Benjamin Guimarães - Hospital da Baleia & MG & Belo Horizonte \\
\hline 5. & Hosp. Trabalhador/FUNPAR/Fund. UFPR p/Cienc. Tec. Cult. & PR & Curitiba \\
\hline 6. & Sociedade Piauiense Combate Câncer Hosp. São Marcos & PI & Teresina \\
\hline 7. & IMIP Instituto Materno lnfantil & PE & Recife \\
\hline 8. & SMS Rio Hospital Municipal N. Sra. do Loreto & RJ & Rio de Janeiro \\
\hline 9. & Hospital Nossa Senhora Conceição S.A & RS & Porto Alegre \\
\hline 10. & Sociedade Beneficência e Caridade & RS & Lajeado \\
\hline 11. & Hospital Infantil Joana de Gusmão & SC & Florianópolis \\
\hline 12. & FHSC Hospital Regional Hans Dieter Shimidt & SC & Joinville \\
\hline 13. & FUNCRAF- Fundação Tratamento de Deformidades Crânio Faciais & SP & Santo André \\
\hline 14. & Hospital de Pesquisa e Reabilitação de Lesões Lábio-Palatais & SP & Bauru \\
\hline 15. & Hospital de Cirurgia Plástica Crânio Facial & SP & Campinas \\
\hline 16. & STA. Cs. Mise. N. Sra. Fátima-Benef. Portuguesa & SP & Araraquara \\
\hline 17. & Fundação Faculdade de Medicina MEC/MPAS & SP & São Paulo \\
\hline 18. & Esc.Paulista de Medicina Hospital São Paulo & SP & São Paulo \\
\hline 19. & Irmandade da STA. Casa de Misericórdia. & SP & Piracicaba \\
\hline 20. & Hospital de Araguaína & TO & Araguaína \\
\hline Fona & & \\
\hline
\end{tabular}

Fonte: Ministério da Saúde

Figura - 10 Estabelecimentos de saúde credenciados pelo Ministério da Saúde

De acordo com Monlléo (2004), esses estabelecimentos se constituem em uma Rede de Referência no Tratamento das Deformidades Craniofaciais no Brasil (RRTDCF), havendo, porém, necessidade de revisão da definição, objetivos, abrangência e critérios de credenciamento dos centros vinculados a RRTDCF, o que é indispensável para a adequação da atenção à saúde das pessoas com anomalias craniofaciais no Brasil.

A organização dessa Rede e a capacitação de seus recursos humanos poderiam viabilizar o direcionamento das pessoas com fissura labiopalatina a centros de atenção mais próximo de sua região de origem à partir das Associações filiadas à REDE 
PROFIS, já firmadas como referências na assistência social e prestação de serviços/reabilitação dos pacientes do HRAC.

Estes dados revelam, ainda, que apesar da ampliação dos credenciamentos de novos serviços pelo Ministério de Saúde, para tais atendimentos, o HRAC continua sendo procurado por pessoas com fissura labiopalatina de todo o País, que buscam um atendimento integrado e não somente cirúrgico, para a sua completa reabilitação.

No ano de 2006, o HRAC foi responsável por 75,86\% dos tratamentos cirúrgicos e 92\% ambulatorial, segundo dados do Departamento de Informática do SUS (DATASUS) ${ }^{18}$, o que evidencia a necessidade de o HRAC ser reconhecido oficialmente pelo Ministério da Saúde como um Centro de Referência Nacional na área de Malformação Craniofacial, também o fosse na Saúde Auditiva e Sindromologia definindo políticas da assistência, ensino e pesquisa, visando uma qualificação de recursos humanos.

\section{6 -Contribuição para a construção de um pólo de capacitação de reabilitadores tendo com compromisso a humanização e qualificação da atenção.}

A partir das dificuldades diagnosticadas pelos profissionais pesquisados no atendimento às pessoas com fissuras labiopalatinas, em diferentes regiões e das experiências de intercâmbio e articulação do HRAC com outras organizações anteriormente relatadas, sugerimos a construção de um pólo de capacitação de reabilitação a partir das seguintes iniciativas:

\section{a) Curso de Anomalias Craniofaciais:}

A programação do Curso de Anomalias Craniofaciais do HRAC deverá ser mantida com relação aos temas abordados previstos para o ano 2007 e também com outras sugestões: Curso básico e específico, abaixo discriminados:

\section{Curso Básico}

- "Panorama geral da estrutura do HRAC/USP"

${ }^{18}$ Dados fornecidos pela superintendência mediante Ofício SUPE/007 2007/HRAC de 23/01/2007 enviado a magnífica reitora, professora Doutora Sueli Vilela pelo Professor Doutor José Alberto de Souza Freitas. 
- "Malformações congênitas labiopalatais: etiologia, classificação das fissuras labiopalatais e crescimento craniofacial"

- "O papel do Serviço Social no contexto hospitalar e no processo de reabilitação interdisciplinar"

- "As especificidades dos pacientes do HRAC/USP e a atuação da Psicologia"

- "Recursos odontológicos para reabilitação e correção dos problemas dentários, alveolares e esqueletais"

- "Características especiais dos pacientes fissurados e deficientes auditivos"

- "Aspectos pediátricos das malformações craniofaciais"

- "A assistência de Enfermagem aos pacientes com anomalias craniofaciais"

- "Contribuição da Nutrição na melhoria da qualidade de vida do paciente"

- "Atuação da Fisioterapia nos pacientes com anomalias craniofaciais"

- "As etapas terapêuticas na Cirurgia Plástica"

- "Humanização hospitalar e a Terapia Ocupacional aos pacientes com anomalias craniofaciais"

- "Condições e benefícios das cirurgias bucomaxilofacial e craniofacial no HRAC/USP"

\section{Cursos Específicos}

- Cirurgia Plástica

- Fisiologia

- Fonoaudiologia

- Nutrição e Pediatria

- Odontologia: Periodontia, Dentística, Endodontia ,Prótese, Implante, Odontopediatria, Ortodontia, Cirurgia Ortognática

- Prótese de Palato

- Psicologia

- Serviço Social

- Anomalias congênitas: da consulta ao aconselhamento genético.

Sugerimos, porém, o aprofundamento no conteúdo dos cursos específicos a partir das dificuldades relatadas pelos profissionais pesquisados, viabilizando a 
organização de workshop ou oficinas, ${ }^{19}$ de forma a garantir o trabalho de qualificação que envolverá a articulação e o diálogo entre a equipe do HRAC e os profissionais das demais organizações. Essas oficinas proporcionarão a discussão de programas do sistema de saúde, as inovações tecnológicas, os protocolos de atendimento às pessoas com fissura labiopalatina, criando continuadamente processo de análise e de problematização. As práticas serão definidas por múltiplos fatores, especialmente com base nas necessidades e expectativas dos sujeitos envolvidos no processo de capacitação.

Os cursos de anomalias craniofaciais poderão ser presenciais no HRAC ou na própria região/estado dos reabilitadores, desenvolvidos em parceria com os pólos de educação permanente do SUS, pautado nos princípios da política de humanização e de qualidade na prestação de serviços. Outra sugestão seria de preparar com antecedência o curso de Anomalias Craniofaciais e por meio do Cybertutor ${ }^{20}$ torná-lo acessível para os profissionais matriculados no curso, para uma interação prévia do conteúdo e melhor aproveitamento do curso presencial.

\section{b) Pós-Graduação do HRAC:}

Sugerimos a ampliação do conteúdo da Disciplina de Política de Saúde e Reabilitação, ministrada no Curso de Especialização em Serviço Social e nos cursos de Mestrado e Doutorado em Ciência da Reabilitação do HRAC e sua inclusão nos demais cursos de modo a fornecer subsídios aos alunos para darem respostas às demandas sociais que se apresentam para a profissão, abrangendo a produção e a socialização de conhecimentos, bem como a prestação da assistência. Neste processo de formação teórico - prática os alunos deverão assumir responsabilidade e compromisso com a sua educação e a capacitação de outros profissionais, tornando-se assim, um agente multiplicador do conhecimento na área da fissura labiopalatina. Além disso, esta capacitação no HRAC deverá ter como uma das metas garantir o atendimento de pessoas com fissuras labiopalatinas no município, por profissionais que já foram alunos do HRAC e que poderão mobilizar e pressionar o poder público para a criação e/ou

\footnotetext{
${ }^{19}$ Workshop - também chamado de oficina caracteriza-se por conter duas partes, uma teórica, em que o tema é apresentado em forma de palestra e na segunda parte, a prática, para a aplicação do que foi apresentado na teoria.

${ }^{20}$ Cybertutor é um sistema baseado na Internet que viabiliza ações de capacitação, formação e educação continuada à distância de larga abrangência.
} 
ampliação de serviços especializados na área, ultrapassando relações de solidariedade para a defesa da saúde como um direito.

Como o HRAC conta com pacientes e alunos de todas as regiões do País, os pósgraduandos serão atendidos pelo Serviço Social de Projetos Comunitários do HRAC e cadastrados como representantes comunitários. Nesse atendimento, serão orientados sobre os recursos socioassistenciais e de saúde das respectivas cidades, bem como sobre a relação de pacientes em tratamento no HRAC, para acompanhamento e/ou intervenção conforme plano de trabalho do orientador.

\section{c) Criação de um Núcleo de Telessaúde do HRAC/USP.}

Diante da confirmação dos profissionais pesquisados sobre a necessidade e interesse na criação de um pólo de capacitação no HRAC, foram estudadas várias propostas viáveis para construção de um pólo como: FIOCRUZ, uma primeira idéia para realização de cursos por meio da Educação a Distância (EAD), da Escola Nacional de Saúde Pública Sergio Arouca ENSP/Fiocruz, na cidade do Rio de Janeiro/RJ, em virtude de já termos realizado curso a distância para facilitadores do SUS; enviamos email solicitando orientações e recebemos a resposta: "O EAD/ENSP não oferece cursos no tema alvo de seu interesse. Sugerimos que visite o endereço www.ead.fiocruz.br/cursos para conhecer a oferta de cursos". Entramos novamente em contato e aguardamos resposta.

Em 07/05/07 recebemos o comunicado Informe SerCom Centrinho/USP Funcraf, ano $4 \mathrm{n}^{\mathrm{o}} 878$ informando da sobre possibilidade de inscrição na Liga de Telessaúde/sistema COL (cursos on-line), no site (http://col.usp.br). Foi estabelecido contato com uma das responsáveis na USP/Bauru, $\operatorname{Prof}^{\mathrm{a}} \mathrm{Dr}^{\mathrm{a}}$ Giedre Berretin Felix, para orientações e o cadastro como professora no COL foi autorizado. Alguns projetos para os uso dessa tecnologia já estão sendo pensados.

Participando de reunião do Grupo de Trabalho 4 (GT4), a Prof ${ }^{\mathrm{a}}$ Dr $^{\mathrm{a}}$ Wanderléia Q. Blasco nos informou sobre outras formas de cursos à distância por meio da internet. Na busca, encontramos o Centro de Computação Eletrônica da USP com os serviços de apoio ao ensino, colocando programas à disposição dos docentes que queiram criar ambientes educacionais na internet: COL, Moodle e outros sistemas históricos (Cybertutor, cyberambulatorio e outros) www.usp.br/cce/servicos/ensino.php. 
Avançando na busca, encontramos a estação digital médica com várias orientações/cursos e a FOB/Bauru como instituição participante.

Com todas as informações e material, convocamos os profissionais das áreas envolvidos na pesquisa, ou seja, fonoaudiologia, psicologia, odontologia e serviço social para apresentação e discussão de alternativas para levar a frente a idéia desse meio de capacitação disponível.

Nessa reunião foi sugerido contato com Dr. Chao Lung Wen (Prof. Associado e chefe da Disciplina de Telemedicina da Faculdade de Medicina da USP e Presidente do Conselho Brasileiro de Telemedicina e Telessaúde) para verificar a possibilidade do HRAC ser incluído nesse novo sistema tecnológico, considerando que ele já preenche os requisitos para tal empreendimento.

O encontro com Dr. Chao Lung Wen aconteceu em 11 de julho de 2007, em São Paulo, onde o mesmo sugeriu um termo de cooperação entre o HRAC/USP e a Faculdade de Medicina da Universidade de São Paulo (FMUSP). Sua vinda a Bauru, para uma conferência aberta aos profissionais do campus/USP de Bauru, além de uma reunião com o Superintendente do HRAC, Diretores da FOB, Diretores do HRAC, Chefias de departamento e Presidentes de Comissões, foi agendada para 23 de julho de 2007, com objetivo de criação de um Núcleo de Telessaúde do HRAC.

Após a conferência e reunião com os diretores de área e outros profissionais do HRAC e FOB, foi proposta a criação de um Núcleo ou um grupo de trabalho GT, a partir de um termo de cooperação entre o HRAC/USP e a Faculdade de Medicina da Universidade de São Paulo (FMUSP), com objetivo de consolidar a Telessaúde no HRAC, por meio de projetos sociais e de pesquisas multicêntricas, cursos de teleducação interativa e teleconsultoria e/ou teleassessoria, agregando e socializando conhecimentos.

Este Núcleo/GT será desenvolvido em parceria com a Rede Universitária de Telemedicina - RUTE - visando apoiar o aprimoramento de projetos em telemedicina e telessaúde já existentes e incentivar o surgimento de futuros trabalhos interinstitucionais, além de proporcionar treinamento e capacitação de profissionais da área da saúde e reabilitação, sem deslocamento para centros de referência. Dentre as instituições participantes da RUTE, destacamos o Hospital das Clínicas da FMUSP e o Hospital Universitário da USP, ambos da Universidade de São Paulo da qual o HRAC é parte. 
O HRAC está em vias de selar um convênio com a Rede Nacional de Associações de Pais e Portadores de Lesões Lábio-Palatais (REDE PROFIS) - que congrega 43 associações localizadas nas cinco regiões, com potencial de cobertura de aproximadamente 22 mil pacientes ${ }^{21}$ - que poderá apropriar-se dessas novas tecnologias fazendo dessas associações pontos de apoio para o seu desenvolvimento a partir da capacitação dos profissionais locais (teleconsultoria e/ou teleassessoria), descentralizando os serviços do hospital, procurando manter a excelência do atendimento nele oferecido.

\section{d) Articulação da Rede Nacional de serviços na área da fissura labiopalatina.}

Considerando a existência de diferentes recursos/serviços na área da fissura labiopalatina a exemplo das associações de pais (43), subsedes do HRAC através da fundação de apoio funcraf (03), núcleos regionais (12), hospitais de alta complexidade (19) e a ausência de uma política nacional de atendimento das pessoas com fissura labiopalatina, que gera a desarticulação dos serviços sugerimos:

- Instituição de um fórum nacional de discussão para definição da política de atendimento a pessoas com fissura labiopalatina, envolvendo os serviços existentes no Brasil e o Ministério da Saúde.

- Oficialização da Rede de Referência no Tratamento das Deformidades Craniofaciais no Brasil (RRTDCF), de forma a garantir a congregação, a integração, o fortalecimento e a defesa dos critérios institucionais das organizações que prestam serviços especializados na área da fissura labiopalatina.

- Necessidade de estruturação dos serviços de atendimento às pessoas com fissura labiopalatina do Brasil, com o apoio multiministerial e da USP, reconhecendo o HRAC como Centro de Referência na Área de Anomalias Craniofaciais, Sindromologia e Deficiência Auditiva.

Todas estas iniciativas deverão estar articuladas com a Política Nacional de Educação Permanente em Saúde do SUS, por meio de parcerias com os pólos regionais e com o programa de descentralização ambulatorial do HRAC.

\footnotetext{
${ }^{21}$ Fonte: Serviço Social de Projetos Comunitários e Serviço de Informática Hospitalar do HRAC
} 
6 CONSIDERAÇÕES FINAIS 


\section{CONSIDERAÇÕES FINAIS.}

Com base nos resultados da pesquisa, foi possível concluir, a partir dos objetivos propostos, que:

a) Quanto ao conhecimento e cadastramento dos serviços de reabilitação, englobando as diferentes áreas (fonoaudiologia, odontologia, psicologia e serviço social):

Identificamos 21 serviços em 19 cidades, oito Estados e três regiões, em sua maioria de natureza pública e do Terceiro Setor, prestando serviços de reabilitação e assistência social. Destaque ocorreu para a área de fonoaudiologia, que tem tido uma participação fundamental no processo de reabilitação por meio de atendimento ambulatorial na própria região de origem dos sujeitos.

b) Com relação às formas de articulação dos serviços/reabilitadores com órgãos locais (universidades, secretarias de saúde e outros) e com o HRAC:

Que a totalidade dos serviços estabelece relações de parceria/convênios com o próprio HRAC, bem como com Prefeituras Municipais/Secretarias de Saúde e Associações de Pais e Pessoas com Fissura Labiopalatina. Houve predominância das modalidades cursos e visitas, dentre outras formas de articulação com o HRAC, sinalizando, portanto, o empenho e o reconhecimento do HRAC como formador de recursos humanos e o interesse dos serviços no desenvolvimento técnico e cientifico de seus profissionais. Observamos, ainda, que existe um comprometimento destes serviços com a própria capacitação de seus profissionais, tendo como referência o HRAC, dentre outros, pautado na filosofia da humanização e qualidade.

c) No tocante ao perfil profissional dos reabilitadores das organizações, identificando seu nível de articulação técnico, científico e funcional com o HRAC:

Os reabilitadores, identificados no estudo totalizam em 72 profissionais distribuídos por área: 24 fonoaudiólogos, 12 psicólogos, 19 dentistas e 17 assistentes sociais procedentes de diferentes Estados (9) cidades (25) e região (3), formados em sua maioria na década 90, com cursos de pós-graduação, com mais de seis anos de experiência profissional e, em sua maioria, contratados dos serviços pesquisados.

Especificamente na área da fissura labiopalatina, a maioria tem algum tipo de 
experiência no atendimento, contando com o apoio do HRAC no seu processo de formação, qualificação e capacitação profissional.

Dentre os meios facilitadores de intercâmbio técnico-científico observamos que a totalidade possui acesso à Internet e proficiência em língua estrangeira, o que certamente facilita o seu processo de capacitação profissional. Esses profissionais mantêm bom nível de articulação técnico-científico com o HRAC nas diferentes áreas da reabilitação, pois conhecem o HRAC in loco, mediante cursos, visitas e estágios, além de manterem contatos diretos e indiretos com a equipe (pessoalmente, telefonemas, correspondência, relatórios e outros).

Neste perfil, destacamos um índice significativo destes profissionais que participam de programas/projetos de humanização e qualidade, porém, o envolvimento com os pólos de educação permanente do SUS ainda é incipiente, exceto na área da odontologia, cuja participação refere-se especialmente ao programa da saúde da família e de câncer bucal.

Todos os profissionais relacionaram as principais situações vivenciadas pelos pacientes do HRAC no tratamento em sua cidade de origem - objeto de sua prática - e também relataram as dificuldades encontradas para a prática profissional na área da fissura, com destaque para área de fonoaudiologia, o que sugere medidas urgentes no sentido de se estabelecer estratégias - um primeiro passo na criação do pólo de capacitação do HRAC.

d) Quanto à identificação das necessidades e ao interesse dos reabilitadores em participar do programa de capacitação do HRAC: Identificamos que um alto índice de profissionais $(95,4 \%)$ demonstrou interesse e afirmou a necessidade de participar de cursos de capacitação para reabilitadores, sugerindo, inclusive, temas de interesse.

e) Com relação às propostas de formas de ampliação de intercâmbio e articulação dos serviços/reabilitadores com diferentes organizações públicas, privadas e/ou do terceiro setor: Sugerimos maior estreitamento das relações de parceria do HRAC com os hospitais de ensino e/ou de alta complexidade do Brasil, cadastrados no Ministério de Saúde, (re)definindo a política de assistência, ensino e pesquisa na área da fissura labiopalatina. A primeira iniciativa seria junto às associações filiadas à REDE PROFIS, (51,4\% dos profissionais que participaram do estudo são 
vinculados às associações), já firmadas como referências na assistência social e prestação de serviços/reabilitação dos pacientes do HRAC.

f) Na contribuição para construção de um pólo de capacitação de reabilitadores por interviniência do HRAC: Sugerimos algumas iniciativas tais como: aprofundamento do conteúdo do curso de anomalias craniofaciais na parte específica nas diferentes áreas da reabilitação (medicina, odontologia, fonoaudiologia, psicologia e serviço social), viabilizando oficinas de forma a garantir o trabalho de qualificação mediante análise, discussão e problematização de programas e sistemas de saúde, inovações tecnológicas, protocolos de atendimentos com base nas necessidades e expectativas dos profissionais envolvidos no processo de capacitação, ou mesmo iniciando com o curso as novas tecnologias de informação (Cybertutor).

Sugerimos também a ampliação do conteúdo da disciplina de política de saúde e reabilitação nos cursos da pós-graduação do HRAC, despertando os alunos para assumirem responsabilidades e compromissos com a educação e capacitação de outros profissionais com agentes multiplicadores do conhecimento na área da fissura labiopalatina, bem como para mobilizar e pressionar poderes públicos para a criação e/ou ampliação dos serviços especializados na área, ultrapassando as relações de solidariedade para as de defesa dos direitos de cidadania.

A criação de um núcleo de telessaúde no HRAC e a articulação da Rede Nacional de serviços na área da fissura labiopalatina destacam-se também dentre as demais iniciativas. A telessaúde, no sentido de consolidar-se por meio de projetos sociais e pesquisas multicêntricas, cursos de teleducação interativa e teleconsultoria/assessoria agrega e socializa conhecimentos.

A articulação da rede nacional de serviços na área da fissura labiopalatina, por meio de um fórum nacional de discussão, foi sugerida para viabilizar a definição da política de atendimento às pessoas com fissura labiopalatina, envolvendo diferentes serviços de atendimento e o Ministério da Saúde. Além disso, sugerimos a oficialização da Rede Nacional de serviços às pessoas com fissura labiopalatina e o reconhecimento do HRAC como Centro de Referência Nacional em Anomalias Craniofaciais, Sindromologia e Deficiência Auditiva.

Sabemos que esse panorama abriga desafios e perspectivas na formação de profissionais da saúde: campo interdisciplinar que materializa diferentes níveis de 
compreensão e intervenção junto aos sujeitos implicando distintos compromissos políticos, sociais e educacionais. No entanto, acreditamos que as iniciativas sugeridas são viáveis e podem impulsionar a criação do pólo de capacitação do HRAC na área, em parceria com outros pólos de educação permanente do SUS no Brasil e do programa de descentralização do HRAC/USP. 


\section{REFERÊNCIAS.}

Almeida HMS. Programa de qualidade do governo federal aplicado à saúde. In: $\underline{\text { VII }}$ Congresso Internacional del CLAD sobre la reforma Del Estado y de la Administración Pública. Lisboa, Portugal, 8-11 Oct. 2002.

Altieri L (1997) apud Serapioni M. Avaliação da qualidade em saúde: delineamento para um modelo multidimensional e correlacional. In: Bosi MLM, Mercado FJ, organizadores. Avaliação qualitativa de programas de saúde: enfoques emergentes, Petrópolis: Vozes; 2006. p. 214.

Altmann EBC, Vaz ACN, Ramos ALNF, Paula MBSF, Khoury RBF, Marques RMF. Tratamento fonoaudiológico. In: Altmann EBC. Fissuras labiopalatinas. 4a. ed. Carapicuíba: Pró- Fono; 1997. p. 367-403.

Amaral VLAR. Aspectos psicossociais. In: Altmann EBC. Fissuras labiopalatinas. 4a. ed. Carapicuiba: Pró-Fono; 1997. p. 501-14.

André M, Lopes LD, Haddad AS, Mattos BSC. Tratamento odontopediátrico. In: Altmann EBC. Fissuras labiopalatinas. 4a. ed. Carapicuiba: Pró-Fono; 1997. p. $237-$ 248.

Arretche MTS. Políticas Sociais no Brasil: descentralização em um estado federativo.

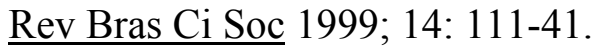

Associação Brasileira de Empresas de Pesquisa. Critérios de classificação econômica Brasil [online]. [Consultado em 20 de jun. 2007; [12 telas]. Disponível: http://www.abep.org/codigosguias/ABEP_CCEB.pdf

Associação Brasileira Beneficente de Reabilitação. Organização Mundial da Saúde. [online]. [Consultado em 20 de jun. 2007; [1 tela]. Disponível:

http://www.abbr.org.br/historiadamedicina.php 
Bauru. Estatuto social. Rede Nacional de Associações de Pais e Portadores de Fissuras Lábio Palatais: Rede PROFIS. Bauru: PROFIS, 2004. 11p.

Bittar OJNV. Indicadores de qualidade e quantidade em saúde. Rev Adm Saúde 2001; $3: 21-8$.

Bordin NA. $O$ acesso aos serviços do HRAC (in)viabilizado por diferentes recursos comunitários: análise do tratamento fora do domicílio numa perspectiva de cidadania [monografia]. Bauru: Hospital de Reabilitação de Anomalias Craniofaciais, Universidade de São Paulo; 2001.

Bosi MLM, Uchimura KY. Avaliação qualitativa de programas de saúde: contribuições para proposta metodológicas centradas na integralidade e na humanização In: Bosi MLM, Mercado FJ, organizadores. Avaliação qualitativa de programas de saúde: enfoques emergentes. Petrópolis: Vozes; 2006. p. 87-117.

Brasil. Constituição, 1988. Constituição da República Federativa do Brasil: promulgada em 5 de outubro de 1988. São Paulo: Imprensa Oficial do Estado; 1988.

Brasil. Presidência da República. Lei no 8.080, de 19 de setembro de 1990, dispõe sobre as condições para a promoção, proteção e recuperação da saúde, a organização e o funcionamento dos serviços correspondentes e dá outras providências [online] 19 set 1990 [Consultado em 1 jul 2001]; Disponível:

http://portal.saude.gov.br/portal/arquivos/pdf/LEI8080.pdf $2001 \mathrm{~b}$.

Brasil. Ministério da Saúde. Atenção à pessoa portadora de deficiência no Sistema Único de Saúde: planejamento e organização de serviços. Brasília: Ministério da Saúde; 1993.

Brasil. Ministério da Saúde. Resolução n. ${ }^{\circ 218}$, de 6 de março de 1997, [a importância da ação interdisciplinar no âmbito da saúde; e o reconhecimento da imprescindibilidade das ações realizadas pelos diferentes profissionais de nível superior, constitui um avanço no que tende a concepção de saúde e a integralidade da atenção resolve] [online] 5 maio 1997 [Consultado em 6 ago 2001]; Disponível:

http://www.saudeemovimento.com.br/profissionais/legislation/profi_saude/resolution218. $\underline{\mathrm{htm}}$ 
Brasil. Ministério da Saúde. Programa Nacional de Humanização da Assistência Hospitalar. 2a. ed. Brasília: Ministério da Saúde; 2002a.

Brasil. Ministério da Educação. Diretrizes curriculares para os cursos de graduação. [online]. 2002b; [Consultado em: 03/11/2003]. Disponível:

http://www.mec.gov.br/SEsu/diretriz.shtm

Brasil. Ministério da Saúde. PNASS: Programa Nacional de Avaliação de Serviços de Saúde, edição 2004/2005. Brasília: Ministério da Saúde, 2004 [online] [Consultados em 8 dez 2004] 2004a; [250 telas]. Disponível:

http://www.sgc.goias.gov.br/upload/links/arq_638_ManualAdoProgramaANacionaldeA AvaliacaoAdeServicosAdeASaudeA.APNASS.pdf

Brasil. Ministério da Saúde. Política de educação e desenvolvimento para o SUS: caminhos para a educação permanente em saúde: pólos de educação permanente em saúde. Brasília: Ministério da Saúde; 2004b. (Série C. Projetos, Programas e Relatórios).

Brasil. Ministério da Saúde. A educação permanente entra na roda: pólos de educação permanente em saúde: conceitos e caminhos a percorrer. Brasília: Ministério da Saúde; 2005. (Série C. Projetos, Programas e Relatórios).

Brasil. Ministério da Saúde. Entendendo o SUS. Brasília: Ministério da Saúde; 2006.

Brasil. Ministério da Saúde. SUS de A a Z. [on_line] [Consultado em 14 mar 2007a]; [1 tela]. Disponível: http://dtr2004.saude.gov.br/susdeaz/

Brasil. Ministério da Saúde. Portaria 399/GM, de 22 de fevereiro de 2006. Divulga o pacto pela saúde 2006 - Consolidação do SUS e aprova as diretrizes operacionais do referido pacto. [online] 23 fev 2006 [Consultado em 10 mar 2007b]; [127 telas]. Disponível: http://www.cvs.saude.sp.gov.br/pdf/pacto_portaria_399_06.pdf 
Brasil. Presidência da Republica. Lei n. 10406, de 10 de janeiro de 2002. Institui o código civil. [online] 11 jan 2002 [Consultado em 12 abr 2007c]; [240 telas]. Disponível: http://www.planalto.gov.br/CCIVIL/leis/2002/L10406.htm

Brasil. Ministério da Saúde. Manual de orientações para contratação de serviços do SUS / Ministério da Saúde, Secretaria de Atenção à Saúde, Departamento de Regulação Avaliação e Controle de Sistemas. Brasília: Ministério da Saúde, 2007d.

Brasil. Ministério do Trabalho e Emprego. CBO: Classificação Brasileira de Ocupações. [online] [Consultado em 23 de jun. 2007e]; [52 telas]. Disponível http://www.mtecbo.gov.br/informacao.asp\#6

Brasil. Ministério da Saúde. Competência profissional [online] [Consultado em 30 de mai.2007f].Disponível:

http://portalweb05.saude.gov.br/portal/sgtes/visualizar_texto.cfm?idtxt=23094

Brasil. Cadastro Nacional de Estabelecimentos de Saúde. [online] [Consultado em 13 jun 2007g]. Disponível: http://cnes.datasus.gov.br/Mod_Ind_Especialidades.asp

Bzoch KR. Etiological factors related to cleft palate speech. In: , editor. Communicative disorders related to cleft lip and palate. 2nd. ed. Austin: Litle Brown, 1979. p.67-76.

Capelozza Filho L, Alvares ALG, Rossato C, Vale DMV, Janson GRP, Beltrami LER. Conceitos vigentes na etiologia das fissuras lábio-palatinas. Rev Bras Cir 1988; 78:23340 .

Cerveira MAC. Apresentação do relatório de avaliação dos pólos de capacitação (DAB). In: Brasil. Ministério da Saúde. Reunião dos coordenadores dos pólos de capacitação, formação e educação permanente em saúde da família: relatório final. Brasília: Ministério da Saúde; 2002. p. 21-4. 
Chiavenato I. Administração em recursos humanos. 2a. ed. São Paulo:Atlas; 1981. v. 3.

Chizzotti A. Pesquisa em ciências humanas e sociais. São Paulo: Cortez; 1995. p.51-87.

Di Pietro (2006) apud Brasil. Ministério da Saúde. Manual de orientações para contratação de serviços do SUS. Brasília: Ministério da Saúde; 2007. (Série A. Normas e Manuais Técnicos). p. 12.

Donabedian A (1989) apud Serapioni M. Avaliação da qualidade em saúde: delineamento para um modelo multidimensional e correlacional In: Bosi MLM, Mercado FJ, organizadores. Avaliação qualitativa de programas de saúde: enfoques emergentes. Petrópolis: Vozes; 2006. p. 210-1.

Ferreira ABH. Novo Aurélio século XXI: o dicionário da língua portuguesa 3a. ed. Rio de Janeiro: Nova Fronteira; 1999 p.1641-64.

Fontana ROC, Souza GCF, Dias ELF, Souza E. Humanização no tratamento oncológico, um novo desafio para a equipe multidisciplinar do ambulatório de oncologia do HC/UNICAMP. In: Anais do $2^{\circ}$ Simpósio de serviço social em saúde: Novas demandas sociais, posicionamento das Instituições e o Serviço Social; 1998 1011 set; São Paulo, Brasil. São Paulo: Universidade de São Paulo; 1998. p.45.

Furtado JP. Avaliação para o conhecimento e transformação In: Bosi MLM, Mercado FJ, organizadores. Avaliação qualitativa de programas de saúde: enfoques emergentes. Petrópolis: Vozes; 2006. p. 191-206.

Genaro KF, Fukushiro AP, Suguimoto MLFCP. Avaliação e tratamento dos distúrbios da fala. In: Trindade ILK, Silva Filho OG, coordenadores. Fisuras labiopalatinas: uma abordagem interdisciplinar. São Paulo: Livraria Santos; 2007. p.109-22.

Gil AC. A pesquisa social. In: . Métodos e técnicas de pesquisa social. 2a. ed. São Paulo: Atlas; 1989. p. 43-51. 
Gomide MR, Costa B. Cuidados odontopediátricos. In: Trindade ILK, Silva Filho OG, coordenadores. In: Fisuras labiopalatinas: uma abordagem interdisciplinar. São Paulo: Livraria Santos; 2007. p.199-211.

Graciano MIG. Construindo espaços: a história das associações de pais e portadores de lesões lábio-palatais e a contribuição do serviço social [tese]. São Paulo: Pontifícia Universidade Católica de São Paulo; 1996.

Graciano MIG. De cliente a agente: os pais coordenadores e a sua ação multiplicadora num programa com portadores de lesões lábio-palatais [dissertação]. São Paulo: Pontifícia Universidade Católica de São Paulo; 1988.

Graciano MIG, Lehfeld NAS, Neves Filho A. Critérios de avaliação para classificação sócio-econômica: elementos de atualização. Serv Social Realid 1999; 8:109-28.

Graciano MIG et al. O perfil social de portadores de fissuras labiopalatais em projeto de pesquisa interdisciplinar da Universidade de São Paulo e a Universidade da Flórida. Relatório Final de pesquisa. Bauru: Hospital de Reabilitação de Anomalias Craniofaciais, Universidade de São Paulo; 2004.

Graciano MIG, Tavano LA, Bachega MI. Aspectos psicossociais da reabilitação. In: Trindade ILK, Silva Filho OG, coordenadores. Fisuras labiopalatinas: uma abordagem interdisciplinar. São Paulo: Livraria Santos; 2007. p.311-33.

Instituto Brasileiro de Geografia e Estatística. Censo Demográfico 2000 [online] [consultado 6 ago 2001]; [1 tela]. Disponível:

http:// www.ibge.gov.br/censo/default.php.

Lima VLAFM, Aprigliano M. Sistema Único de Saúde: SUS. In: [Anais] V Semana do Serviço Social: Curso a prática do serviço social na área da saúde; [Bauru], Brasil. [Bauru: Hospital de Pesquisa e Reabilitação de Lesões Labiopalatais, Universidade de São Paulo]; 1996. [p.17.26]. 
Marques IL, Thomé S, Peres SPBA. Aspectos pediátricos. In: Trindade ILK, Silva Filho OG, coordenadores. Fisuras labiopalatinas: uma abordagem interdisciplinar. São Paulo: Livraria Santos; 2007. p.51- 71.

Meirelles (2003a) apud Brasil. Ministério da Saúde. Manual de orientações para contratação de serviços do SUS. Brasília: Ministério da Saúde; 2007. (Série A. Normas e Manuais Técnicos). p.12.

Minayo MCS. Ciência, técnica e arte: o desafio da pesquisa social. In: Minayo MCS, organizadora. Pesquisa social: teoria, método e criatividade. 7a ed. Petrópolis: Vozes; 1994. p. 22-3.

Monlléo IL. Anomalias Craniofaciais, genética e saúde pública: contribuições para o reconhecimento da situação atual da assistência no Sistema Único de Saúde [dissertação]. Campinas: Faculdade de Ciências Médicas, Universidade Estadual de Campinas; 2004.

Montagnolli LC, Rocha CMG. Manual de orientação sobre fissuras orofaciais. Bauru: Hospital de Pesquisa e Reabilitação de Lesões Labiopalatais, Universidade de São Paulo; 1990.

Nogueira RP (1994) apud Serapioni M. Avaliação da qualidade em saúde: delineamento para um modelo multidimensional e correlacional. In: Bosi MLM, Mercado FJ, organizadores. Avaliação qualitativa de programas de saúde: enfoques emergentes. Petrópolis: Vozes; 2006. p.207.

Okumura L. As perspectivas e oportunidades nas organizações do terceiro setor no Brasil. [on_line] [Consultado em 19 jun 2007]; [6 telas]. Disponível: http://www.fea.usp.br/Publicacoes/controversa/3setor-5.html.

Ovretveit J (1996) apud Serapioni M. Avaliação da qualidade em saúde: delineamento para um modelo multidimensional e correlacional. In: Bosi MLM, Mercado FJ, 
organizadores. Avaliação qualitativa de programas de saúde: enfoques emergentes. Petrópolis: Vozes; 2006. p. 212.

Pesquisa avalia grau de satisfação dos clientes da Fertimport. Rumos [online] 1997 [Consultado em 18 out. 2002]; 2(23): [10 telas]. Disponível:

http://www.fertimport.com.br/rumos23/pagina23/pagina23.htm.

Reis VPF. O perfil de empregabilidade: o desafio do autodesenvolvimento [online] [Consultado em 19 jun 2007]; [28 telas]. Disponível:

http://www.senac.br/informativo/BTS/241/boltec241c.htm

Rodrigues, MCP. Terceiro setor: para que serve? In: FEDERAÇÃO DE OBRAS SOCIAIS. Terceiro setor: coletânea de artigos de jornal. [São Paulo]: Federação de Obras Sociais, 1998. [18p.].

Roemer MI, Aguilar M (1988) apud Serapioni M. Avaliação da qualidade em saúde: delineamento para um modelo multidimensional e correlacional. In: Bosi MLM, Mercado FJ, organizadores. Avaliação qualitativa de programas de saúde: enfoques emergentes. Petrópolis: Vozes; 2006. p. 209.

Roque FS, Graciano MIG, Custódio SAM. Parceria cidadã: uma prática do serviço social na saúde. Constr Serv Social 2001; (8):177-237.

Roxo CEMB, Lacerda DJC, Bacigalupo MLJ. Cronologia precoce do tratamento cirúrgico. In: Altmann EBC. Fissuras labiopalatinas. 4a. ed. Carapicuiba: Pró-Fono; 1997. p. 73-85.

Sampaio CC, Rossi D, Biajoni MC, Colodo M, Tacco MAC, Savassi TR. Interdisciplinaridade em questão: análise de uma política de saúde voltada à mulher. In: Sá JLM, organizadora. Serviço social e interdisciplinaridade: dos fundamentos filosóficos à prática interdisciplinar no ensino, pesquisa e extensão. São Paulo: Cortez; 1989. p. 77-95. 
Santana JP, Cristofaro MAC. Educação, trabalho e formação profissional em saúde. [online] [Consultado em 3 nov 2003]; [36 telas]. Disponível:

http://www.nesp.unb.br/polrhs/Temas/edc_trab_form_prof_em_saude2.htm

Santos CR, Toledo NN, Silva SC. Humanização em unidade de terapia intensiva: paciente-equipe de enfermagem-família. Nursing 1999; 2:26-9.

Sassaki RK. Inclusão: construindo uma sociedade para todos. Rio de Janeiro, WVA; 1997.

Sena EC. Capacitação profissional. [on_line] [consultado em 13 mar 2007]; [3 telas]. Disponível: http://www.entreamigos.com.br/textos/trabalho/capacitacao.htm.

Serapioni M. Avaliação da qualidade em saúde: delineamento para um modelo multidimensional e correlacional In: Bosi MLM, Mercado FJ, organizadores. Avaliação qualitativa de programas de saúde: enfoques emergentes. Petrópolis: Vozes; 2006. p 207-27.

Shaw WC, Semb G. Princípios e estratégias da reabilitação: recomendações da Organização Mundial da Saúde (OMS). In: Trindade ILK, Silva Filho OG, coordenadores. Fisuras labiopalatinas: uma abordagem interdisciplinar. São Paulo: Livraria Santos; 2007. p.1-16.

Silva MOS. Formação profissional do assistente social: inserção na realidade social e na dinâmica da profisssão. São Paulo: Cortez; 1984.

Silva EL, Cunha MV. A formação profissional no século XXI: desafios e dilemas. Ci Inf $2002 ; 31: 77-82$.

Silva Filho OG, Freitas JAS. Caracterização morfológica e origem embriológica. In: Trindade ILK, Silva Filho OG, coordenadores. Fisuras labiopalatinas: uma abordagem interdisciplinar. São Paulo: Livraria Santos; 2007. p.17-49. 
Silva Filho OG, Ferrari Junior FM, Rocha DL, Freitas JAS. Classificação das fissuras lábio-palatais: breve histórico, considerações clínicas e sugestão de modificação. $\underline{\operatorname{Rev}}$ Bras Cir 1992; 82:59-65.

Spina V, Psillakis JM, Lapa FS. Classificação das fissuras lábio-palatinas: sugestão de modificação. Rev Hosp Clin Fac Med São Paulo 1972; 27:5-6.

Truite MB. Controle da qualidade total para um hospital. Ribeirão Preto: Universidade de Ribeirão Preto; 1995.

Universidade de São Paulo. Hospital de Reabilitação de Anomalias Craniofaciais, Fundação para o Estudo e Tratamento das Deformidades Crâniofaciais. Relatório de atividades do ano de 1999. Bauru: Hospital de Reabilitação de Anomalias Craniofaciais, Universidade de São Paulo; 1999.

Universidade de São Paulo. Hospital de Reabilitação de Anomalias Craniofaciais, Manual de etapas e condutas terapêticas, HRAC/USP e FUNCRAF: fissuras labiopalatinas, anomalias craniofaciais, deficiências auditivas e síndromes. Bauru: Hospital de Reabilitação de Anomalias Craniofaciais, Universidade de São Paulo; 2001. 


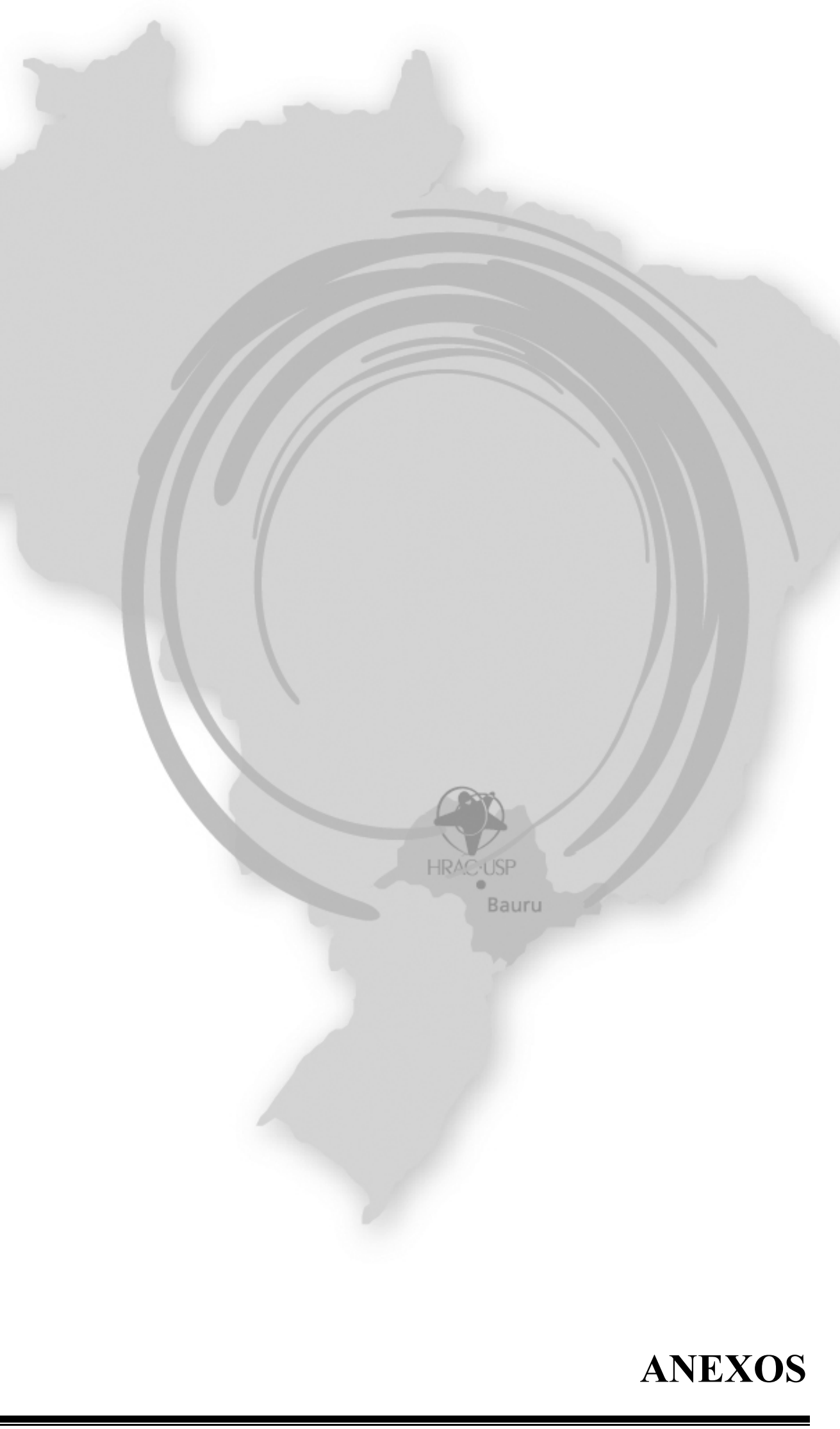


ANEXO 1

Prezados responsáveis

Estamos desenvolvendo uma pesquisa intitulada "Os serviços de apoio a reabilitação aos usuários do Hospital de Reabilitação de Anomalias Craniofaciais: diagnóstico das necessidades de capacitação de reabilitadores", com o objetivo de mapear e caracterizar os serviços de reabilitação no Brasil, utilizados pelos usuários do HRAC e também diagnosticar a necessidade de capacitação dos reabilitadores nas áreas de fonoaudiologia, odontologia, psicologia e serviço social, identificando os profissionais que os atendem na sua cidade.

Contamos com sua colaboração no sentido de preencher o questionário para podermos contatar com os profissionais e/ou serviços que atendem as pessoas com fissuras labiopalatinas em sua cidade ou região de origem.

Aguardamos sua resposta o mais breve possível para iniciarmos a $2^{\mathrm{a}}$ etapa da pesquisa.

Gratos pela sua colaboração!

Cordialmente,

Silvana Ap. Maziero Custódio Assistente Social - CRESS: 16043 Aluna de Doutorado/USP
Prof. Dr. José Alberto de Souza Freitas Superintendente do HRAC/USP Orientador

Nome do pesquisador responsável: Silvana Aparecida Maziero Custódio Rua: Silvio Marchione, 3-20 Bauru - SP CEP: 17043-900 Fone: (14) 3235-8124 ou 3235-8135 e-mail: smaziero@centrinho.usp.br 


\section{QUESTIONÁRIO PARA O PACIENTE/FAMÍLIA}

\section{IDENTIFICAÇÃO}

Nome do Paciente: RG no HRAC :

Município da residência: Est.:

Município do local de tratamento: Est.:

Nome do responsável pelo preenchimento do questionário:

Vínculo com o paciente: Pai ( ) Mãe ( ) Outros ( ) - Especificar:

\section{DESENVOLVIMENTO}

1. O seu filho(a) realiza tratamento para reabilitação das lesões labiopalatais na sua cidade ou região? Sim（） Não（）

1.1. Se seu filho(a) não realiza nenhum tipo de tratamento na sua cidade/região, explique o porque:

( ) não foi indicado pelo hospital nenhum tipo de tratamento na cidade

( ) foi indicado mas não tem o tratamento na cidade. Especifique qual área não tem: ( ) fonoaudiologia ( ) odontologia ( ) outras áreas

( ) foi indicado mas não tinha vaga para tratamento na cidade

( ) foi indicado mas não teve condições financeiras para tratamento na cidade (tratamento particular)

( ) foi indicado mas estava insatisfeito com tratamento na cidade

( ) foi indicado mas não tinha condições financeiras para o transporte até o tratamento na cidade

( ) outros motivos

1.2. Se seu filho(a) realiza tratamento na sua cidade/região responda: Nome(s) do(s) serviço(s)/ clínica /Instituição

Endereço(s) completo(s): Rua, bairro, CEP, telefone, fax, e-mail

Especifique, este serviço é : （ ) clínica （）núcleo （）associação （） sub sede ( ) fundação ( ) Prefeitura Municipal ( ) Outros Especifique:

Natureza: ( ) pública ( ) privada ( ) $3^{\circ}$ Setor (Associação/Fundação) 
Continuação

Em quais áreas seu filho(a) é atendido?:

( ) medicina: pediatria ( ) otorrinolaringologia ( ) neurologia ( ) Outras ( ) Especifique a(s) área(s)

( ) odontologia: ( ) odontopediatria ( ) Outras Especifique a(s)

( ) fonoaudiologia ( ) psicologia( ) serviço social( ) outros Especifique a(s) área(s)

Qual o nome completo dos profissionais que atendem seu filho(a) na sua cidade/região? (caso possuam e-mail, favor informar)

( ) médico(s)

( ) dentista(s)

( ) fonoaudióloga

( psicóloga

( ) serviço social

( ) outros

2. Estão satisfeitos com o tratamento realizado em sua cidade/região?

$\operatorname{Sim}($ ) Não ( ) Porque:

4. Participam de alguma associação de pais em sua cidade/região?

Sim ( ) Não ( ) Porque:

3. Comentários/observações

Assinatura: Data: 


\begin{abstract}
ANEXO 2
Prezado responsável pela Instituição,

Estamos desenvolvendo uma pesquisa intitulada "Os serviços de apoio a reabilitação aos usuários do Hospital de Reabilitação de Anomalias Craniofacias: diagnóstico das necessidades de capacitação de reabilitadores", com o objetivo de mapear e caracterizar os serviços de reabilitação no Brasil, utilizados pelos usuários do HRAC e também diagnosticar a necessidade de capacitação dos reabilitadores nas áreas de fonoaudiologia, odontologia, psicologia e serviço social.

Na primeira fase da pesquisa foi aplicado um questionário aos pacientes para identificar os profissionais/serviços que os atendem na sua cidade. Como a Instituição foi citada, tomamos a liberdade de solicitar que preencha o questionário para que a pesquisa possa atingir seus objetivos e assim, contribuir para a criação de um pólo de capacitação na área de fissura labiopalatina.

Ressaltamos que sua participação será muito importante. Portanto solicitamos sua colaboração no sentido de responder o questionário em anexo, seguido do termo de consentimento livre esclarecido, e enviando-nos até 06 de agosto de 2006.
\end{abstract}

Gratos pela sua colaboração!

Cordialmente,

Silvana Ap. Maziero Custódio

Assistente Social - CRESS: 16043

Aluna de Doutorado/USP
Prof. Dr. José Alberto de Souza Freitas

Superintendente do HRAC/USP

Orientador

Nome do pesquisador responsável: Silvana Aparecida Maziero Custódio

Rua: Silvio Marchione, 3-20 Bauru - SP CEP: 17043-900

Fone: (14) 3235-8124 ou 3235-8135 e-mail: smaziero@centrinho.usp.br 


\section{I - IDENTIFICAÇÃO DA INSTITUIÇÃO/SERVIÇOS}

Nome da instituição/serviço:

Natureza: Público ( ) Privado ( )

Finalidade:

Nome do responsável

Cargo:

II - SERVIÇOS

2 - Quais os serviços prestados:

( ) medicina especificar:

( ) odontologia especificar:

( ) fonoaudiologia especificar:

( ) psicologia ( ) serviço social ( ) outros. Especifique:

3 - Esse serviço possui parcerias/intercâmbios/convênios com outras instituições?

$\operatorname{Sim}($ ) Não ( )

Se sim assinale e especifique:

( ) universidades Especifique:

( ) prefeituras municipais Especifique:

( ) secretarias de saúde Especifique:

( ) associação Especifique:

( ) HRAC

( ) outras. Especificar:

4 - Quais os critérios de elegibilidade dos usuários?

5 - A instituição/serviço desenvolve programas de capacitação dos profissionais?

( ) $\operatorname{Sim}($ ) Não

Se sim quais os temas desenvolvidos?

6 - A instituição/serviço desenvolve programas e/ou projetos com enfoque à:

( ) humanização ( ) sim ( ) não Especifique

( ) qualidade ( ) sim ( ) não Especifique

( ) outros. Especifique 
Continuação

7 - A instituição/serviço tem algum sistema de avaliação de satisfação dos usuários?

( ) $\operatorname{Sim}$ ( ) Não

Se sim comente sobre os resultados.

8 - Você conhece o Hospital de Reabilitação de Anomalias Craniofaciais? ( ) sim ( ) não Se sim como?

( ) visita ( ) estágio ( ) curso(s) ( ) internet ( ) outro Especifique

7.1. Se não conhece, gostaria de conhecer o HRAC e seus serviços? ( ) sim ( ) não Justifique:

9 - Comentários

Assinatura: Data:

Os questionários a seguir são para os profissionais que atendem ao paciente. Favor encaminhar um para cada profissional das áreas de odontologia, fonoaudiologia, psicologia e serviço social. 


\section{II -PROFISSIONAIS}

Área: ( ) fonoaudiologia ( ) odontologia ( ) psicologia ( ) serviço social

Nome:

e-mail

Conselho Regional: No Ano de graduação: Tempo de experiência profissional:

Vínculo empregatício: ( ) Sim ( ) Não Especifique:

Curso/dominio de informática: ( ) básico ( ) intermediário

Tem acesso a internet ( ) Sim ( ) Não Qual Local utiliza:

Curso de língua estrangeira: （ ) básico （）intermediário ( ) avançado

Curso de pós-graduação (aperfeiçoamento, especialização, mestrado, doutorado) especifique:

( ) aperfeiçoamento ( ) especialização ( ) mestrado ( ) doutorado.

Outros:

Você conhece o Hospital de Reabilitação de Anomalias Craniofaciais? ( ) não （ ) sim. Como?

( ) visita ano: _ ( ) estágio duração/ano:

( ) curso(s) duração/ano: Especifique

( ) internet Especifique

Realização de estágios ${ }^{22}$ na área de fissura labiopalatal em outros serviços. Sim ( ) Não ( ) Se sim qual o: Nome da Instituição (duração/ano):

Realização do Curso de Malformação/Anomalias no Hospital de Reabilitação de Anomalias Craniofaciais. ( ) Sim ano ( ) Não

Realização de $\operatorname{cursos}^{\mathbf{2 3}}$ na área de fissura labiopalatal em outros serviços: ( ) Sim （ ） Não Se sim:

Especifique os temas dos cursos, gerais e específicos (duração/ano/local/quem promoveu):

Cursos realizados com enfoque na: humanização ( ) qualidade ( ) política de saúde( ) SUS ( ) outros ( ) Especifique:

Participação em programas/projetos de humanização e qualidade:

Utilização de instrumentos de avaliação de satisfação dos usuários na sua área de atuação?

Sim ( ) Não ( ) Especifique e comente resultado:

Experiências profissionais com pessoas com fissura lábio palatal: ( ) Sim ( ) Não

Se sim Especifique:

Qual o tempo de experiência

Contatos com profissionais do HRAC : ( ) Sim ( ) Não

${ }^{22}$ não esquecer de referenciar a duração dos estágios

${ }^{23}$ não esquecer de referenciar a duração dos cursos 
Se sim especifique: ( ) pessoalmente ( ) cartas ( ) e-mail ( ) relatórios ( ) telefônicos Quais os principais problemas na sua área (de fonoaudiologia, odontologia, social e psicologia) diagnosticados nos pacientes com fissura lábio palatal?

Especificar:

Você apresenta dificuldades em atender o paciente com fissura lábio palatal? Sim ( ) Não ( ) Sem sim, quais as dificuldades?

Quais os principais programas/atividades/ações desenvolvidos na sua área

Quais os recursos (terapêuticos e outros) utilizados nos atendimentos:

A sua cidade ou região conta com Pólo de Formação e Educação Permanente para o Sistema Único de Saúde - SUS ? Sim ( ) Não ( )

Se existe você conhece o Pólo de Formação e Educação Permanente da sua região? Sim ( ) Não ( )

Participa? Sim ( ) Não ( ) Se sim responda:

Quais os projetos/cursos desenvolvidos pelo Pólo de Formação e Educação Permanente: Especifique

Nesses cursos abordados assuntos relacionados a fissura lábio palatal ( ) Sim （ ) Não Especifique

Necessidades e interesse em participar de cursos de capacitação para reabilitadores no HRAC ( ) Sim ( ) Não Se sim sugira tema(s)

Qual sua opinião sobre a criação de um pólo de capacitação na área de fissura lábio palatal por iniciativa do HRAC?

Comentários e sugestões:

Endereço:

Fone: - E-mail:

Assinatura: Data: 


\section{ANEXO 3 \\ "TERMO DE CONSENTIMENTO LIVRE E ESCLARECIDO"}

$\mathrm{Eu}$,

portador de RG $\mathrm{n}^{\circ}$ residente e domiciliado à rua (Av.). $n^{0}$

na cidade de Estado na qualidade de responsável pelo paciente …….................................................. em tratamento no HRAC sob o RG: concordo em participar na pesquisa: "Os serviços de apoio a reabilitação aos usuários do Hospital de Reabilitação de Anomalias Craniofaciais: diagnóstico das necessidades de capacitação de reabilitadores", realizada pela Assistente Social Silvana Aparecida Maziero Custódio CRESS nº 16043, sob a orientação do Prof. Dr. José Alberto de Souza Freitas e Dra. Maria Inês Gândara Graciano.

A referida pesquisa tem como objetivo geral mapear e caracterizar os serviços de reabilitação no Brasil utilizados pelos pacientes do HRAC e também diagnosticar a necessidade de capacitação dos reabilitadores nas áreas de fonoaudiologia, psicologia, odontologia e serviço social.

Estou ciente também, de que minha participação é voluntária e dela posso desistir a qualquer momento, sem explicar os motivos e sem comprometer o tratamento no HRAC/USP.

Outrossim, tenho conhecimento que será mantido completo sigilo sobre minha identidade e a do profissional que prestou o atendimento, caso queira me identificar como paciente e/ou responsável.

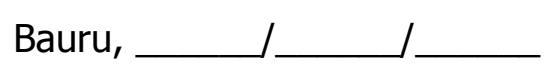

Paciente/Responsável

Nome do pesquisador responsável: Silvana Aparecida Maziero Custódio

Rua: Silvio Marchione, 3-20 Bauru - SP CEP: 17043-900

Fone: (14) 3235-8124 ou 3235-8135 e-mail: smaziero@centrinho.usp.br

Fax: (14) $3234-7818$ 


\section{ANEXO 4}

"TERMO DE CONSENTIMENTO LIVRE E ESCLARECIDO"

$\mathrm{Eu}$, portador de RG residente e domiciliado à rua No na cidade de Estado na

qualidade de responsável pela instituição:

concordo em participar na pesquisa: "Os serviços de apoio a reabilitação aos usuários do Hospital de Reabilitação de Anomalias Craniofaciais: diagnóstico da necessidade de capacitação de reabilitadores", realizada pela Assistente Social Silvana Aparecida Maziero Custódio CRESS nº 16043, sob a orientação do Prof. Dr. José Alberto de Souza Freitas e Dra. Maria Inês Gândara Graciano.

A referida pesquisa tem como objetivo geral mapear e caracterizar os serviços de reabilitação no Brasil utilizados pelos usuários do HRAC e também diagnosticar a necessidade de capacitação dos reabilitadores nas áreas de fonoaudiologia, odontologia, psicologia e serviço social.

Estou ciente também, de que minha participação é voluntária e dela posso desistir a qualquer momento, sem explicar os motivos e sem comprometer o HRAC/USP.

Outrossim, tenho conhecimento que será mantido completo sigilo sobre minha identidade profissional.

Bauru,

Responsável

Nome do pesquisador responsável: Silvana Aparecida Maziero Custódio

Rua: Silvio Marchione, 3-20 Bauru - SP CEP: 17043-900

Fone: (14) 3235-8124 ou 3235-8135 e-mail: smaziero@centrinho.usp.br 
Eu,

residente e domiciliado à rua

na cidade de

de profissional da área

instituição: portador de RG No Estado na qualidade (especificar) da concordo em participar na pesquisa:

"Os serviços de apoio a reabilitação aos usuários do Hospital de Reabilitação de Anomalias Craniofaciais: diagnóstico da necessidade de capacitação de reabilitadores", realizada pela Assistente Social Silvana Aparecida Maziero Custódio CRESS no 16043, sob a orientação do Prof. Dr. José Alberto de Souza Freitas e Dra. Maria Inês Gândara Graciano.

A referida pesquisa tem como objetivo geral mapear e caracterizar os serviços de reabilitação no Brasil utilizados pelos usuários do HRAC e também diagnosticar as necessidades de capacitação dos reabilitadores nas áreas de fonoaudiologia, odontologia, psicologia e serviço social.

Estou ciente também, de que minha participação é voluntária e dela posso desistir a qualquer momento, sem explicar os motivos e sem comprometer o HRAC/USP.

Outrossim, tenho conhecimento que será mantido completo sigilo sobre minha identidade profissional.

Bauru, 1

Profissional

Nome do pesquisador responsável: Silvana Aparecida Maziero Custódio

Rua: Silvio Marchione, 3-20 Bauru - SP CEP: 17043-900

Fone: (14) 3235-8124 ou 3235-8135 e-mail: smaziero@centrinho.usp.br 